\title{
Animal models of gene-environment interaction in schizophrenia: A dimensional perspective
}

\author{
Yavuz Ayhan ${ }^{\mathrm{a}, \mathrm{e}}$, Ross McFarland ${ }^{\mathrm{a}, \mathrm{d}}$, Mikhail V. Pletnikov ${ }^{\mathrm{a}, \mathrm{b}, \mathrm{c}, \mathrm{d}, *}$ \\ ${ }^{a}$ Department of Psychiatry and Behavioral Sciences, Johns Hopkins University School of Medicine, USA \\ ${ }^{\mathrm{b}}$ Solomon H Snyder Department of Neuroscience, Johns Hopkins University School of Medicine, USA \\ ${ }^{\mathrm{c}}$ Department of Molecular and Comparative Pathobiology, Johns Hopkins University School of Medicine, USA \\ d Department of Molecular Microbiology and Immunology, Johns Hopkins Bloomberg School of Public Health, USA \\ ${ }^{\mathrm{e}}$ Hacettepe University Faculty of Medicine, Department of Psychiatry, Turkey
}

\section{A R T I C L E I N F O}

\section{Article history:}

Received 18 March 2015

Received in revised form 7 September 2015

Accepted 22 October 2015

Available online 25 October 2015

\section{Keywords:}

Animal models

Dimensional perspective

Psychotic disorders

RDoC

\begin{abstract}
A B S T R A C T
Schizophrenia has long been considered as a disorder with multifactorial origins. Recent discoveries have advanced our understanding of the genetic architecture of the disease. However, even with the increase of identified risk variants, heritability estimates suggest an important contribution of non-genetic factors. Various environmental risk factors have been proposed to play a role in the etiopathogenesis of schizophrenia. These include season of birth, maternal infections, obstetric complications, adverse events at early childhood, and drug abuse. Despite the progress in identification of genetic and environmental risk factors, we still have a limited understanding of the mechanisms whereby gene-environment interactions $(G \times E)$ operate in schizophrenia and psychoses at large. In this review we provide a critical analysis of current animal models of $G \times E$ relevant to psychotic disorders and propose that dimensional perspective will advance our understanding of the complex mechanisms of these disorders.
\end{abstract}

\section{Contents}

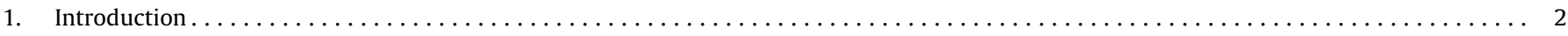

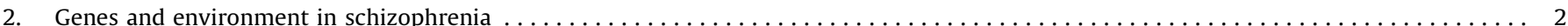

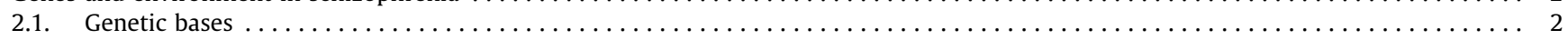

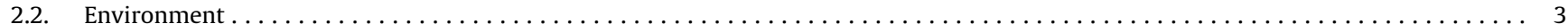

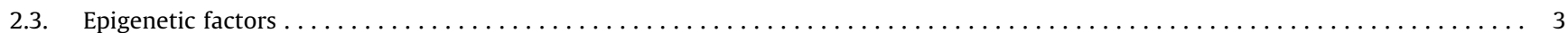

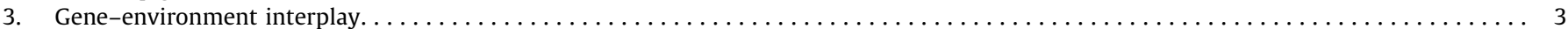

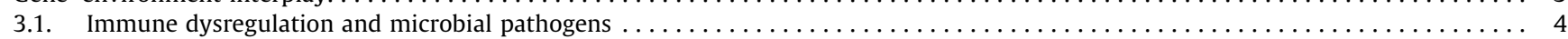

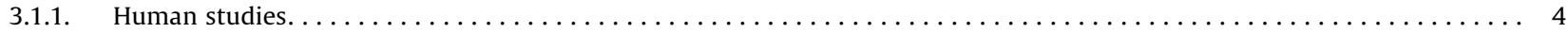

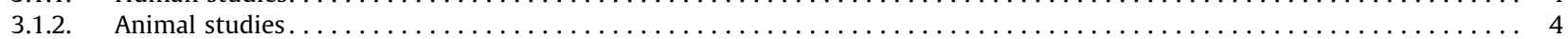

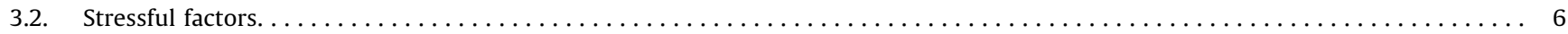

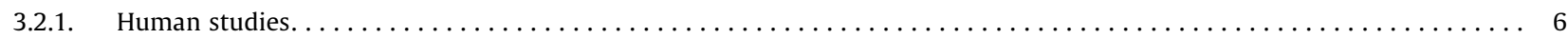

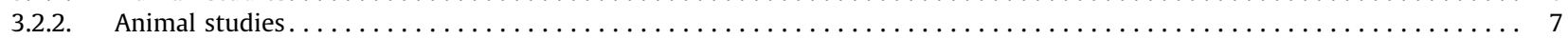

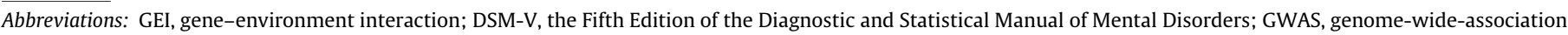

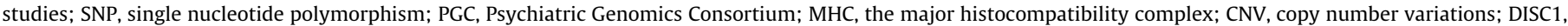

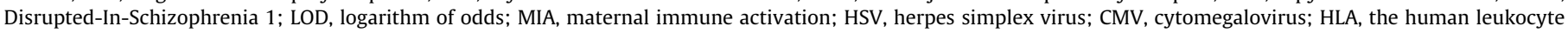

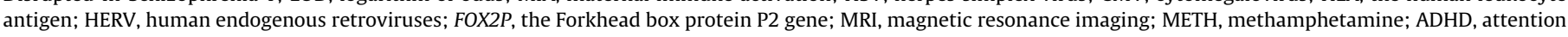

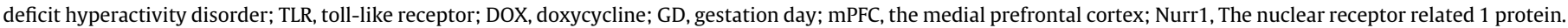

* Corresponding author at: Johns Hopkins School of Medicine, Department of Psychiatry and Behavioral Sciences, 600 North Wolfe Street, CMSC 8-117, Baltimore, MD 21287, USA.

E-mail address: mpletnik@jhmi.edu (M.V. Pletnikov). 


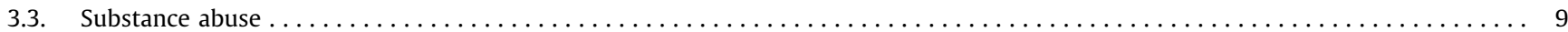

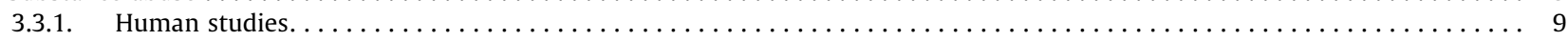

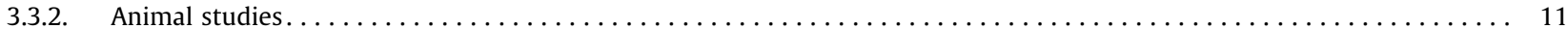

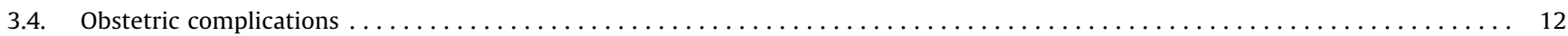

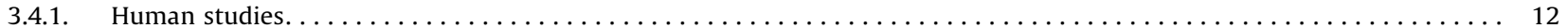

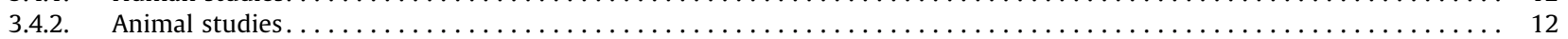

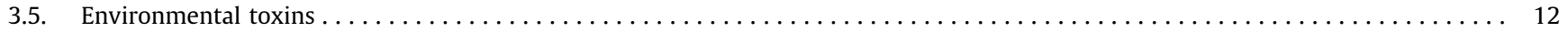

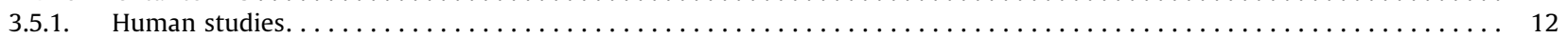

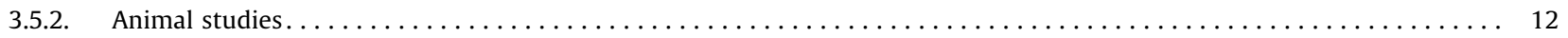

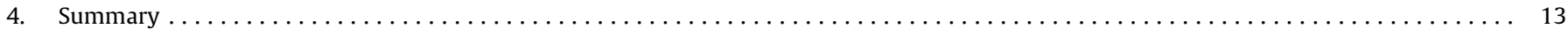

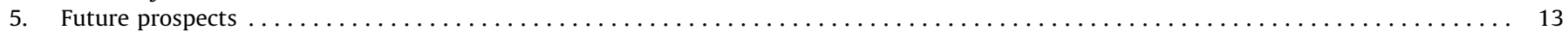

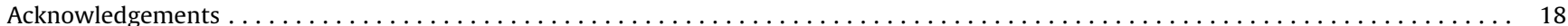

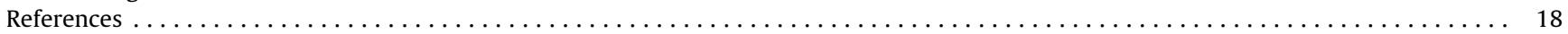

\section{Introduction}

Awareness of the burden of psychiatric disorders is growing, as is the body of research on the causes of mental illnesses. With $0.5 \%$ of the total human population affected by schizophrenia over their lifetime (Saha et al., 2005), it represents a major public health concern, having an overall disability burden exceeding that of many infectious diseases (Murray et al., 2012). Schizophrenia is a debilitating psychiatric disorder characterized by positive (e.g., hallucinations and delusion), negative (e.g., social withdrawal and flat affect) and cognitive impairments. These abnormalities usually lead to a lifetime disability for affected patients. The disease is commonly diagnosed in the early 20s, with the diagnosis being made on average 5 years earlier in males than females (Tandon et al., 2008).

The heterogeneous symptoms and clinical manifestations of schizophrenia overlap with those of other major mental illnesses (i.e., bipolar disorders). Prompted by the growing genetic evidence, the conceptual scope of the disorder has been questioned (Berrios et al., 2003), leading to the development of perspectives for psychotic disorders that are independent of diagnosis category, including dimensional approaches and the Research Domain Criteria (RDoC) matrix. In their influential review, van Os and Kapur (2009) propose that symptoms of psychotic disorders be grouped into five dimensions, including psychosis ("the positivesymptom dimension"), avolition and social withdrawal ("the negative-symptom dimension"), cognitive impairments ("the cognitive-symptom dimension"); and affective disorders clustered into depressive and manic symptoms. Another indication of the shifting diagnostic landscape within psychotic disorders can be seen in the Fifth Edition of the Diagnostic and Statistical Manual of Mental Disorders (DSM-V). This latest edition now includes dimensional assessments, with the classification of domains being expanded over those described above, but based on the same principles (Heckers, 2013).

Concurrent with these changes, research in psychiatry has worked to identify genetic variants and environmental adversities that may be significant risk factors for schizophrenia. However, there is a growing consensus that the pathogenesis of the disorder may rely on a constellation of causative factors that lead to disease. Collectively, the interplay of these factors is referred to as geneenvironment interaction or $\mathrm{G} \times \mathrm{E}$ (van Os and Kapur, 2009; Uher, 2014).

Recently, there have been published a number of reviews of human and animal studies of $\mathrm{G} \times \mathrm{E}$ in schizophrenia (Ayhan et al., 2009; van Winkel et al., 2010; Kannan et al., 2013; Réthelyi et al., 2013; Hida et al., 2013; Cash-Padgett and Jaaro-Peled, 2013; Karl, 2013). The novel feature of this review is to propose dimensional approach to animal models instead of recapitulating the entire disorder by adhering to the clinical diagnostic criteria. We argue that dimensional perspective will be more successful in addressing the molecular mechanisms underlying $\mathrm{G} \times \mathrm{E}$ in order to facilitate search for new therapeutic interventions of this complex disorder.

\section{Genes and environment in schizophrenia}

\subsection{Genetic bases}

The etiology of schizophrenia is poorly understood, and the disease defies any single definition of where risk may originate. A genetic component of risk is well established with twin studies showing an estimated heritability of schizophrenia in the range of $70-80 \%$ (Neale and Sklar, 2015). With regards to genetics of the disease, the greatest progress has come from the large samplesized genome-wide-association studies (GWAS). The Psychiatric Genomics Consortium (PGC), established in 2007, includes more than 500 investigators from $25+$ countries and deserves strong consideration in this field (Sullivan, 2010). The Consortium has been collecting genome wide single nucleotide polymorphism (SNP) data worldwide to establish meta-analyses that highlight common disease causing polymorphisms. The leading hypothesis resulting from this work is that the genetic architecture of schizophrenia is similar to that of height, Crohn's disease or diabetes and relies on common variants of small effects (Sullivan et al., 2012).

The latest PGC paper describes the genotyping data of 36,989 cases and 113,075 controls (Schizophrenia Working Group of the Psychiatric Genomics Consortium, 2014). With this sample size, 108 loci of genome wide significance were identified, with 83 being newly described. More than $80 \%$ of these loci were found in or near known gene regions, including haplotypes with polymorphisms coding for dopaminergic receptors, glutamatergic transmission proteins and calcium gated voltage channels. When the causal sequences were mapped with epigenetic markers of specific tissues, the risk variants were found to be enriched in the brain, particularly in the cortex and the striatum, compared to other organs. This study identified genes that encode for the proteins involved in the pathophysiological mechanisms of schizophrenia, including dopaminergic and glutamatergic systems. In addition, this work reported single nucleotide polymorphisms on chromosome 6, where the major histocompatibility complex (MHC) genes are located. Although this region contains genetic elements beyond those involved in immunity, the MHC locus variants suggest etiological relevance of immune genes and inflammatory pathways (Anon, 1999; Schizophrenia Working Group of the Psychiatric Genomics Consortium, 2014). GWAS share concerns about the population stratification, clinical and genetic heterogeneity, the absence/presence of marginal effects, and the multiple testing problem as reviewed in (Price et al., 2010).

Another development in schizophrenia genetics is the demonstration of the role of structural variations (Walsh et al., 2008; Purcell et al., 2014). Some of these mutations are rare and have a 
moderate-to-large effect. Most are related to copy number variations (CNVs) as well as other types of structural genomic variation including deletions, duplications, and chromosomal rearrangements with potentially different pathogenic mechanisms and phenotypic outcomes (Levinson et al., 2011; Merikangas et al., 2014; Ruderfer et al., 2013; Timms et al., 2013; Warnica et al., 2014). The rate of CNVs in schizophrenia patients is increased, with deletions being observed more frequently than duplications (BuizerVoskamp et al., 2011; Szatkiewicz et al., 2014). Structural variations can be inherited or originate de novo, and their role appears limited to a small fraction of patients (Ruderfer et al., 2013). There have been reports on prevalence of de novo $\mathrm{CNV}$ mutations in genes encoding for synaptic proteins (Xu et al., 2008, 2012; Kirov et al., 2012). Notably, some de novo genetic variants found in patients with schizophrenia overlap with those found in autism spectrum disorder and intellectual disability (Fromer et al., 2014), suggesting the common genetic bases of these developmental brain disorders.

Several families were found to carry structural variations affecting single genes with large impacts (Goate et al., 1991; Rogaev et al., 1995; Klein and Westenberger, 2012). One wellknown example is Disrupted-In-Schizophrenia 1 (DISC1) identified in the large Scottish pedigree carrying a balanced translocation $\mathrm{t}(1: 11)(\mathrm{q} 43, \mathrm{q} 21)$ that segregates with schizophrenia, schizoaffective disorder, recurrent major depression, alcohol dependence and conduct disorder (St Clair et al., 1990). The LOD (logarithm of odds) score for this translocation was found to be 7.1 for all mental disorders and 3.6 for schizophrenia. The translocation is inherited with a dominant mode and reduced penetrance (Millar et al., 2000). Another example of a rare mutation in DISC1 is a frame-shift mutation of DISC1 that segregates with schizophrenia and schizoaffective disorder in a US family (Sachs et al., 2005). Although the pathogenic potential of this mutation remains to be clearly demonstrated (Green et al., 2006), the latest study has provided some interesting insights into the mechanisms whereby this mutation may contribute to abnormal neuronal development (Wen et al., 2014). For in-depth discussions of schizophrenia genetics, the readers are referred to several comprehensive reviews of the topic (McGrath et al., 2013; Mitchell and Porteous, 2011; Sullivan et al., 2012; Harrison, 2015).

Despite the progress in GWAS, the search for the genetic architecture of schizophrenia continues, since the identified variants explain only a small proportion of the overall phenotypic variance. Studies of the potential role of environmental stressors and their interplay with genetic liabilities are anticipated to better explain the etiology of schizophrenia (Réthelyi et al., 2013).

\subsection{Environment}

Many environmental adversities have been associated with schizophrenia, including in utero exposure to infection, perinatal complications, and stressful events during prenatal and early postnatal development, malnutrition, infection and substance abuse (Brown, 2011; Meyer and Feldon, 2010). It has been argued that at least some cases of schizophrenia might be directly related to strong effects of vitamin D deficiency during pregnancy (McGrath et al., 2010), childhood abuse (Mortensen et al., 1999), or adolescent cannabis exposure (Moore et al., 2007).

\subsection{Epigenetic factors}

There is an increasing appreciation that, in addition to DNA sequence and the environment, epigenetic alterations may contribute to psychiatric disorders. Indeed, epigenetic modification is a major mechanism whereby adverse effects of environmental risk factors impact gene expression (Egger et al., 2004; Feinberg, 2007; Bagot and Meaney, 2010). Here, we only briefly review the epigenetics of schizophrenia and refer readers to several recent reviews of the topic (Petronis et al., 1999; Labrie et al., 2012; Abdolmaleky et al., 2005).

Epigenetic mechanisms are predominantly related to chemical modifications of the genome that influence gene expression without changing the DNA sequence (Martin et al., 2011; Helin and Dhanak, 2013). Although DNA methylation and histone modifications comprise the major processes of epigenetic modifications, a growing variety of noncoding RNAs are also being increasingly recognized as another important epigenetic mechanism regulating gene transcription (Hannon, 2002; Chitwood and Timmermans, 2010; Dethoff et al., 2012). Similar to the early days of psychiatric genetics, most recent epigenetic studies have evaluated epigenetic abnormalities in so-called candidate genes, focusing on genes involved in synaptic neurotransmission, oxidative stress, inflammatory pathways or myelination (Svrakic et al., 2013; Pishva et al., 2014; Shorter and Miller, 2015). These studies are being followed by methylome-wide association analysis (MWAS) in patients with psychotic disorders. MWAS finds DNA methylation differences in numerous genetic loci related to neurotransmitter systems and neurodevelopment. Thus, epigenetic studies have convincingly demonstrated that altered epigenetic processes may mediate environmental effects to increase the risk for schizophrenia and other psychotic disorders (Petronis et al., 1999; Labrie et al., 2012; Ibi and González-Maeso, 2015).

Furthermore, growing evidence indicates that complex interactions between genetic variants, environmental factors and epigenetic modifications likely moderate genetic liability toward psychotic disorders. This review then focuses on the role that gene-environment interactions $(\mathrm{G} \times \mathrm{E})$ play in the pathogenesis and pathophysiology of schizophrenia (van Os, 2009; Uher, 2014).

\section{Gene-environment interplay}

Gene-environment interdependence encompasses several scenarios of how genes and environment work together in a particular disorder (Kendler and Eaves, 1986; Rutter et al., 2006). As indicated above, a frequent example of gene-environment interdependence includes environmentally triggered epigenetic modifications (Labrie et al., 2012; Akbarian, 2014). De novo mutations have been also associated with advanced paternal age (Matheson et al., 2011; Goriely et al., 2013). Additive effects of genetic and environmental factors describe what is commonly thought of when liability genes and adverse environment act together to increase one's chances to develop a disease. In their influential early review, Kendler and Eaves indicate two central features of this interaction: "the effects of exposure to a given environment on liability to illness are the same regardless of a phenotype; and the probability of an individual's exposure to a given environment is independent of the individual's genotype" (1986). As separate from interaction, gene-environment correlations then refer to genetic control of exposure to the environment (Kendler and Eaves, 1986; Dick, 2011). In other words, exposure to environment is driven by individual predisposition to choose a particular milieu. There are three main types of these correlations. Passive correlation denotes effects of environment stemmed from a genetic predisposition external to the subject. For example, a genetically controlled parental behavior can influence early life environment that, in turn, shapes a child's personality and behavior. Active correlations and evocative correlations are believed to result from the genes of an individual and are related to actively selecting a preferred environment, or stimulating the existing environment to respond to the individual (Kendler and Eaves, 1986; Dick, 2011). Geneenvironment interaction $(G \times E)$ includes a genetic control of responses to protective or adverse environmental factors, and 
dependency of genetic effects on an environment. Such that genetic effects can have a stronger impact in one environment in comparison to another (Kendler and Eaves, 1986; Rutter, 2008; Rutter et al., 2006; Moffitt et al., 2005; Rutter et al., 2006; Dick, 2011).

Human $\mathrm{G} \times \mathrm{E}$ studies have emphasized the importance of integrating identified genetic risks with environmental factors also associated with disease (van Winkel et al., 2010). The following sections summarize the main findings in recent human and animal studies of $\mathrm{G} \times \mathrm{E}$ in schizophrenia.

\subsection{Immune dysregulation and microbial pathogens}

\subsubsection{Human studies}

In utero or maternal exposure to influenza, Toxoplasma gondii and infections of reproductive organs are identified risk factors for schizophrenia in offspring (Canetta and Brown, 2012; Brown, 2011).

Thus far, only a handful studies have explored $\mathrm{G} \times \mathrm{E}$ in the cases of infection exposure.

One study investigated simplex and multiplex families and found that odds of exposure to cytomegalovirus (CMV) were increased in multiplex families and significant linkage with the D6S2672 region in CMV positive patients (Kim et al., 2007). A study from the same group with a larger sample size and a more detailed genetic evaluation found a positive association between seropositivity for HSV-1 or CMV and a SNP, rs1051788, located to the MHC region (Shirts et al., 2007). The same polymorphism was associated with greater reduction of volume in the prefrontal cortex of schizophrenia patients (Prasad et al., 2010). When focusing on the immune signaling, SNPs located within the IL18R1 gene or IL18RAP gene were all found to be associated with HSV-2, CMV and HSV-1 seropositivity in schizophrenia patients (Shirts et al., 2008). A recent study evaluating the possible interaction between genetic background and exposure to infection in schizophrenia patients utilized a GWA approach in 4500 European cases and controls (Borglum et al., 2014). Neonatal blood samples obtained from Danish filter papers were analyzed for CMV serology in a subgroup of 488 patients and controls. A significant interaction was observed between CMV exposure and a SNP (rs7902091) in the catenin-alpha 3 gene CTNNA3, which was not associated with schizophrenia without exposure. Another study evaluated the association of HSV2 seropositivity with several different polymorphisms from the GRIN family of genes. The GRIN family encode for different NMDA receptor subunits (NLM, 2014). The authors report an interaction between maternal HSV-2 seropositivity and the GRIN2B genetic variations, rs1805539 and rs1806205 (Demontis et al., 2011).

Several studies have reported associations between schizophrenia and season of birth, which may be considered a proxy for maternal infection risk (Torrey et al., 1997; Mortensen et al., 1999). One Japanese study (Narita et al., 2000) found an association between incidence of winter births and the human leukocyte antigen (HLA)-DR1 in patients with schizophrenia. In contrast, Tochigi et al. report no association between HLA-A24 or HLA-A26 and season of birth in schizophrenia (2002). Chotai and colleagues investigated associations between psychosis and polymorphisms within the genes for the tryptophan hydroxylase, serotonin transporter and dopamine D4 receptors. They found that the effects of the polymorphisms were dependent on season of birth (2003). No association with winter birth was reported for the SNP (rs1801133) in the methylenetetrahydrofolate gene in a case-control study (Muntjewerff et al., 2011).

Another group of risk factors that might be influenced by the season of birth are those related to nutritional status during pregnancy. Among maternal nutritional alterations, reduced vitamin D (Sullivan et al., 2013), folate levels (Glaser et al.,
2010) and elevated homocysteine levels (Brown et al., 2007) were associated with increased risk of schizophrenia in the offspring. Vitamin D deficiency is not only associated with prenatal malnutrition, but also observed in adult schizophrenia patients (Bao et al., 2012; Belvederi Murri et al., 2013). Maternal or child genetic background may be important during the process. For example, methylene tetra-hydro-folate reductase (MTHFR) gene C677T polymorphism influences DNA methylation, therefore it may have effect on regulation of schizophrenia-associated genes. In particular, TT genotype, in the presence of low folate levels, decreases DNA methylation (Friso et al., 2002). In different studies, more schizophrenia subjects were found to carry TT genotype than controls (Gilbody et al., 2007; Lewis et al., 2005), and this effect may be more prominent in Asians (Hu et al., 2014).

In addition to maternal immune activation, another possible mechanism whereby microbial infection can interact with risk factors is related to the possibility that some risk factors (e.g., DISC1) may be used by microbes for replication and dissemination (Carter, 2009). Certain features of retroviral genetic interference could also provide a mechanistic explanation for how microbes may interact with genetic liability. Human endogenous retroviruses (HERV) are integrated in the human genome as a result of retroviral infection in germ line cells at several points during our evolution. They can be transmitted person to person, and are thought to play a role in the diversity of the human genome (Leboyer et al., 2013). A specific type of HERV, called HERV-W, has been associated with schizophrenia in several studies (Karlsson et al., 2001, 2004; Huang et al., 2006; Weis et al., 2007; Yao et al., 2008; Dickerson et al., 2012) but negative findings have been also reported (Frank et al., 2005). Notably, HSV-1 and influenza have been demonstrated to activate HERV-W elements, suggesting that environmentally precipitated re-activation of HERV-W may be an important intermediary factor by which exogenous infections contribute to the disorder (Leboyer et al., 2013; Young et al., 2013).

\subsubsection{Animal studies}

One of the most popular approaches to model maternal infection in animal preparations is to stimulate pregnant females with compounds that target toll-like receptors (TLRs), leading to activation of the innate immune response (Meyer and Feldon, 2010, 2012). Prenatal treatment with either the TLR3 agonist polyinosinic-polycytidylic acid (poly (I:C)), an analog of doublestranded RNA, or the TLR4 agonist, Gram-negative lipopolysaccharide (LPS), produces brain and behavior changes that resemble aspects of neurodevelopmental disorders such as schizophrenia and autism (Meyer, 2014). Although basic research has suggested that maternal immune activation (MIA) following exposure to infection may play an important role in causing brain and behavioral pathology analogous to that found in patients with schizophrenia, the exact mechanisms of how microbes can bring about abnormal neurodevelopment remain poorly understood. Further, most animal models that use prenatal immune activation as an environmental factor typically utilize high doses of immune activating compounds, beyond what would be physiologically present during natural infection. This strategy allows the criticism that these models often misrepresent the effect of infection and also the validity of the claim that prenatal infections are responsible for disease. Our group and others have recently proposed that, given the clear genetic components related to schizophrenia risk, experimental studies should focus on studying interactions between prenatal infection and susceptibility genes. Integrating $\mathrm{G} \times \mathrm{E}$ modeling in this system would allow the advance of our understanding of MIA as it relates to the pathogenesis of schizophrenia (Kannan et al., 2013; Brown, 2011). Many animal models of $\mathrm{G} \times \mathrm{E}$ have used this approach with mice carrying variants of candidate genes. 
3.1.2.1. DISC1 models. The first models to use prenatal immune activation in $\mathrm{G} \times \mathrm{E}$ studies were the ones with expression of variants of Disrupted-In-Schizophrenia (DISC1) (Millar et al., 2000). DISC1 has been implicated in various brain functions, including neural proliferation, migration, dendritic arborization and spine formation and the maintenance of synapses (Brandon and Sawa, 2011; Wen et al., 2014). Recently, it has been also demonstrated that DISC1 is involved in mitochondrial functions, oligodendrocyte differentiation and astrocyte functioning (Eykelenboom et al., 2012; Kim et al., 2012; Ma et al., 2013; Park et al., 2010; Wood et al., 2009). Different DISC1 mouse models have been generated. For detailed information on those models, interested readers are referred to previously published reviews (Ayhan et al., 2011b; Jaaro-Peled, 2009).

Our group generated a transgenic model for inducible expression of mutant human DISC1, a putative product of the translocation (Pletnikov et al., 2008a). In this Tet-off model, one can regulate expression of mutant DISC1 in a cell-specific manner with administration of doxycycline (DOX). Expression of mutant DISC1 in forebrain neurons leads to increased spontaneous locomotor activity, decreased social interaction and increased aggressive behavior in males and decreased spatial recognition memory in Morris water maze in females. These behavioral changes are accompanied by lateral ventricles enlargement and reduced dendritic arborization (Pletnikov et al., 2008b). We also found that prenatal expression of mutant DISC1 was sufficient to produce smaller brain size and aggression in mice. Prenatal expression also resulted in lateral ventricle enlargement and associated increased sensitivity to psychostimulants in male mice and depressive-like behaviors in female mice (Ayhan et al., 2011a).

In order to assess possible effects of $\mathrm{G} \times \mathrm{E}$ in mutant DISC1 mice, we exposed them to prenatal immune stimulation using poly I:C treatment (Abazyan et al., 2010). Pregnant mice carrying both mutant DISC1 and control fetuses were injected with $5 \mathrm{mg} / \mathrm{kg}$ poly I:C or saline (as a control group) at gestational day (GD) 9. It was found that mutant DISC1 altered the normal pattern of poly I:Cinduced secretion of cytokines in the fetal brains. In adulthood, prenatal poly I:C exposure increased anxiety-like and depressivelike behaviors and decreased sociability only in mutants but not in controls. Poly I:C also altered functioning of the hypothalamuspituitary-adrenal (HPA) axis by blunting the corticosterone response to restraint stress in mutant mice. The morphometric measurements showed that poly I:C decreased the volumes of the amygdala and periaqueductal gray matter, the areas involved in the brain circuitries of fear- and anxiety related responses in rodents (Canteras et al., 2010). We also demonstrated that expression of mutant DISC1 was necessary during the entire period of prenatal and postnatal development required for the immune challenge to produce the observed neurobehavioral alterations (Abazyan et al., 2010). One of the main outcomes of this study is that pre-existing phenotypic alterations in mutant DISC1 mice were not significantly affected by MIA. Instead, we observed that mutant mice challenged with MIA began to demonstrate the neurobehavioral changes resembling affective disorders. This outcome is consistent with the genetic data that DISC1 can be associated with different psychiatric diseases and also underscores importance of testing different behavioral abnormalities that may not be congruent with a specific diagnostic category but rather reflect different dimensions of the psychopathological continuum as discussed later.

Another group used a mouse model of constitutive expression of mutant DISC1 and evaluated the effects of poly I:C applied during early postnatal development (Hikida et al., 2007; Ibi et al., 2009). Neonatal mutant and control mice were injected with poly I:C for 5 days from postnatal day 2 to 6 and the effects were evaluated at adulthood. Early postnatal poly I:C exposure impaired a short-term memory assessed in Y maze and worsened novel object recognition in both control and mutant mice. When compared to control saline-treated mice, mutant DISC1 mice treated with poly I:C had impaired fear memory, increased locomotor activity, decreased social interaction and increased aggressive behaviors. The decreased number of parvalbumin positive cells in medial prefrontal cortex (MPFC) and the increased number of BrdU positive cells, an indicator of neurogenesis, in the granular cell layer of the dentate gyrus of the hippocampus were found only in mutant DISC1 mice treated with poly I:C. This study demonstrated how an environmental factor can exacerbate pre-existing mild schizophrenia resembling abnormalities (e.g., reduced parvalbumin reactivity) in DISC1 mice (Ibi et al., 2010).

Synergistic effects of genetic variants and environmental challenge were also described by the study that used DISC1 mutant lines, with exon 2 missense point mutations resulting in Q31L and L100P amino acid changes (Clapcote et al., 2007). In the initial paper, $31 \mathrm{~L}$ mutant mice demonstrated increased immobility in the forced swim test (FST), decreased sociability and decreased sucrose consumption, consistent with a depressive-like phenotype. L100P mutant mice had increased locomotor activity, decreased PPI and Latent Inhibition and a poor memory assessed in $\mathrm{T}$ maze. Antidepressant treatment improved FST in Q31L mutants whereas antipsychotics, rolipram (an inhibitor of PDE4 that binds to DISC1 (Millar et al., 2005)) and a GSK3 inhibitor (VP1.15), increased PPI in L100P and Q31L mice (Lipina et al., 2013). Decreased neurogenesis, the number of neurons in the cortex, and altered neuronal morphology were observed in both mutant models, suggesting cortical maldevelopment (Lee et al., 2011).

Q31L and L100P heterozygous animals were challenged with MIA induced by poly I:C at GD9. MIA reduced sociability, worsened pre-existing impairment in PPI, and affected novel object recognition in L100P mutants that were considered a model of schizophrenia-related abnormalities (Clapcote et al., 2007). Prenatal immune challenge up-regulated expression of IL-6 in the fetal brains, with the strongest effect being found in L100P mice. Notably, anti-IL6 treatment reversed the effects of poly I:C on PPI and LI in mutant mice, supporting the previous findings that IL-6 may play a leading role in mediating adverse effects of maternal immune activation (Smith et al., 2007; Lipina et al., 2013).

3.1.2.2. Nurr 1. The nuclear receptor related 1 protein (NURR1) is an inducible transcription factor, an orphan member of the steroid/ thyroid nuclear receptor superfamily. Nurr1 expression starts early during development and continues throughout adulthood. Nurr1 is expressed in mesencephalic dopamine neurons and is responsible for their differentiation (Buervenich et al., 2000; Moore et al., 2008; Xing et al., 2006). Given the role of dopamine neurotransmission in the pathophysiology of schizophrenia, the function of this protein was evaluated in Nurr1 knockout (KO) mice. The heterozygous Nurr1 KO mice displayed increased activity at baseline and after administration of PCP or amphetamine. Both basal and druginduced hyperactivity was reversed by haloperidol (Rojas et al., 2007). In cognitive tests, no learning deficit was observed but memory retention was significantly impaired in males in passive avoidance test. In addition, increased immobility on the second day of FST was found, suggesting a depression-like response in mutant mice. The alterations in the dopamine and serotonin metabolism were detected in the frontal cortex, striatum and hippocampus of mutant animals (Rojas et al., 2007). It should be noted that some of these results were not replicated in a recent study (Moore et al., 2008).

Urs Meyers group evaluated the effects of $\mathrm{G} \times \mathrm{E}$ in Nurr1 mutant mice exposed to MIA with poly I:C at GD17. When tested at 
postnatal days (PND) 70-120, synergism of the effects of both factors was observed in increased locomotor activity, startle reactivity, PPI and latent inhibition (LI). Immunohistochemical analysis revealed decreased tyrosine hydroxylase staining in the nucleus accumbens (NAc) and PFC and increased COMT staining. Interestingly, poly I:C increased production of IL-6, IL-10 and TNF- $\alpha$ only in control but not mutant mice, which had already decreased levels compared to wild-type littermates (Vuillermot et al., 2011, 2012).

The study of O'Leary and colleagues (2014) is an example of using a sophisticated design of cross-fostering in an attempt to distinguish multiple effects of $\mathrm{G} \times \mathrm{E}$ and control for dams' behaviors following an adverse environmental exposure during pregnancy. The authors examined the neurobehavioral schizophrenia-related interactions between prenatal immune activation with Poly I: $C$ and disruption of the schizophrenia risk gene, Neuregulin 1 (NRG1). A variety of schizophrenia-related behavioral abnormalities were found depending on the combinations of $\mathrm{Nrg} 1$ disruption, prenatal insult and cross-fostering. The authors argue that multiple timedependent interactions that involve individual genes interacting with diverse biological and psychosocial environmental factors should be taken into account and recapitulated in animal models.

In a recent exciting paper, Nurr1 KO mice were exposed to chronic infection with $T$. gondii and were tested in an emergence test, activity in an open field and with a novel object, response to bobcat urine and prepulse inhibition of the acoustic startle response (PPI) prior to and 6 weeks after infection. T. gondii infection produced a greater elevation of open field activity in Nurr1 HET mice consistent, with the hypothesis that the Nurr1 genotype can exacerbate parasite-induced behavioral abnormalities (Eells et al., 2015).

Another example of using live pathogen associated with schizophrenia is a series of studies performed by a Swedish group who infected neonatal immunodeficient (Tap1 KO) mice lacking functional CD8 (+) T cells with influenza A/WSN/33 virus. Three to four months after the infection, deficits in working memory, increased rearing activity and anxiety were observed in KO but not WT mice. No group differences were found in virus replication, distribution or clearance. One possible mechanism for $\mathrm{G} \times \mathrm{E}$ in this model may be related to a more pronounced glia response in Tap1 KO mice to viral infection (Asp et al., 2009). A subsequent study evaluated long-term effects of the infection on PPI and transcription of genes encoding enzymes in the kynurenine pathway and levels of kynurenic acid (KYNA) that have been shown by the same group to be activated in this viral model. Influenza infection upregulated transcripts encoding indoleamine-pyrrole 2,3-dioxygenase (IDO), degrading tryptophan in the first step of the kynurenine pathway, and transiently increased KYNA in the brain of infected mice. At age 5-6 months, neonatally infected Tap1 KO but not WT mice showed reduced PPI. The authors conclude that a neonatal infection targets the brain kynurenine pathway contributing to deficient sensorimotor gating in genetically vulnerable mice (Asp et al., 2010; Liu et al., 2014).

The main drawbacks of the $G \times E$ MIA models as reviewed include: (1) limited examinations of dose- and time-dependent effects of MIA; (2) a handful of molecular factors analyzed, calling for a global unbiased profiling with RNA-seq; (3) focus on "conventional" cytokines while practically leaving out measures of other immune factors, particularly peripheral markers of the immune response of dams and offspring. Although using poly I: $\mathrm{C}$ or LPS has helped to generate several exciting $\mathrm{G} \times \mathrm{E}$ models, their utility may be limited as these immune activators are artificial compounds and mimic only some aspects of MIA. More studies with live pathogens relevant to human conditions (e.g., T. gondii) are clearly needed. It would be also important to expand use of anti-inflammatory treatment in animal models to further explore the potential of this therapeutic approach.

\subsection{Stressful factors}

There is an increasing appreciation that stressful events during prenatal and early postnatal development are major environmental risk factors for psychiatric illness and that stress can disrupt brain functioning in a variety of ways (Fine et al., 2014; Dvir et al., 2013). Here, we overview the recent human and basic research on the role of stressful factors in schizophrenia.

\subsubsection{Human studies}

3.2.1.1. Residential status. Residential status, where a person was born, raised or still lives, has been considered an established risk factor for schizophrenia. Systematic reviews assessing the effects of residential status demonstrated that the majority of studies, both with register-based and interview-based methodologies, found a positive association between any period of urban living and schizophrenia (Kelly et al., 2010). A recent meta-analysis which pooled registry based data from over 22,000 cases collected in Denmark, Sweden and Netherlands demonstrated that with an increasing "urban exposure index", the incidence rate for schizophrenia increases. Urbanicity increases the odds risk of developing schizophrenia 2.4 times compared to rural residency (Vassos et al., 2012). The effect of urban residency was also evident for psychotic disorders at large and for "psychotic-like symptoms" in different studies from several different regions of the world (Kelly et al., 2010; Szoke et al., 2014; van Os et al., 2001). In addition, some studies reported positive association between urbanicity and development of other mental disorders, such as bipolar disorder (Paksarian et al., 2014), post-traumatic stress disorder (Reeves et al., 2013), depression and anxiety symptoms (Lundberg et al., 2009) but contradicting findings also exist (Baxter et al., 2006; Breslau et al., 2014).

Findings from NEMESIS (Netherlands Mental Health Survey and Incidence Study) pointed to the possible genetic interaction with urbanicity for the first time. Proband patients with a family history of psychosis have significantly higher risks to develop psychosis with increased urbanicity than probands without the same family history (van Os et al., 2003, 2004). The authors suggest that as many as $60-70 \%$ of individuals with familial liability who had also experienced urban exposure went on to develop a psychotic disorder. In the aforementioned studies, urbanicity was rated according to the degree of the density of the population in address counts per square-kilometer and the effect of prominent urbanicity was discussed as an environmental factor that interacts with genetic liability. This interaction resulted in an increase in risk for psychotic illness, rather than 'lower level of urbanicity' having a protective effect. The reader should note, however, that these studies, by design, provide correlative data and models are often needed to identify causal disease origins within the observed risk factors.

3.2.1.2. Childhood trauma. For the last two decades, epidemiological research has rekindled interest in the role of early childhood adversity in schizophrenia (Rossler et al., 2014). A Swedish national cohort study of more than 2 million subjects evaluated the hospital inpatient registry against childhood living circumstances, including parental status, housing status, socioeconomic level, and employment status. The authors found the increased number of adverse childhood events in hospitalized patients (Wicks et al., 2005). Frequency of episodes of childhood trauma was found to be higher in patients compared to healthy controls or their siblings. It was also reported that trauma increased the severity of schizophrenia symptoms, was then also associated with high scores of schizotypy in the siblings and even healthy subjects (Heins et al., 2011), enhanced severity of prodromal symptoms 
(Thompson et al., 2009), or decreased cognitive competencies in patients with schizophrenia (Shannon et al., 2011). All these findings are consistent with the notion that childhood trauma can increase the risk for psychosis or moderate the severity of positive symptoms. Beyond the impact of childhood adverse events on adult psychopathology in schizophrenia, the same profile also exists in anxiety disorders, depression, substance use disorders, and bipolar disorder (Gilman et al., 2014; Green et al., 2010; Pietrek et al., 2013). In this context, one could describe the effects of childhood adversity as nonspecific.

Considering that childhood abuse is a strong environmental risk factor for the development of psychotic symptoms and disorders, there has been considerable interest in understanding its association with genetic risk. This association between abuse and disease could be due to genetic factors influencing exposure to traumatic environments or increasing sensitivity to the detrimental impact of abuse. However, one recent study exploring the interaction between early life abuse and genetic markers showed no significant additive effect of childhood abuse combined with the known risk haplotype of the nitric oxide synthase 1 adaptor protein (NOSAP1) gene (Husted et al., 2010). In another study, Alemany et al. (2011) evaluated interactions between childhood abuse and the BDNF Val66Met polymorphism on the prevalence of positive and negative symptoms in adult patients. This work showed that compared to Val homozygotes, Met carriers had higher scores on a psychotic experiences scale if childhood adversities were present, indicating interaction between childhood abuse and genetics.

McCarthy-Jones and colleagues examined potential $\mathrm{G} \times \mathrm{E}$ between SNPs of the Forkhead box protein P2 gene (FOX2P), which was previously weakly associated both with auditory verbal hallucination (AVHs), and childhood emotional abuse (Lai et al., 2001). Human FOXP2 is known to have a role in the development of speech and language in humans (Lai et al., 2001). Data on parental child abuse and FOXP2 SNPs previously linked to AVHs were evaluated in people with schizophrenia-spectrum disorders, both with ( $n=211$ ) and without $(n=122)$ a lifetime history of AVHs. The authors report that although SNP frequencies did not differ between abused and non-abused groups, there was a statistically significant interaction between childhood parental emotional abuse and rs1456031 in predicting lifetime experience of AVH. Curiously, this interaction was found to be specific to AVHs, and was not found for non-verbal auditory hallucinations. The findings are a preliminary but promising example of $\mathrm{G} \times \mathrm{E}$ in which a weak genetic effect can be moderated by childhood abuse (McCarthyJones et al., 2014).

Although not directly related to schizophrenia, Rabl et al. provide an example of an endophenotypic evaluation of additive gene-environment effects on the hippocampus, the volume changes in which have been linked to chronic stress. This MRI study investigated interaction effects on hippocampal volume between functional genetic variants (COMT Val158Met, BDNF Val66Met, 5-HTTLPR) and environmental adversity in 153 healthy subjects. The variants examined showed significant interactions with environmental adversity with respect to hippocampal volume. The effects of this interaction were additive in nature. Notably, an analysis of hippocampal subfields revealed sub-regionspecific volumetric effects for each genetic variant, i.e., 5-HTTLPR for the subiculum, BDNF Val66Met for CA4/dentate gyrus, and COMT Val158Met for CA2/3. The findings indicate that $\mathrm{G} \times \mathrm{E}$ can determine hippocampal volume, which may in turn be relevant to stress-related conditions, including psychotic disorders (Rabl et al., 2014).

Fisher et al. used a large epidemiological case-control sample (172 cases and 246 controls) to explore the interaction between a specific form of childhood abuse and family psychiatric history, in place of specific genetic markers, in the onset of psychosis. The study found no evidence that familial risk accounts for associations between childhood physical abuse and psychotic disorder, or that it substantially increases the odds of developing psychosis among individuals reporting abuse (Fisher et al., 2014).

3.2.1.3. Stress. Several recent studies have evaluated the interactions between candidate genes and stress interaction in psychosis (Modinos et al., 2013). Using a sample of healthy military servicemen, Stefanis et al. (2007) found that compared to COMT Met homozygous, COMT Val heterozygotes were more prone to a psychotic outcome under stressful conditions (Stefanis et al., 2007).

Similarly, Simons et al. reported that healthy female carriers of the COMT Val allele exhibited greater paranoia in response to stress (Simons et al., 2009) However, an opposing interaction was reported by van Winkel et al. (2008) and Collip et al. (2011) who found that stress led to the greatest increase in psychosis in COMT Met homozygous patients. Peerbooms et al. (2012) studied an interaction between stress and the polymorphisms in the COMT gene (Val158Met) and in the methylenetetrahydrofolate reductase (MTHFR) gene (C677T and MTHFR A1298C) known to differentially affect cognition in patients with schizophrenia and healthy individuals. The authors report that stress reactivity associated with COMT Val158Met in patients with psychosis may be moderated by the patient's MTHFR C677T genotype. In an investigation of how interaction between polymorphisms in a candidate gene, Neuregulin 1, and psychosocial stress may affect unusual thoughts in patients with schizophrenia, Keri et al. found that compared to C-carriers at rs6994992, T homozygotes had more unusual thoughts in conflict-related conditions (Keri et al., 2009).

Howes and Murray propose that childhood social adversity or similar stressful experiences may interact with genetic predisposition to enhance dopamine synaptic transmission in subcortical areas. The ensuing biased "cognitive schema" predisposes the individual to construe experiences toward paranoid interpretations by misattributing salience to stimuli. Repeated experiences of paranoia and hallucinations exacerbate stress and any associated dopamine dysregulation, eventually solidifying psychotic ideas and beliefs (Howes and Murray, 2014).

\subsubsection{Animal studies}

There are several approaches to model stressful events in animals, including prenatal stress, maternal separation, isolated rearing or social defeat paradigm (Cryan and Slattery, 2007; Boksa, 2007; Koenig, 2006). A number of recent reviews have described the effects of prenatal and postnatal stress on activity of the hypothalamus-pituitary-adrenal (HPA) axis and resultant behavioral phenotypes (Koenig, 2006; Weinstock, 2008).

3.2.2.1. Reelin. Potential synergistic interactions between maternal separation and genetic risk factors have been studied in reeler mice. Reeler mice are a genetic model of a loss-of-function of Reelin (D'Arcangelo, 2005; Costa et al., 2002). The reelin glycoprotein is involved in controlling neuronal cellular interaction as well as migration and positioning (Rogers and Weeber, 2008) Reelin was first implicated in schizophrenia when both mRNA and protein levels of this factor were found to be decreased in temporal and prefrontal cortices, hippocampi and cerebellum in patients (Impagnatiello et al., 1998; Guidotti et al., 2000; Fatemi et al., 2005; Fatemi et al., 2000) although there are negative findings as well (Tochigi et al., 2008). Reelin blood levels were also found to be decreased in schizophrenia and mood disorder patients (Fatemi et al., 2001).

Decreased neuronal levels of reelin were related to increased activity of D-N-methyltransferase (DNMT), suggesting that hypermethylation in the reelin promoter might be responsible for 
decreased reelin expression in different layers of the cortex and the white matter (Eastwood and Harrison, 2003; Grayson et al., 2005).

Early maternal separation (PND 2-6) was used to investigate $\mathrm{G} \times \mathrm{E}$ in reeler mice (Laviola et al., 2009). Social motivation was assessed in the 'homing test paradigm' in which 9-day-old mice had to use olfaction to find the nest. Maternal separation was found to reduce social motivation (i.e., increased the latency to reach the nest) in WT but not reeler mice (Ognibene et al., 2007). Further, early maternal separation was associated with reduced social interaction and expression of reelin and BDNF levels in the PFC, striatum and hippocampus in adult WT but not mutants (Ognibene et al., 2008). These reports on reeler mice clearly indicate what appears to be a common theme in many basic $\mathrm{G} \times \mathrm{E}$ studies when two adverse factors (e.g., stress and a genetic variant) might interact in a somewhat unexpected fashion to minimize rather than potentiate each other's effects (Laviola et al., 2009).

3.2.2.2. Nurr1. Another approach to recapitulate aspects of childhood trauma as a schizophrenia risk factor includes social isolation during adolescence. Social isolation of HET Nurr1 mice during adolescence led to impaired PPI when assessed 12 weeks after the cessation of isolation in adult mice. The behavioral phenotype was associated with decreased tissue content of dopamine (DA) and 3,4-dihydroxyphenylacetic acid (DOPAC) in the PFC in mutants but not in WT animals (Eells et al., 2006), suggesting the synergistic effects. Corticosterone levels were also measured in mutants and controls under the basal conditions and after restraint stress but no group-related differences were detected, arguing that social isolation did not seem to affect stress reactivity in mutant mice (Eells et al., 2006).

3.2.2.3. Sept5. The effects of social isolation were also studied in a mouse model of the SEPTIN 5 (SEPT5) gene. The gene is located within 22q11 region linked to schizophrenia (Harper et al., 2012). SEPT5 is expressed in the brain both during neurodevelopment and adulthood (Asada et al., 2010) and is involved in vesicular exocytosis by binding to syntaxin in presynaptic SNARE (Soluble N-ethylmaleimide-sensitive factor Attachment Protein Receptor) complexes (Beites et al., 2005). Sept5 KO mice exhibit decreased social interaction, spent more time in the open arms of the elevated plus maze and showed increased PPI. Sept 5 deletion was also associated with the longer latency to reach the goal in the L maze. However, no differences were observed in spontaneous activity, T-maze, rewarded alternation and tail suspension tests (Suzuki et al., 2009). When Sept5 KO mice were individually housed after weaning, the amygdalar SEPT5 levels were found to be increased. Compared to group-housed mutants, single-housed ones demonstrated less thigmotaxis in open field, spent more time in the open arms of the elevated plus maze and spent more time in active social interaction compared to group housed mutants, consistent with reduced anxiety levels. This study is another example where adverse factors interact to counteract the negative effects of one another when studied separately (Harper et al., 2012).

3.2.2.4. PACAP. The effects of stress were also studied in mice deficient in pituitary adenylate cyclase activating polypeptide (PACAP). PACAP is a neuropeptide which displays structural similarity to vasoactive intestinal peptide (VIP) and a member of the secretin/glucagon/VIP family. PACAP is involved in circadian rhythms, axonal maturation, axonal integrity and cellular stress responses (Waschek, 2013). PACAP is encoded by the ADYCAP1 gene located in the $18 \mathrm{p} 11.32$ region, a locus linked with schizophrenia (Faraone et al., 2005; Mukherjee et al., 2006; Schwab et al., 1998). Additionally, ADYCAP1 variants were associated with schizophrenia, deficits in verbal memory and hippocampal volume (Koga et al., 2010). The role of PACAP-DISC1 interaction in neurite outgrowth can be relevant to schizophrenia (Hattori et al., 2007). Mice lacking the Adycap1 gene do not express PACAP. These mice were subjected to two different rearing conditions, namely a short-term social isolation (SI) at PND 28 or environmental enrichment (EE) starting at PND28 or 56. SI of mutants increased their locomotor activity, decreased latency to attack and increased attacking time in social interaction tests, consistent with elevated aggression. In addition, SI further decreased PPI in mutants. On the contrary, EE at PND 28 but not PND 56 decreased hyperactivity; increased time spent in social interaction tests and decreased duration of immobility in FST. Still, similar to SI, EE worsened PPI in mutant mice (Ishihama et al., 2010). A follow-up study demonstrates that EE for 4 weeks could ameliorate deficits in a contextual fear conditioning test and a novel object recognition test. Intriguingly, these protective effects were still present 2 weeks after cessation of EE even if the brain effects of EE on expression of NMDA receptors, phospho-ERK, phospho-CaMKII, and brain-derived neurotrophic factor (BDNF) were no longer observed. The results suggest that the EE-induced molecular changes in the hippocampus might be required for initiation but not maintenance of long-lasting effects of EE on cognitive function (Takuma et al., 2014).

3.2.2.5. DISC1. Recently, a dominant negative mouse model with expression of mutant DISC1 under the PrP promoter was used to study synergistic effects of the mutation and social stress. Mutant and control were exposed to 3-week isolation beginning from 5 weeks of age. It was found that only mutants exposed to SI displayed increased locomotor activity, deficient PPI, and increased immobility in FST, suggesting $\mathrm{G} \times \mathrm{E}$ effects. These effects were associated with decreased extracellular levels of dopamine and $\mathrm{TH}$ expression, increased $\mathrm{D} 2 \mathrm{R}$ expression in the frontal cortex and increased DA levels in the NAc, the main forebrain targets of DA projections of the ventral tegmental area. The authors also report increased levels of corticosterone in SI challenged mutants and were able to reverse the effects of SI with the glucocorticoid receptor antagonist, mifepristone. SI-increased glucocorticoids production resulted in methylation of the $\mathrm{TH}$ promoter, leading to reduced $\mathrm{TH}$ expression selectively in the mesocortical pathway. This reduction was also reversed with mifepristone. This study provides an example of the convergent target of $G \times E$ relevant to schizophrenia (Niwa et al., 2013). Mice carrying Disc1 point mutations were exposed to chronic social defeat (CSD). CSD were applied to Q31L or L100P mutants during PND 50-70 followed by behavioral testing. CSD increased time spent in open arms of the elevated plus maze in Q31L/+ mice while significantly decreasing the same in L100P/+ mice. CSD also decreased PPI and increased sociability and social novelty in L100P/+ mutants, suggesting an interactive effect (Haque et al., 2012).

3.2.2.6. GAD. Stress influences the development and function of GABAergic neurons (Fine et al., 2014). Glutamic acid decarboxylase (GAD) is the enzyme responsible for conversion of glutamate to GABA. GAD is coded by GAD1 located within 2q31.1 region. Initial studies have revealed decreased expression of GAD, specifically the GAD67 isoform, in the PFC of schizophrenia subjects (Akbarian et al., 1995; Volk et al., 2000). Subsequent studies demonstrated that this reduction was mainly related to Parvalbumin-positive interneurons (Curley et al., 2011; Kimoto et al., 2014; Volk et al., 2012; Beneyto et al., 2012). Additionally, the levels of the enzyme that methylates the promoter of GAD67 to decrease its expression were elevated in PFC interneurons of psychosis patients (Veldic et al., 2007). Prenatal stress was applied in an animal model using knock-in (KI) mice that express GFP with endogenous Gad67 promoter to label Gad67 expressing interneurons (Tamamaki et al., 2003). Heterozygous mice express Gad67 in one allele (Gad67+/GFP) and can be 
considered as a knock-down model in which the total expression of Gad67 is half of the WT level (Tamamaki et al., 2003). Restraint-andlight stress at GD17 increased maternal cortisol levels in both WT and Gad67+/GFP mothers, with mutant having a greater increase. Fetal body weight was significantly reduced and fetal cortisol levels were much higher in the mutant fetuses exposed to stress (Uchida et al., 2011). In a follow-up study, mutant mice were exposed to restraint-light stress during GD 15-17.5. This intrauterine exposure was associated with the decreased number of parvalbumin positive interneurons in the PFC, somatosensory cortex and hippocampi of mutant offspring only (Uchida et al., 2014).

3.2.2.7. SNAP25. A similar paradigm was used in Bdr mice that expresses a defective SNAP25 protein that alters its binding to SNARE complex and affects presynaptic vesicular exocytosis (Jeans et al., 2007). Synaptosomal-associated protein-25 (SNAP25) is a presynaptic protein that takes part in vesicular exocytosis (Chen and Scheller, 2001), neurite outgrowth (Wu et al., 2011) and longterm potentiation (Jurado et al., 2013) Evaluation of synaptic proteins in the post-mortem samples revealed altered SNAP25 levels in the frontal and temporal lobes (Karson et al., 1999; Thompson et al., 1998), and also in the entorhinal cortex (Young et al., 1998), hippocampus (Fatemi et al., 2001; Thompson et al., 2003) and cerebellum (Mukaetova-Ladinska et al., 2002) of schizophrenia patients. Additional evidence for the role of SNAP25 came from relatively small scale genetic epidemiologic studies, some of which reported positive association with SNAP25 variants and schizophrenia (Carroll et al., 2009; Lochman et al., 2013) but negative studies also exist (Kawashima et al., 2008; Dai et al., 2014). Bdr mice displayed ataxia (hence blind-drunk), PPI impairment, reduced social interaction and exploratory behavior (Jeans et al., 2007). Circadian rhythm impairment, namely phase advance in the sleep pattern, as well as altered blood corticosterone and argininevasopressin levels were observed in these mice (Oliver et al., 2012). Prenatal stress decreased time spent with another mouse (as a sociability index) and decreased time spent with a novel stranger mouse (as a social novelty index) in Bdr mice only. Stressful treatment of Bdr and control mice resulted in reduced PPI that could be ameliorated with antipsychotics (Oliver and Davies, 2009).

3.2.2.8. NRG1. A different model of a candidate genetic risk factor, Neuregulin 1 (NRG1), was also evaluated with regard to a putative interaction with cannabis. The association of NRG1 and schizophrenia was first suggested in a large Icelandic sample (Stefansson et al. 2002). Follow-up epidemiologic studies reported both positive and negative associations of different NRG1 variants and schizophrenia (Iwata et al., 2004; Li et al., 2014; Stefansson et al., 2003; Thiselton et al., 2004; Williams et al., 2003). In some postmortem studies NRG1 signaling components have been found increased in schizophrenic patients (Chong et al., 2008; Hahn et al., 2006; Hashimoto et al., 2004). NRG1 plays an important role in neuronal migration, axonal guidance, neuronal and glial maturation, myelination and synaptogenesis. NRG1 mutations are associated with impairments in glutamatergic, dopaminergic and GABAergic neurotransmission (Li et al., 2007; Newell et al., 2013). With regard to the pathogenesis of schizophrenia, increased NRG1 signaling is proposed to lead to increased GABAergic inhibition of glutamatergic pyramidal neurons, resulting in a hypoglutamatergic state (Mei and Xiong, 2008; Deng and Dean, 2013; Mei and Nave, 2014). The Nrg1 KO homozygosity has a fatal effect on mice. In a heterozygous state, there were no gross differences in the appearance of the mice and, behaviorally, the mutant mice displayed increased spontaneous activity and deficit in PPI (Golub et al., 2004).

A Nrg1-transmembrane-domain knockout mice exhibited increased locomotor activity, decreased PPI, impaired social novelty, and increased sensitivity to NMDAR antagonists in their heterozygous state (O'Tuathaigh et al., 2007; O'Tuathaigh et al., 2010; Stefansson et al., 2002). These mice were utilized in studies for several different types of $\mathrm{G} \times \mathrm{E}$. $\mathrm{Nrg} 1$ HET mice were exposed to CSD starting on PND 35. When evaluated in adulthood, CSD decreased locomotor activity, numbers of alternation in Y-maze, decreased the proportion of time spent with a novel subject in a social interaction test and increased the number of walkovers in social investigation in Nrg1 mutant mice. Analyses for selected immunological variables were carried out and revealed that CSD in mutants differentially increased the levels of basal cytokines and caused variable changes in IL1 $\beta$ and TNF $\alpha$ levels in different brain regions (Desbonnet et al., 2012).

Nrg1 transmembrane heterozygous mutants were exposed to acute restraint stress in two different periods, younger (3-4 months) and older (6-7 months) ages. Stress reduced locomotor activity and exploratory behavior in both groups of mice. However, additive genotype-stress interaction only occurred in older mice. In particular, mutants did not display anxiety-like behavior in the open field while WT mice did. Contrary to the behavioral test results, corticosterone response to stress was more pronounced in younger mice (Chesworth et al., 2012). In a different study, the authors applied a subchronic restraint stress paradigm during adolescence (PND 36-49, $30 \mathrm{~m} /$ day). Repeated, but not acute, stress caused disruption in PPI only in the stressed-mutant group. Acute and repeated stress resulted in increased levels of corticosterone levels, however the response was significantly less in the mutants after repeated stress. Interestingly stress decreased apical dendritic length and complexity in the medial prefrontal cortex and hippocampus of the mutants (Chohan et al., 2014a). NMDA receptor binding of MK-801 was increased but the response was blunted in the ventrolateral septum, more pronounced in the dentate gyrus, and binding was decreased in the inferior-lateral region of the mPFC of the mutants (Chohan et al., 2014b).

The effects of stress were also evaluated in genetic models created in genetically modified rats. A rat model was created by disrupting the $5^{\prime}$ region of $\mathrm{Nrg} 1$. This genetic manipulation produced decreased type II NRG1 mRNA and protein expression. The mutants displayed deficient habituation in the open field, impaired memory in visuo-spatial discrimination and cued fear conditioning (Taylor et al., 2011, 2012). When these animals were exposed to a chronic variable stress paradigm at PN37 through 44, both mutant and WT rats displayed less anxiety-related behavior. As an indication of sex-specific effects of $\mathrm{G} \times \mathrm{E}$, only mutant females showed enhanced cued-fear extinction following stress exposure (Taylor et al., 2013). A further discussion of different NRG1 models can be found in a review by Karl (2013).

Similar to the immune models, the weaknesses of the $\mathrm{G} \times \mathrm{E}$ stress models include lack of time- and dose-dependent effects of stressful factors. There have been very few if any studies of pathogenic factors that can be activated by stress in addition to glucocorticoids, e.g., immune factors or markers of oxidative stress. There is still a limited examination of epigenetic modifications following developmental exposure of genetically modified animals to stressful conditions. At a more fundamental level, modeling stressful exposures relevant to human conditions remains a challenge given that some stressful events appear to be uniquely human, e.g., sexual and physical child abuse or urban settings. Although some approaches to mimic urban upbringing have been described (e.g., Lambert et al., 2015).

\subsection{Substance abuse}

\subsubsection{Human studies}

3.3.1.1. Cannabis. The cannabis plant, Cannabis sativa, contains more than 60 cannabinoids (Brenneisen, 2007). The main 
psychoactive component of cannabis is $\Delta 9$-tetrahydrocannabinol (THC). THC exerts its psychoactive effects such as relaxation, confusion, anxiety, and effects on memory through cannabinoid 1 (CB1) receptors that are widely expressed in the central nervous system, most prominently in the basal ganglia, cerebellum, hippocampus and the cortex (Wachtel et al., 2002; D'Souza et al., 2004; Pertwee, 2008; Wong et al., 2010). Notably, another major compound found in the cannabis plant, cannabidiol (CBD), is thought to be responsible for potentially medically beneficial applications including anxiolytic, anti-depressive, anti-psychotic and anti-convulsive effects (de Mello Schier et al., 2014; Devinsky et al., 2014; Iseger and Bossong, 2015). CBD may act as a CB1/CB2 inverse agonist by antagonizing endogenous cannabinoids, anandamide and 2-arachidonoylglycerol, e.g., inhibiting degradation of anandamide (Bisogno et al., 2001; Pertwee, 2008). CBD is suggested to possess antipsychotic properties as well as the ability to reverse the acute effects of THC (Iseger and Bossong, 2015; Schubart et al., 2014). Still, the data on clinical efficacy of CBD are still limited and more studies are clearly needed to conclusively support the beneficial role of the compound (McLoughlin et al., 2014).

Long-term heavy cannabis use during adolescence has been associated with increased risk of schizophrenia (Andreasson et al., 1987; Arseneault et al., 2002; Fergusson et al., 2005; van Os et al., 2002; Evins et al., 2012; Radhakrishnan et al., 2014). Epidemiologic data suggest that an early use of cannabis is associated with an earlier onset of schizophrenic symptoms (Barnes et al., 2006), and cannabis use is also increased in patients years prior to the diagnosis (Boydell et al., 2006). Still, the causative role of cannabis use in schizophrenia risk remains unclear. One suggestion is that heavy cannabis use during adolescence may have particularly detrimental effects on cognition and brain development in vulnerable individuals (van Os et al., 2003).

The polymorphism in the COMT gene, COMT Val158Met, was demonstrated to moderate the effects of cannabis use on adult psychosis. In particular, Val allele carriers were more prone to develop psychosis in the presence of adolescent cannabis use (Caspi et al., 2005; Henquet et al., 2006, 2009). However, negative results for the association were also reported (Costas et al., 2011; Zammit et al., 2007; Kantrowitz et al., 2009). AKT1 is another candidate gene in which mutations may be associated with cognitive and behavioral symptoms in cannabis users. AKT1 is known to play a role in apoptosis, cellular migration, transcription and cell proliferation (Staal et al., 1977). The initial study identifying AKT1 mutations as a risk factor assessed 152 SNPs in 46 genes, determined by a hypothesis driven approach. In both patients with disease and at-risk individuals, AKT1 rs2494732 polymorphisms indicated interaction with cannabis use toward the generation of psychotic symptoms. In particular, a C/C genotype was associated with psychosis, and the risk increased with higher cannabis consumption (van Winkel and GROUP Investigators, 2011). AKT1 rs2494732 was also associated with cognitive impairment increased by heavy cannabis use, with $\mathrm{C} / \mathrm{C}$ genotype carriers having decreased accuracy and longer reaction times in the continuous performance test (van Winkel et al., 2011). The interaction of AKT1 rs2494732 with cannabis in schizophrenia was confirmed in a case-control study, which displayed a dosedependent increase in psychosis risk among cannabis users (Di Forti et al., 2012). Another study found a cannabinoid receptor 1 polymorphism, rs12720071, associated with smaller frontotemporal white matter volume in schizophrenia patients also using cannabis (Ho et al., 2011). This work provides additional evidence for the interactive effect of cannabis and genetic background on morphological alterations in schizophrenia.

In a magnetic resonance imaging (MRI) study in 47 first-episode schizophrenia patients and 30 healthy control subjects, Malchow et al. investigated effects of previous cannabis abuse and increased familial risk on the hippocampus, amygdala, caudate nucleus, putamen, thalamus and sub-segments of the corpus callosum. In a subsequent single-volume ${ }^{1} \mathrm{H}$ magnetic resonance spectroscopy study, they also analyzed spectra in the left hippocampus and putamen to detect metabolic alterations. Patients with a family history of schizophrenia combined with previous cannabis abuse, showed lower volumes of the bilateral caudate nucleus compared to all other patients, implicating an interaction between the genetic background and cannabis abuse (Malchow et al., 2013). In a sample of 2082 healthy individuals, Power et al. show an association between an individual's inheritance of schizophrenia risk alleles and use of cannabis. This was significant for comparing those who have used cannabis compared to those who have never used it. These findings suggest that a portion of the association between schizophrenia and cannabis appears to be linked to a potential genetic predisposition toward use. This research exemplifies a form of gene-environment correlation within this system (Power et al., 2014).

The effects of cannabis' use were also associated with another candidate gene for schizophrenia, Neuregulin-1 (NRG1). Cannabisderived compounds were found to be associated with alterations in the electrophysiological markers related to schizophrenia, such as mismatch negativity (MMN) and p300 (Juckel et al., 2007; Roser et al., 2008). In particular, acute administration of THC reduced p300 amplitude in a way similar to that seen in schizophrenia patients, while cannabis extract, which also includes CBD, increased the amplitude of auditory evoked MMN. THC administration was associated with a reduced MMN amplitude in people carrying NRG1 rs7834206C/C genotype (Stadelmann et al., 2010). Notably, a recent GWA study identified a NRG1 variant, rs17664708, as a risk allele for the development of cannabis dependence in Americans of both African and European descent (Han et al., 2012).

3.3.1.2. Methamphetamine. Methamphetamine (METH) induced psychosis, a concept that originated in Japan following an epidemic of methamphetamine abuse there in the 1950s, was described as a long-lasting psychotic syndrome precipitated by METH associated brain damage (Sato, 1992). Following further peaks of METH abuse in the 1980s and 90s, the characteristics of the syndrome were redefined as progressive impairment in mental and cognitive status with repeated use, and vulnerability to relapse of psychotic symptoms, with a long duration for this vulnerability (Ujike and Sato, 2004). A series of studies from Australia also evaluated the association between METH use and psychotic symptoms. A faceto-face interview method was applied to 309 self-reported recreational users (McKetin et al., 2006). Psychotic symptoms were found in almost one-fourth of the users and METH use increased the odds of psychotic symptoms three times (OR 3.1, 95\% CI 1.6-5.9). A follow-up cross sectional survey also revealed that METH use was associated with the occurrence of psychotic symptoms. More than $80 \%$ of those who had experienced at least two psychotic symptoms in the past year reported the concurrent use of METH (McKetin et al., 2010). In a larger sample, active METH use was associated with the severity of psychotic symptoms. METH use lasting more than 2 weeks during the preceding month increased the odds of psychotic symptoms more than 11 times (OR 11.2, 95\% CI 5.9-21.1). In this study, comorbid cannabis and alcohol use also increased the risk of psychotic symptoms almost two fold (McKetin et al., 2013). However, these studies do not differentiate the acute effects of METH use from chronic ones; therefore they may not be supportive of the syndrome as described by Japanese researchers.

Similar to cannabis use, $G \times E$ may play a role in the genesis of METH-associated psychosis. It is likely that some individuals are 
more vulnerable to developing psychotic symptoms than others and it is also plausible to suppose that their genetic backgrounds may explain this susceptibility. Because of the previously described history, the majority of genetic association studies in this system were reported from Japan. Briefly, those genetic association studies found positive association between METH induced psychoses and certain haplotypes of neurotransmission associated genes. These genes included dopamine $\beta$-hydroxylase (Kalayasiri et al., 2014), dopamine transporter (Ujike et al., 2003), dopamine receptor 2 (DRD2) (Harano et al., 2004), DRD4 (Chen et al., 2004), COMT (Jugurnauth et al., 2011; Suzuki et al., 2006), glycine transporter-1 (Morita et al., 2008), PICK1 (Matsuzawa et al., 2007), G72 (Kotaka et al., 2009), GRM2 (Tsunoka et al., 2010), GRIN1 (Chanasong et al., 2013), Serotonin transporter (5- HTTLPR) (Ezaki et al., 2008), serotonin $1 \mathrm{~A}$ receptor (Kishi et al., 2010), serotonin 6 receptor (Kishi et al., 2011) and monoamine oxidase-A (Nakamura et al., 2009). Additional associations have been seen with various other genes such as alpha-synuclein (in females only) (Kobayashi et al., 2004), glutathione-S-transferase (Hashimoto et al., 2005; Hashimoto et al., 2008), quinone oxireductase (Ohgake et al., 2005), dysbindin (Kishimoto et al., 2008a), frizzled-3 (Kishimoto et al., 2008b), estrogen receptor alpha gene (Kishi et al., 2009), and neuropeptide Y1 receptor (Okahisa et al., 2009). However, the $\mathrm{G} \times \mathrm{E}$ picture in METH associated psychosis is inconsistent for several of these genes (Chen et al., 2004; Hosak et al., 2011; Liu et al., 2004). Finally, a recent study revealed that the risk alleles for METH-induced psychosis were enriched in the schizophrenia GWAS dataset (Ikeda et al., 2013).

\subsubsection{Animal studies}

3.3.2.1. COMT. Clinical and preclinical studies have indicated that genes encoding proteins of dopamine signaling contribute to the cannabis-psychosis association (O'Tuathaigh et al., 2014). As COMT (catechol O-methyl transferase) degrades dopamine, the putative role of COMT in pathogenesis of schizophrenia has been extensively evaluated. In addition to its functional role, the genomic location of COMT (22q11.21) also points to the role of this enzyme in schizophrenia (Gothelf et al., 2014; Paterlini et al., 2005) given that individuals with 22q11 deletion syndrome carry the higher risk of psychosis (Karayiorgou et al., 1998; Murphy et al., 1999). The discovery of val158met functional polymorphism (rs4680) has fueled the research in the role of this polymorphism in the development of psychosis, and regulation of affect and cognition (Heim et al., 2013; Nixon et al., 2011; Ucok et al., 2010; Wirgenes et al., 2010). Comt deficient mice were produced almost two decades ago (Gogos et al., 1998).

Homozygous mice have no COMT activity and increased levels of 3,4-dihydroxyphenylacetic acid (DOPAC) and homovanillic acid (HVA), with no changes in striatal, cortical or hypothalamic content of DA or noradrenaline (NA) (Huotari et al., 2002). By using rapid-time sampling behavioral checklist technique, the ethogram of these mice was studied in detail. Heterozygous mutants displayed increased sifting and chewing, and reduced 'free' rearing (Babovic et al., 2007). Spontaneous locomotion of mutants did not differ from that of controls, although male mutants displayed increased locomotor activity after acute amphetamine injection (Huotari et al., 2004).

In order to evaluate possible effects of $\mathrm{G} \times \mathrm{E}$, Comt HET mice were exposed to chronic adolescent THC at PND 32-52. Adolescent THC exposure decreased density and soma size of the ventral tegmental area (VTA) dopaminergic cells (Behan et al., 2012). A follow-up study assessed the effects of chronic adolescent exposure to the cannabinoid receptor agonist, WIN 55212, in COMT mutants. The agonist was administered at PND 32-52, and the behaviors were assessed 21 days later. The agonist increased the startle response, decreased PPI and increased time spent in light area in light/dark test in mutant mice. Notably, the COMT inhibitor, tolcapone, reversed these effects of the agonist, consistent with the notion that at least some of the behavioral effects of the agonist were mediated by DA metabolism regulated by COMT (O’Tuathaigh et al., 2012).

3.3.2.2. NRG1. An Australian group has studied the effects of THC on $\mathrm{Nrg} 1$ transmembrane HET mice. 48-84 week-old WT and HET Nrg1 KO animals were given a battery of behavioral tests after acute administration of THC in the dose of 5 and $10 \mathrm{mg} / \mathrm{kg}$. Without THC exposure, Nrg1 HET mice showed less aversion to light in the light-dark box. They also spent more time in the open arms during elevated-plus maze testing and showed general hyperactivity. In only Nrg1 heterozygous mutants but not in controls, THC reduced locomotor activity, decreased time spent in open arms, increased aversion to the light area, changed PPI and altered the neuronal activity pattern as measured by c-fos expression in the lateral septum (Boucher et al., 2007). Longterm cannabis administration was modeled in Nrg1 transmembrane domain mutant mice. Mice were treated with THC from PND 21 to 32 and a comprehensive evaluation was carried out at adulthood. Unexpectedly, THC administration resulted in a decrease in hyperactivity in mutant mice. The reduction in sniffing (an index of social interaction) observed in control mice treated with THC was not evident in Nrg1 mutants. Chronic THC administration increased CBR1 binding in Nrg1 mutants and affected 5HT2A binding (Long et al., 2013). Tolerance to some of the effects of cannabinoids was modulated by neuregulin- 1 in a repeated cannabinoid administration model. The effects of repeated CP55,940, a THC analogue, on thermoregulation and locomotor activity was abolished in neuregulin-1 mutants, however anxiogenic effects remained stable in the mutants and improved in WT mice (Boucher et al., 2011). Same mutants were also administered CBD in variable doses and the mice were tested at different time periods. Long-term treatment of CBD at high doses reduced the hyperlocomotion and increased social interaction in Nrg1 TM HET mutant mice, however anxiolytic-like effects were only seen in WT. Acute but not chronic administration of high-dose CBD improved PPI. There were slight differences in the binding patterns of 5- HT2A and GABAA receptors between the mutants and the WT mice (Long et al., 2012).

3.3.2.3. DISC1. We have recently reported that a perturbation in DISC1 expression exacerbates the response to adolescent exposure to THC. We demonstrated that chronic adolescent treatment with THC intensified deficits in fear-associated memory in adult mice that express a putative dominant-negative mutant of DISC1 (DNDISC1). A synergistic reduction of c-Fos expression induced by cue-dependent fear memory retrieval was found in DN-DISC1 THC-treated mice. These results suggest that mutant Disc1 could contribute to the detrimental effects of adolescent cannabis exposure (Ballinger et al., 2015).

A similar but inducible DN-DISC1 model was used to evaluate putative effects of chronic methamphetamine administration. In order to mimic a pattern of human methamphetamine abuse, a non-toxic, gradually escalating dose regimen (ED) was used. Specifically, METH doses were gradually increased over a 2-week period. Mutant Disc1 mice exhibited a blunted METH-induced locomotor sensitization and attenuated conditioned place preference in female mice. We also found decreased DA D2 receptor binding and altered AKT/GSK3 signaling in the ventral striatum in female mutant Disc1 mice. These findings suggest that DISC1 signaling may be involved in the neurobehavioral changes induced by psychostimulants, potentially moderating their contribution to schizophrenia (Pogorelov et al., 2012). 
The main weakness of all $\mathrm{G} \times \mathrm{E}$ drug studies is the lack of behavioral paradigms that would more accurately mimic human drug use, i.e., drug self-administration. Use of contingent paradigms could also help uncover common molecular pathology of drug abuse and other major psychiatric disorders that are often co-morbid (Volkow, 2004).

\subsection{Obstetric complications}

Obstetric complication has been long known as a risk factor for schizophrenia (Schmidt-Kastner et al., 2012; Mittal et al., 2008; Suvisaari et al., 2013; Forsyth et al., 2013; Walshe et al., 2011).

\subsubsection{Human studies}

A meta-analysis conducted with data derived from 2 prospective studies in 2002 revealed that the biggest risk factor was gestational diabetes, with an OR of 7.76, 95\% 1.37-43.90 (Hultman et al., 1999; Jones et al., 1998). This is followed by factors such as birth weight under $2000 \mathrm{~g}$, emergency cesarean section, congenital malformations, uterine atony, rhesus incompatibility, asphyxia, bleeding in pregnancy, and preeclampsia (Cannon et al., 2002a). Overall obstetric risk factors determined from prospective studies show moderate effects on schizophrenia risk, with OR between 1.5 and 2 (Cannon et al., 2002b). Some of these factors are associated with fetal hypoxia, such as neonatal cyanosis, apnea and required resuscitation, suggesting the possibility of common underlying mechanisms of pathogenesis. Obstetric complications may also be associated with adverse brain abnormalities, including the lateral ventricle enlargement (Bersani et al., 2009). For a more detailed overview of obstetric complications in schizophrenia, the readers are referred to the review by Mittal et al. (2008).

Further research in the field has emerged on the interaction of obstetric complications and genetic liability for schizophrenia. In familial cases, having two parents with schizophrenia compared to one parent-only or healthy controls, increased the magnitude of lateral ventricle enlargement in the presence of obstetric complications (Cannon et al., 1993). Patients who were exposed to hypoxia had reduced gray matter and decreased CSF volume compared to their siblings, who also were seen to have smaller volume than controls (Cannon et al., 2002c). Van Erp and colleagues found that schizophrenia patients who had experienced hypoxia had smaller hippocampal volumes than those who had not, or their siblings and controls, demonstrating enhanced effects of hypoxia on genetically vulnerable individuals (Van Erp et al., 2002). In a similar association, patients with a family history of schizophrenia had enlarged lateral ventricles, and this enlargement was not observed in non-familial cases (McDonald et al., 2002).

Nicodemus and colleagues tested potential interactions between schizophrenia candidate genes regulated by hypoxia or involved in vascular function in the brain (AKT1, BDNF, CAPON, CHRNA7, COMT, DTNBP1, GAD1, GRM3, NOTCH4, NRG1, PRODH, RGS4, TNF-alpha) and serious obstetric complications. A familybased study of transmission disequilibrium was conducted in 116 trios. Despite the small sample size and limited power of analysis, AKT1 (three SNPs), BDNF (two SNPs), DTNBP1 (one SNP) and GRM3 (one SNP) showed significant gene-environmental interaction. The findings are consistent with the hypothesis that genes involved in neurovascular function, or regulated by hypoxia, could interact with obstetric complications to increase the risk for schizophrenia (Nicodemus et al., 2008).

Another study found that rs2518824 polymorphism of the ARVCF gene, which is deleted in 22q11 syndromes, and rs174576 SNP in the fatty acid desaturase 2 gene, a rate-limiting synthetic enzyme for endogenous long chain polyunsaturated fatty acids, were both associated with white matter abnormalities in preterm infants. These results suggest that genetic variants may influence the effects of preterm birth on white matter development (Boardman et al., 2014). Severe fetal hypoxia was associated with smaller volume of the hippocampus in schizophrenia patients, and this pathology correlated with rs13242038 polymorphism in the GRM3 gene (Haukvik et al., 2010). Given these findings, Geoffroy et al. emphasize a growing need to apply neuroimaging studies on cases involving $\mathrm{G} \times \mathrm{E}$ associations already known to have a clinical effect, such as infections, early stress, urbanicity, and substance abuse (Geoffroy et al., 2013).

\subsubsection{Animal studies}

There are several approaches to model obstetric complications in animal (Boksa, 2004). Among most popular models are those that include diabetes during pregnancy and encompass systemic administration of streptozotocin (an agent cytotoxic to pancreatic B cells) and those utilizing alloxan-induced diabetes or hyperglycemia produced by glucose administration. Another pathological condition, preeclampsia, can be modeled using acute administration of low doses of bacterial endotoxin, long-term nitric oxide synthase (NOS) inhibition, and aortic co-arctation. Perinatal hypoxia, as a common pathogenic factor for several obstetric complications, can be reproduced in animals with global anoxia during a C-section birth (Boksa, 2004).

There have been very few studies of how genetic factors can modulate the brain and behavior effects of obstetric complications. For example, Berger et al. (2000) compared the effects of vaginal and C-section birth on amphetamine (AMPT)-induced locomotor activity in different strains of rats. Amphetamine-induced locomotion was increased in Sprague-Dawley rats and reduced in Lewis rats after $\mathrm{C}$-section birth as compared to vaginal birth. It was suggested that C-section might produce differing long-term changes in dopaminergic function, depending on the genetic composition of the individual. A different approach was taken by Wakuda and colleagues. They examined the effects of hypoxia on expression of schizophrenia genetic risk factors. They found that a 15-min exposure to intrauterine anoxia during cesarean section birth altered expression of $\mathrm{Nrg} 1$ and Comt mRNA in the prefrontal cortex but not the hippocampus at 6 and 12 weeks after birth (Wakuda et al., 2015).

\subsection{Environmental toxins}

\subsubsection{Human studies}

Although the putative role of environmental toxins in schizophrenia is only now becoming a focus of epidemiological and basic research, the detrimental effects of neurotoxins on brain and behavior have been convincingly demonstrated. For example, prenatal organophosphates exposure has been linked to neurocognitive impairment and is used in $\mathrm{G} \times \mathrm{E}$ modeling of abnormal neurodevelopment (Whyatt and Barr, 2001). Chlorpyrifos (CPF) is an organophosphate pesticide that might induce behavioral disturbances after intrauterine exposure, suggested by epidemiological (Whyatt and Barr, 2001) and animal data (Levin et al., 2002).

Recent evidence suggests a potential association between prenatal lead $\left(\mathrm{Pb}^{2+}\right)$ exposure and schizophrenia (Guilarte et al., 2012; Opler et al., 2004, 2008; Opler and Susser, 2005). Although the epidemiological evidence for this association is relatively weak, there is the strong biological plausibility for the putative link as both schizophrenia and developmental $\mathrm{Pb}^{2+}$ exposure are characterized by hypoactivity of the N-methyl-D-aspartate receptors (NMDAR) (Guilarte, 2009).

\subsubsection{Animal studies}

3.5.2.1. Reelin. Chlorpyrifos (CPF) is an organophosphate pesticide that might induce behavioral disturbances after intrauterine 
exposure, suggested by epidemiological (Whyatt and Barr, 2001) and animal data (Levin et al., 2002). It was hypothesized that a deficiency in reelin may affect the compensatory changes following early CPF exposure. Pregnant HET reelin females were exposed to CPF to assess the effects on neurobehavioral development of the offspring. Decreased ultrasonic vocalization (USV) as a measure of communication in mice (Scattoni et al., 2009) was "restored" to WT levels in CPF exposed reeler mice when measured at PND 7. Similar modulatory effects of CPF exposure were found with regard to amphetamine-induced hyperactivity and increased stereotypy (Laviola et al., 2006). The behavioral effects of CPF were associated with the brain changes in the olfactory bulb and the cerebellum in reeler mice (Mullen et al., 2013). On the one hand, these findings may be relevant to cholinergic abnormalities in autism and schizophrenia (Laviola et al., 2009). On the other hand, the above studies again demonstrate how adverse effects of environmental toxins could become paradoxical when combined with genetic variants.

3.5.2.2. DISC1. In order to experimentally test this hypothesis, we investigated the effects of prenatal exposure to $\mathrm{Pb}^{2+}$ in mutant Disc1 mutant mice (Abazyan et al., 2014; Guilarte, 2009). The experimental groups of mice were fed with moderate levels of $\mathrm{Pb}^{2+}$ containing diet throughout their lifetime while the control group received non- $\mathrm{Pb}^{2+}$ containing diet. Male mutant Disc1 mice exposed to $\mathrm{Pb}^{2+}$ displayed increased peripheral activity and decreased rearing. $\mathrm{Pb}^{2+}$ decreased the time spent in open arm in both mutants and controls consistent with increased anxiety-like behavior. In both female and male mice, Pb2+ exposure and mutant Disc1 additively increased locomotor activity induced by the NMDA receptors antagonist, MK-801.

Since $\mathrm{Pb}^{2+}$ plays a role in vesicular exocytosis and high doses alter the structure and formation of NMDA containing synapses (Neal et al., 2010, 2011), we attempted to rescue the effects of $\mathrm{Pb}^{2+}$ by administering a NMDAR co-agonist, D-serine. D-serine is an allosteric modulator of NMDAR and has been used in translational studies as well as in clinical trials (Kantrowitz et al., 2010; Labrie and Roder, 2010; Yang and Svensson, 2008). DISC1 binds serine racemase (SR), the enzyme producing D-serine and mutant DISC1 decreases $D$-serine production by altering the binding properties of SR (Ma et al., 2013). Administration of D-serine was able to rescue the effects of $\mathrm{Pb}^{2+}$ on PPI (Abazyan et al., 2014). The results seem to support the hypothesis that some environmental neurotoxins may be able to contribute to the pathogenesis of schizophrenia or related mental illnesses via interacting with genetic liability in susceptible individuals.

The main drawbacks of the $\mathrm{G} \times \mathrm{E}$ environmental studies are related to insufficiently accurate methods of exposure to different environmental pollutants, limited studies of time- and dosedependent effects of neurotoxins, lack of analyses of systemic and whole-body abnormalities that could contribute to behavioral pathology independently of the brain effects. Further, more epidemiological studies are clearly needed to better understand if environmental pollutants play a role in the pathogenesis of schizophrenia.

\section{Summary}

Recent epidemiological studies have advanced our understanding of the putative mechanisms of $\mathrm{G} \times \mathrm{E}$ relevant to psychotic disorders, particularly related to genetic interactions with cannabis, stress and immune dysfunction (Modinos et al., 2013; Khandaker et al., 2014). Generally, $G \times$ E research in schizophrenia has used candidate genes-based approaches. Recent reviews of the topic have indicated several fundamental problems with those approaches, including insufficient sample sizes, statistical artifacts and publication biases (Duncan and Keller, 2011; lyegbe et al., 2014). Even if these $G \times E$ findings are plagued with inconsistent results, they have provided the initial guidance for follow-up experimental research in animal models that are better poised to identify the underlying biological mechanisms, whereby environmental and genetic risk factors interact to cause psychiatric disease (lyegbe et al., 2014). Progress in psychiatric genetics and epidemiology has facilitated the development of animal models that combine genetic and environmental factors relevant to schizophrenia. This has allowed for an exciting opportunity to model the complex interactions between different factors implicated in the disorder. Tables 1 and 2 summarize the reviewed human research on and animal models of $\mathrm{G} \times \mathrm{E}$ in schizophrenia.

Here, we try to summarize the recent $G \times E$ animal studies. Fig. 1 presents a few examples of the major outcomes of $\mathrm{G} \times \mathrm{E}$ effects in mouse models published within the last decade. Although synergistic effects remain a major outcome of $G \times E$, we now appreciate that this is not the only result of $G \times E$ despite expectations mostly influenced by the two-hit hypothesis (Bayer et al., 1999; Maynard et al., 2001; Feigenson et al., 2014). It is not rare to see that combining a genetic mutation and an environmental stressor results in emergence of neurobehavioral phenomena that suggest "protective" effects of the combination. There are now several examples when modeling $\mathrm{G} \times \mathrm{E}$ in mutant mice with some pre-existing abnormalities gives rise to phenotypes that are not observed in challenged control mice or unchallenged mutant animals. One should anticipate such results by designing $\mathrm{G} \times \mathrm{E}$ experiments to avoid a trap of a limited set of pre-planned tests used to "capture" specific disease-related alterations. Appearance of new brain and behavioral changes, particularly while using the genetic mutation implicated in various psychiatric conditions, could inform us about the role of environment in bringing about diverse clinical outcomes in patients with the same mutation. The Scottish pedigree with the disruption of DISC1 due to the chromosomal defect is an example of such a possibility (Blackwood et al., 2007). Variability of phenotypic outcomes of $G \times E$ in animal models is congruent with heterogeneity in normal and abnormal human behaviors observed in $\mathrm{G} \times \mathrm{E}$ studies (e.g., Grishkevich and Yanai, 2013). We suggest that abandoning the idea of modeling the entire disorder and focusing on more tangible and biologically meaningful endophenotypes and dimensions may help overcome the issue of heterogenic outcomes and inconsistency in $\mathrm{G} \times \mathrm{E}$ research. However, before describing this idea in details, we briefly overview the field of animal models of psychiatric disorders.

\section{Future prospects}

McKinney and Bunney (1969) proposed criteria for a model of a psychiatric disease. A valuable animal model should demonstrate analogy of symptoms, observable and measurable behavioral changes, consistency between observers, and similarity in responses to treatments. Willner (1984) formalized the criteria of validity and proposed that face, predictive, constructive and etiological validity are the foundation criteria. Face validity models are defined as those that recapitulate individual symptoms of a disorder. In case of schizophrenia, behavioral similarities can be difficult to obtain, as the key symptoms of the disorder, e.g., hallucinations or delusions are of an exclusively human nature. Even when schizophrenia-related behaviors such as hyperactivity or impaired pre-pulse inhibition (PPI) of the acoustic startle are modeled, it is often unclear whether they arise from pathogenic processes relevant to schizophrenia. This is because hyperactivity, for example, can be induced by numerous experimental manipulations. It is not uncommon to encounter publications that 
Table 1

Selected positive $\mathrm{G} \times \mathrm{E}$ interactions obervered in human cases of schizophrenia.

\begin{tabular}{|c|c|c|c|}
\hline Genetic variant & $\begin{array}{l}\text { Environmental } \\
\text { factor }\end{array}$ & Outcomes & References \\
\hline MHC (rs1051788) & Infection & $\begin{array}{l}\text { Positive association between MHC SNP and seropositivity for CMV } \\
\text { and HSV-1. SNP also associated with reduced PFC volume in SCZ } \\
\text { patients }\end{array}$ & $\begin{array}{l}\text { Shirts et al. (2007) } \\
\text { Prasad et al. (2010) }\end{array}$ \\
\hline IL18R & Infection & $\begin{array}{l}\text { Positive association between IL-18r SNP and seropositivity for } \\
\text { HSV-1/2, and CMV in SCZ patients }\end{array}$ & Shirts et al. (2008) \\
\hline CTNNA3 (rs7902091) & Infection & $\begin{array}{l}\text { Association between SCZ exposure and genotype only found in } \\
\text { combination with CMV exposure }\end{array}$ & Borglum et al. (2014) \\
\hline GRIN & Maternal infection & $\begin{array}{l}\text { Maternal HSV-2 exposure linked to GRIN2B genetic variation, } \\
\text { encoding for NMDAR subunits }\end{array}$ & Demontis et al. (2011) \\
\hline HLA-DR1 & Season of birth & $\begin{array}{l}\text { Association between winter birth and HLA-DR1 genotype in SCZ } \\
\text { patients }\end{array}$ & Narita et al. (2000) \\
\hline HLA-A24, A26 & Season of birth & No association observed between genotype and season of birth & Tochigi et al. (2002) \\
\hline DRD4 & Season of birth & $\begin{array}{l}\text { Risk association between psychosis and polymorphisms were } \\
\text { dependent on season of birth }\end{array}$ & Chotai et al. (2003) \\
\hline MTHFR (rs1801133) & Season of birth & No association between season of birth and genotype observed & Muntjewerff et al. (2011) \\
\hline \multicolumn{4}{|l|}{ Residential status } \\
\hline $\begin{array}{l}\text { Established family } \\
\text { history of } \\
\text { disease }\end{array}$ & Urban living & $\begin{array}{l}\text { Significant contribution to risk of developing psychosis seen in } \\
\text { proband patients with family history of disease and living in an urban } \\
\text { setting. }\end{array}$ & van Os et al. $(2003,2004)$ \\
\hline \multicolumn{4}{|l|}{ Childhood trauma } \\
\hline NOSAP1 & Childhood abuse & No observed additive effect of risk haplotype and abuse & Husted et al. (2010) \\
\hline BDNF (Val66Met) & Childhood abuse & Met carriers show positive interaction between abuse and genetics & Alemany et al. (2011) \\
\hline FOXP2 (rs1456031) & Childhood abuse & $\begin{array}{l}\text { Significant positive interaction between genotype and abuse, in } \\
\text { predicting AVH in patients }\end{array}$ & McCarthy-Jones et al. (2014) \\
\hline $\begin{array}{l}\text { Established family } \\
\text { history of } \\
\text { disease }\end{array}$ & Childhood abuse & $\begin{array}{l}\text { No significant association between abuse, family history and the } \\
\text { development of psychotic disorders, in individuals reporting abuse }\end{array}$ & Fisher et al. (2014) \\
\hline \multicolumn{4}{|l|}{ Stress } \\
\hline $\begin{array}{l}\text { COMT, BDNF, } \\
\text { 5-HTTLPR }\end{array}$ & Chronic stress & $\begin{array}{l}\text { Additive interaction between genotype and stress on reduced } \\
\text { hippocampal volume in human subjects }\end{array}$ & Rabl et al. (2014) \\
\hline COMT & Stress & $\begin{array}{l}\text { COMT Val allele conveys a higher risk of psychotic outcome under } \\
\text { stress }\end{array}$ & $\begin{array}{l}\text { Stefanis et al. (2007) } \\
\text { Simons et al. (2009) }\end{array}$ \\
\hline COMT & Stress & $\begin{array}{l}\text { COMT Met homozygous patients show more psychotic symptoms } \\
\text { under stress }\end{array}$ & $\begin{array}{l}\text { van Winkel et al. (2008) } \\
\text { Collip et al. (2011) }\end{array}$ \\
\hline COMT, MTHFR & Stress & $\begin{array}{l}\text { Reactions to stress influenced by COMT genotype may be moderated } \\
\text { by MTHFR genotype }\end{array}$ & Peerbooms et al. (2012) \\
\hline NRG1 (rs6994992) & Stress & $\begin{array}{l}\text { NRG-1 genotype influences likelihood of unusual thoughts in conflict } \\
\text { conditions }\end{array}$ & Keri et al. (2009) \\
\hline \multicolumn{4}{|l|}{ Substance abuse } \\
\hline COMT & Cannabis & $\begin{array}{l}\text { COMT Val carriers show higher likelihood to develop psychosis after } \\
\text { adolescent cannabis use }\end{array}$ & $\begin{array}{l}\text { Caspi et al. (2005) } \\
\text { Henquet et al. (2006) }\end{array}$ \\
\hline COMT & Cannabis & Negative findings to the above association & $\begin{array}{l}\text { Costas et al. (2011) } \\
\text { Zammit et al. (2007) } \\
\text { Kantrowitz et al. (2009) }\end{array}$ \\
\hline AKT1 (rs2494732) & Cannabis & $\begin{array}{l}\text { Positive and dose dependent association between genotype, cannabis } \\
\text { consumption and the development of psychosis }\end{array}$ & $\begin{array}{l}\text { van Winkel and GROUP } \\
\text { Investigators (2011) } \\
\text { van Winkel et al. (2011) } \\
\text { Di Forti et al. (2012) }\end{array}$ \\
\hline CBD1 (rs12720071) & Cannabis & $\begin{array}{l}\text { Positive association between cannabis use, CBD1 genotype and white } \\
\text { matter volume in SCZ patients }\end{array}$ & Ho et al. (2011) \\
\hline $\begin{array}{l}\text { Established family } \\
\text { history of } \\
\text { disease }\end{array}$ & Cannabis & $\begin{array}{l}\text { Significant association between cannabis use, family history of } \\
\text { disease, and brain region volume }\end{array}$ & Malchow et al. (2013) \\
\hline NRG1 & Cannabis & $\begin{array}{l}\text { NRG1 genotype and cannabis administration have an additive effect } \\
\text { on electrophysiology results reminiscent of schizophrenia }\end{array}$ & Stadelmann et al. (2010) \\
\hline $\begin{array}{l}\text { Various, including } \\
\text { DRD2, DRD4, } \\
\text { COMT, DAT }\end{array}$ & Methamphetamine & $\begin{array}{l}\text { Numerous significant associations have been found between meth } \\
\text { use, psychotic symptoms and subject genotype }\end{array}$ & See Section 3.3 .2 \\
\hline \multicolumn{4}{|l|}{ Obstetric complications } \\
\hline $\begin{array}{l}\text { Established family } \\
\text { history of } \\
\text { disease }\end{array}$ & $\begin{array}{l}\text { Obstetric } \\
\text { complications }\end{array}$ & Additive effect of family history and OC on CSF volume & Cannon et al. (2002a,b,c) \\
\hline SCZ patient status & Neonatal hypoxia & $\begin{array}{l}\text { Patients who had experienced hypoxia showed reduced hippocampal } \\
\text { volume }\end{array}$ & Van Erp et al. (2002) \\
\hline $\begin{array}{l}\text { AKT1, BDNF, } \\
\text { DTNBP1, GRM3 }\end{array}$ & $\begin{array}{l}\text { Obstetric } \\
\text { complications }\end{array}$ & $\begin{array}{l}\text { Linkage found between serious obstetric complications, risk of SCZ } \\
\text { and mutations in several hypoxia related genes }\end{array}$ & Nicodemus et al. (2008) \\
\hline ARVCG, FADS2 & Pre-term birth & Genotype influenced white matter abnormalities in pre-term infants & Boardman et al. (2014) \\
\hline GRM3 & Fetal hypoxia & $\begin{array}{l}\text { Severe fetal hypoxia associated with smaller hippocampal volume in } \\
\text { SCZ patients, correlated to GRM3 genotype }\end{array}$ & Haukvik et al. (2010) \\
\hline
\end{tabular}


Table 2

Selected animal models of $\mathrm{G} \times \mathrm{E}$ in schizophrenia.

\begin{tabular}{|c|c|c|c|}
\hline Gene & $\begin{array}{l}\text { Environmental } \\
\text { insult }\end{array}$ & Effects & References \\
\hline \multicolumn{4}{|c|}{ Infection and immunity models } \\
\hline DISC1 & Prenatal poly I:C & Synergistic increases in anxiety and depressive like behaviors & Abazyan et al. (2010) \\
\hline DISC1 & $\begin{array}{l}\text { Early postnatal } \\
\text { poly I:C }\end{array}$ & Synergistic impairment of short term memory & $\begin{array}{l}\text { Hikida et al. (2007) } \\
\text { Ibi et al. (2010) }\end{array}$ \\
\hline DISC1 & Prenatal poly I:C & Synergistic increase in IL6, impaired NOR and PPI & Lipina et al. (2013) \\
\hline Nurr1 & Prenatal poly I:C & Synergistic impact on PPI, startle response, and latent inhibition & $\begin{array}{l}\text { Vuillermot et al. (2011) } \\
\text { Vuillermot et al. (2012) }\end{array}$ \\
\hline Nurr1 & Toxopsalma gondii & Synergistic effect on locomotor activity in open field & Eells et al. (2015) \\
\hline Nrg1 & Prenatal poly I:C & Several impacts: some additive, some with no combined effect & O'Leary et al. (2014) \\
\hline Tap1 & Influenza virus & Synergistic effects on working memory, rearing activity and anxiety & Asp et al. $(2009,2010)$ \\
\hline \multicolumn{4}{|l|}{ Stress models } \\
\hline Reelin & $\begin{array}{l}\text { Maternal } \\
\text { separation }\end{array}$ & Protective effect of mutation on social motivation & $\begin{array}{l}\text { Laviola et al. (2009) } \\
\text { Ognibene et al. (2007) } \\
\text { Ognibene et al. (2008) }\end{array}$ \\
\hline Nurr1 & $\begin{array}{l}\text { Social isolation, } \\
\text { restraint stress }\end{array}$ & Synergistic impairment of PPI & Eells et al. (2006) \\
\hline Sept5 & Social isolation & Protective effect of mutation on anxiety like behaviors & Harper et al. (2012) \\
\hline \multirow[t]{2}{*}{ Adycap1 (PACAP) } & Social isolation vs. & Synergistic elevation of aggression and impact on PPI & Ishihama et al. (2010) \\
\hline & $\begin{array}{l}\text { environmental } \\
\text { enrichment }\end{array}$ & Amelioration of deficit in fear conditioning by social enrichment & Takuma et al. (2014) \\
\hline DISC1 & Social isolation & $\begin{array}{l}\text { Synergistic increases in locomotion, immobility in FST, and PPI } \\
\text { deficiencies }\end{array}$ & Niwa et al. (2013) \\
\hline Disc1 & $\begin{array}{l}\text { Chronic social } \\
\text { defeat }\end{array}$ & $\begin{array}{l}\text { Opposite effects of social defeat stress on mutant vs. WT in tests of } \\
\text { anxiety, synergistic effect on PPI and social interaction }\end{array}$ & Haque et al. (2012) \\
\hline Gad67 & Maternal stress & Synergistic effects on fetal cortisol and birth weight & $\begin{array}{l}\text { Uchida et al. (2011) } \\
\text { Uchida et al. (2014) }\end{array}$ \\
\hline SNAP25 $(b d r)$ & Maternal stress & Synergistic effects on sociability and PPI & Oliver and Davies (2009) \\
\hline Nrg1 & Social stress & $\begin{array}{l}\text { Additive effects on locomotion, memory, sociability, and synergistic } \\
\text { effect on brain cytokine levels }\end{array}$ & Desbonnet et al. (2012) \\
\hline Nrg1 & $\begin{array}{l}\text { Stress in young } \\
\text { ( } 3-4 \text { months) } \\
\text { and adult } \\
\text { ( } 6-7 \text { months) } \\
\text { mice }\end{array}$ & $\begin{array}{l}\text { Additive genotype-stress interaction in older mice } \\
\text { Mutants did not display anxiety-like behavior while WT did }\end{array}$ & Chesworth et al. (2012) \\
\hline Nrg1 & $\begin{array}{l}\text { Restraint stress } \\
\text { during } \\
\text { adolescence } \\
\text { (PND 36-49) }\end{array}$ & $\begin{array}{l}\text { Synergistic disruption in PPI Decreased apical dendritic length and } \\
\text { complexity in the medial prefrontal cortex and hippocampus }\end{array}$ & Chohan et al. (2014a,b) \\
\hline Rat model of Nrg1 & $\begin{array}{l}\text { Chronic stress } \\
\text { at PND 37-44 }\end{array}$ & $\begin{array}{l}\text { Mutant and WT displayed less anxiety } \\
\text { Only mutant females showed enhanced cued-fear extinction }\end{array}$ & $\begin{array}{l}\text { Taylor et al. } \\
(2011,2012,2013)\end{array}$ \\
\hline \multicolumn{4}{|c|}{ Drug exposure models } \\
\hline COMT & Cannabis & Additive decreases in size and density of dopaminergic cells & Behan et al. (2012) \\
\hline COMT & Cannabis & $\begin{array}{l}\text { Additive increase in startle response, PPI deficit, and decreases in } \\
\text { anxiety }\end{array}$ & O'Tuathaigh et al. (2012) \\
\hline Nrg1 & Cannabis & $\begin{array}{l}\text { Synergistic reduction of locomotor activity, increased anxiety, and } \\
\text { impact on PPI }\end{array}$ & $\begin{array}{l}\text { Boucher et al. (2007) } \\
\text { Long et al. (2013) }\end{array}$ \\
\hline Nrg1 & Cannabidiol (CBD) & $\begin{array}{l}\text { Reduced hyperlocomotion and increased social interaction in Nrg1 } \\
\text { improved PPI }\end{array}$ & Long et al. (2012) \\
\hline DISC1 & Methamphetamine & $\begin{array}{l}\text { Mutation blunted response to methamphetamine, synergistic } \\
\text { attenuated response to conditioned place preference }\end{array}$ & Pogorelov et al. (2012) \\
\hline \multicolumn{4}{|c|}{ Toxin exposure models } \\
\hline Reelin & $\begin{array}{l}\text { Prenatal } \\
\text { chlorpyrifos (CPF) }\end{array}$ & $\begin{array}{l}\text { Protective impact of toxic exposure on USV and on stimulant } \\
\text { response }\end{array}$ & $\begin{array}{l}\text { Scattoni et al. (2009) } \\
\text { Laviola et al. (2006) } \\
\text { Mullen et al. (2013) }\end{array}$ \\
\hline DISC1 & Prenatal lead & $\begin{array}{l}\text { Synergistic increases in anxiety like behaviors and in response to } \\
\text { MK-801 administration }\end{array}$ & Abazyan et al. (2014) \\
\hline
\end{tabular}

present hyperactivity as a behavioral abnormality relevant to ADHD, mania, or autism, to name a few (Ridley and Baker, 1982).

The predictive validity criterion refers to the ability of a model to predict the effects of pharmacological drugs. These models are also known as pharmacological isomorphism models (Matthysse, 1986). Since pharmacological treatments of schizophrenia are symptom-oriented and are also used to treat behavioral abnormalities in other psychiatric disorders, pre-clinical models that mimic the behavioral responses to a drug provide limited insight into the molecular pathology of the disorder (Ellenbroek and Cools, 1995).
Animal models designed to achieve construct and etiological validity use epidemiologically relevant environmental and/or genetic factors to recapitulate the pathogenesis and pathophysiology of the disorder. These models are based on the notion that some behavioral abnormalities observed in humans are rooted in brain alterations that can be recapitulated in animals (Pletnikov et al., 2002).

Many current models of schizophrenia meet all the above criteria. Even so, we would like to emphasize that the main goal of a model is to address specific hypotheses or questions. Thus, there seems to be a pervasive misunderstanding of animal models 


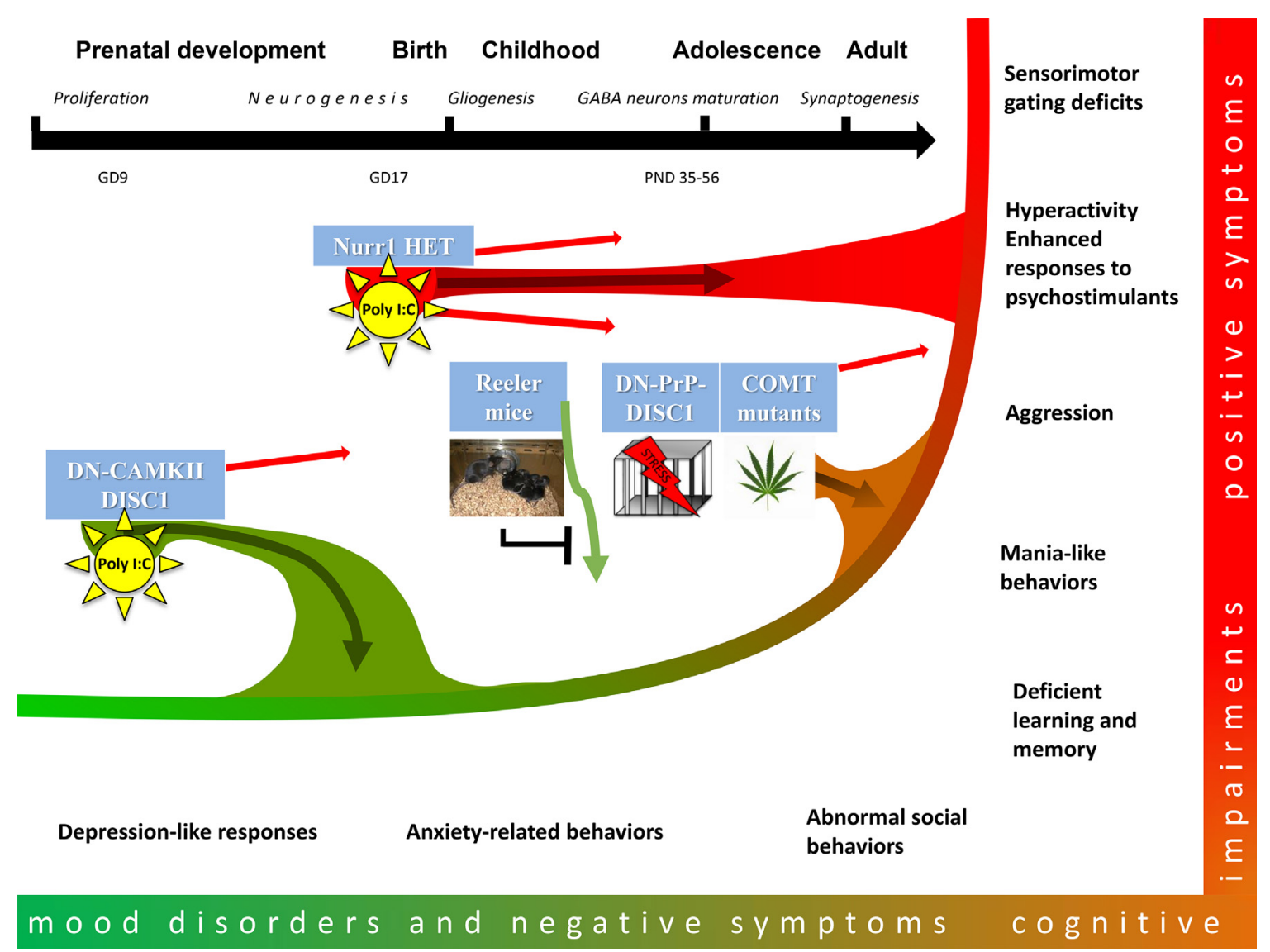

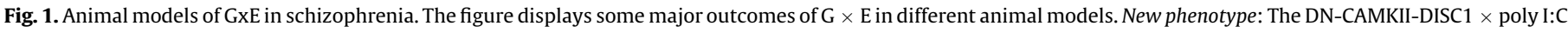

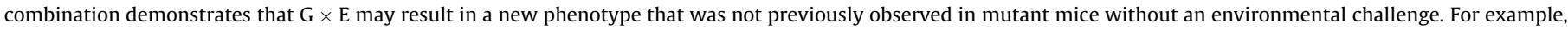

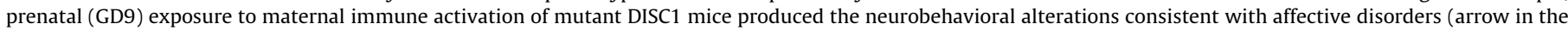

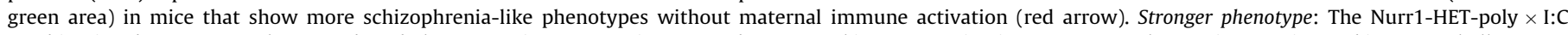

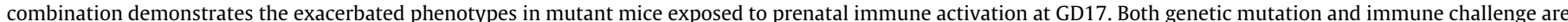

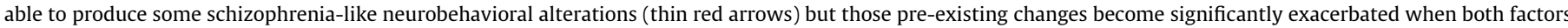

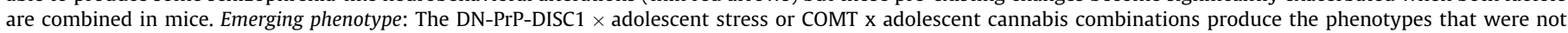

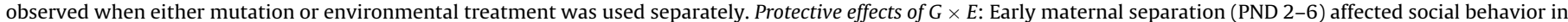

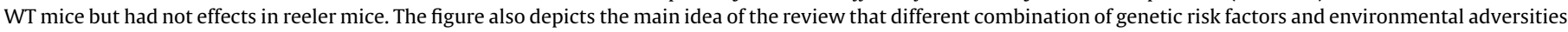

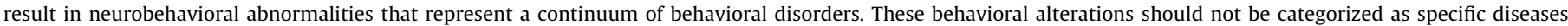

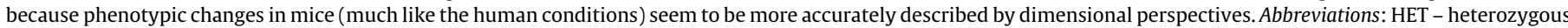
mice; DN - dominant negative mutant human DISC1; CAMKII or PrP - the promoters used to express DN-DISC1.

among experimental investigators and clinicians alike. It is important we avoid both overzealous promotion of any single animal model as a superior one as well as an unwarranted skepticism regarding the utility of animal models (for further discussion, see Keeler and Robbins, 2011; Fernando and Robbins, 2011). A model is valuable as far as it is able to incisively address the questions that help us understand the disease or develop a new treatment. In this context, the more animal models are used to address the diversity of pathophysiological mechanisms of a disease, the sooner we can make a real progress in this area.

Furthermore, there is a growing understanding that many psychiatric disorders share etiology and underlying pathobiology (Hall et al., 2015). Thus, the field of animal models needs to move beyond the mold of disease categories, and instead should focus on behavioral domains and dimensions. It has been argued that new preclinical models should focus on a dimensional construct and domains of psychopathology, which do not conform to the nosological categories and are consistent with increasing evidence of genetic, environmental and biological commonality between schizophrenia, bipolar disorder and other psychiatric disorders (O'Tuathaigh and Waddington, 2015). This approach is anticipated to shed more light on mental disorders as varying constellations of functional domains and will advance our knowledge of the neurobiology of basic processes that transcend diagnostic boundaries and are based on measurable phenotypes easily translatable across different species and more amenable to future biologydriven treatment (Petrinovic and Kunnecke, 2014; Hoffman, 2013; Argyropoulos et al., 2013; Mahoney and Olmstead, 2013; Cuthbert, 2014). For example, Fig. 1 depicts as different combinations of the same genetic and environmental risk factors result in varying phenotypic domains impertinent to the specific nosological category. The dimensional and $\mathrm{RDoC}$ framework underscores the necessity to assess the effects of genetic and/or environmental factors on domains of functions by breaking from psychiatric diagnoses and remaining agnostic toward diagnostic constrains of human psychopathology. In other words, animal models need to wean themselves from a-model-for-a-disease mold and recognize evaluating dimensions and/or endophenotypes constitutes as a way forward not only for $G \times E$ models of schizophrenia but also for the entire field of animal models of psychiatric disorders. Analyzing neurobehavioral abnormalities resulted in various $\mathrm{G} \times \mathrm{E}$ models within the dimensional or RDoC framework will provide a closer mechanistic connection between the model and specific domains (of the disorder) being modeled. 
Prior to the RDoC concept, the approach using 'endophenotype' and 'intermediate phenotype' has been introduced (Gottesman and Gould, 2003; Kellendonk et al., 2009; Desbonnet et al., 2009; Kaffman and Krystal, 2012; Amann et al., 2010). In this context, basic research on $\mathrm{G} \times \mathrm{E}$ in psychotic disorders should incorporate more detailed and sophisticated examination of endophenotypes readily translatable to humans. For example, the development of cognitive tests for attention, impulsivity, working memory, and executive function has been emphasized. The perception being that these cognitive dysfunctions are the core symptoms of psychotic disorders (Powell and Miyakawa, 2006; Young and Geyer, 2015) and, as some argue, might even constitute a primary psychopathology in patients with psychotic disorders (e.g., Uhlhaas and Singer, 2015). In addition, the next generation of animal models should expand use of physiological and neural circuitry intermediate phenotypes, genome-wide gene expression and epigenetic modification profiling in specific cell types (e.g. neurons vs. astrocytes) (Kannan et al., 2013). Utilization of endophenotypic measures may not only help minimize variability in effects of $\mathrm{G} \times \mathrm{E}$ but also bring in new model organisms to study the molecular mechanisms of $\mathrm{G} \times \mathrm{E}$ across species (e.g., worms, fruit flies, zebrafish). The value of using multiple model animals is particularly evident when comparing the advantages and disadvantages mouse and rat models for $G \times E$ studies. While genetically modified mice have been, and still remain, the major workhorses among animal models, an expanding tool box of genetic manipulations in rats and the availability and reproducibility of sophisticated tests for social and cognitive behaviors are bringing back rat as a model organism for psychiatric disorders (Ellenbroek et al., 2002; Ratajczak et al., 2013).

Essentially all basic (and human) $\mathrm{G} \times \mathrm{E}$ studies have been performed using candidate risk factors, the majority of which have not been confirmed by the recent GWA studies (McCarroll et al., 2014; Nestler and Hyman, 2010). Although $G \times$ E studies based on rare highly penetrants mutations will remain the mainstream direction for some time, we can already see the emergence of new models that incorporate polymorphisms identified by the PGC (Quednow et al., 2014).

Further, as schizophrenia is increasingly considered a disorder of brain development, animal models with manipulation of genes involved in neurodevelopment are going to be particularly informative (Insel, 2010; Jaaro-Peled, 2009). It is important to take developmental considerations into account when interpreting environmental effects that vary across different time points (Moffitt et al., 2005; Rutter, 2008). In the past, addressing timedependent interaction in $\mathrm{G} \times \mathrm{E}$ models has been achieved by changing the time when genetically modified animals are challenged with an environmental adversity. Future studies should also attempt to regulate timing of the effects of a specific mutation as exemplified by a recent study with inducible expression of mutant DISC1 in mice prenatally exposed to maternal immune activation (Abazyan et al., 2010). Similarly, more attention should be paid to time-dependent and dose-dependent effects of environmental factors. For example, maternal immune activation can produce distinct brain band behavior pathology depending on the time of prenatal exposure to poly I:C, with maternal immune activation at GD9 affecting maturation of dopamine neurons while exposure at GD17 leading to abnormalities in the development of cortical neurons (Meyer et al., 2005, 2006).

The focus of most published $G \times E$ research has been on risk factors. However, the contribution of protective factors is also important and has so far been relatively neglected, with some exceptions. Identification of genes conferring resilience to schizophrenia-related abnormalities is a new emerging field of research looking to uncover unrecognized molecular targets (Mihali et al., 2012). New models using neurodevelopmental factors of resilience are clearly needed to advance this promising research. In this context, the role for environment enrichment in ameliorating/rescuing genetically produced abnormalities has been studied in various neurodevelopmental and neurodegenerative models (Laviola et al., 2008; McOmish et al., 2008; Burrows et al., 2015) and has been recently reviewed (Nithianantharajah and Hannan, 2006; Takuma et al., 2011; Burrows et al., 2011; Pang and Hannan, 2013). Combining this type of preventive "therapy" with current $\mathrm{G} \times \mathrm{E}$ models would be interesting toward determining whether environmental enrichment can overcome effects caused by aversive environmental insults (e.g. psychosocial stress, infection, drug use) and offer a novel approach to treatments of the cognitive and negative symptoms that resistant to the current antipsychotics (Pratt et al., 2012; McOmish et al., 2014).

An additional step in approximating animal models to complex human condition could include combining genetic liability with several environmental factors as has been exemplified by a recent study (O'Leary et al., 2014). This line of investigation is an extension of the growing research of the role of ExE that include exposures to different environmental adversities across the lifespan with both negative and positive synergistic effects of different environmental factors (Ellenbroek and Cools, 2002; Ellenbroek, 2004; Macrì and Laviola, 2004; Harvey and Boksa, 2013; Hida et al., 2013, 2014). Meyer's lab has recently reported the potential molecular and cellular mechanisms whereby prior environmental exposure can prime the immune system of the developing brain to detrimental effects of later environmental adversity (Giovanoli et al., 2013, 2014).

We need to take animal model based research beyond studying a single pathophysiological process involved in $\mathrm{G} \times \mathrm{E}$, even if the model only encompasses interaction with a single adverse event. As an example, in addition to the HPA axis, studies of stress exposure should include the immune response to stressful stimuli (Pryce and Klaus, 2013; Dantzer et al., 2008). Similarly, the role of innate and adaptive immune responses in mediating effects of illicit drugs will need to be addressed in future $G \times E$ models, going as far as to include the immune responses taking place in the intestinal tract (Severance et al., 2014).

Another issue is the under appreciation of sex-dependent effects. Many models demonstrate sex-dependent alterations, yet most $\mathrm{G} \times \mathrm{E}$ models focus on a single sex. Future research in $\mathrm{G} \times \mathrm{E}$ models should address if sex-specific abnormalities result from the effects of $\mathrm{G} \times \mathrm{E}$, or the individual components, on actions of gonadal hormones or from the modulatory influence of sex hormones on the pathways involved in $G \times E$. Advancing our knowledge of the underpinnings of sex differences in psychiatric disorders could help uncover both risk and protective factors to develop better treatments (Godar and Bortolato, 2014).

The methodologies to manipulate the mouse genome at different levels of its organization (DNA, RNA regulatory sequences) are constantly improving. Simple knockout and transgenic technologies, while remaining the workhorse of mouse genetics, produce artificial systems inconsistent with the molecular pathology of schizophrenia. New models with mutations in regulatory elements of candidate genes, which show subtler, and temporally specific expression changes, or human genetic variants knock-in models, both better reflect the complex genetic and molecular mechanisms of schizophrenia (Chen et al., 2006; Papaleo et al., 2012). Therefore, time-dependent, circuitry- or cell-specific manipulations to target mRNA and/or proteins should be utilized where available.

There is growing appreciation that combining multiple genetic mutations or several environmental factors in a single model could be more informative. In addition to conventional breeding approaches, newer technologies include plasmid-based celltype-specific and inducible expression systems using in utero 
gene transfer by targeting multiple genes (Taniguchi et al., 2012). A complementary methodology is to suppress the expression of target genes using RNA interference (RNAi) knockdown technology (Mello and Conte, 2004). Several susceptibility genes can be knocked down simultaneously in mice carrying multiple siRNA expression transgenes.

Most studies have focused on neuronal functions of susceptibility genes. However, these genes are also expressed by glial cells (Iijima et al., 2009). Given, growing interest in the role for glia cells in mediating the effects of stress and microbial pathogens, $\mathrm{G} \times \mathrm{E}$ models with cell-specific perturbation of candidate genes are also needed. A recent study has provided the first evidence for the potential role of DISC1 in astrocytes, connecting DISC1 and serine racemase in modulating NMDA receptor functions (Ma et al., 2013). Our understanding of neuron-astrocyte interaction in health and disease is unlikely to be facilitated without tools that allow us to monitor and manipulate astrocytes in behaving animals. Recent studies utilizing optogenetics and two-photon microscopy in combination with behavioral tests have demonstrated the possibility of developing and characterizing such models (Sasaki et al., 2012; Paukert et al., 2014).

In conclusion, $\mathrm{G} \times \mathrm{E}$ animal models have already begun to provide new insights into the etiological complexity and heterogeneity of schizophrenia. We believe $\mathrm{G} \times \mathrm{E}$ animal models will continue to be a crucial tool to advance our knowledge about this debilitating disorder. The challenge ahead for $\mathrm{G} \times \mathrm{E}$ animal models is to provide mechanistic insights in how genetic and environmental factors interact, with the hope that identifying the convergent molecular pathways will lead to uncovering new therapeutic targets and/or disease biomarkers.

\section{Acknowledgements}

We thank the following funding agencies for the support: MH-083728, MH-094268 Silvio O. Conte Center and the Brain and Behavior Research Foundation (MVP).

\section{References}

Abazyan, B., Dziedzic, J., Hua, K., Abazyan, S., Yang, C., Mori, S., Pletnikov, M.V., Guilarte, T.R., 2014. Chronic exposure of mutant DISC1 mice to lead produces sex-dependent abnormalities consistent with schizophrenia and related mental disorders: a gene-environment interaction study. Schizophr. Bull. 40, 575-584.

Abazyan, B., Nomura, J., Kannan, G., Ishizuka, K., Tamashiro, K.L., Nucifora, F., Pogorelov, V., Ladenheim, B., Yang, C., Krasnova, I.N., Cadet, J.L., Pardo, C., Mori, S., Kamiya, A., Vogel, M.W., Sawa, A., Ross, C.A., Pletnikov, M.V., 2010. Prenatal interaction of mutant DISC1 and immune activation produces adult psychopathology. Biol. Psychiatry 68, 1172-1181.

Abdolmaleky, H.M., Thiagalingam, S., Wilcox, M., 2005. Genetics and epigenetics in major psychiatric disorders: dilemmas, achievements, applications, and future scope. Am. J. Pharmacogenomics 5, 149-160.

Akbarian, S., 2014. Epigenetic mechanisms in schizophrenia. Dialogues Clin. Neurosci. 16 (3), 405-417.

Akbarian, S., Kim, J.J., Potkin, S.G., Hagman, J.O., Tafazzoli, A., Bunney Jr., W.E., Jones, E.G., 1995. Gene expression for glutamic acid decarboxylase is reduced without loss of neurons in the prefrontal cortex of schizophrenics. Arch. Gen. Psychiatry $52,258-266$.

Alemany, S., Arias, B., Aguilera, M., Villa, H., Moya, J., Ibáñez, M.I., Vossen, H., Gastó, C., Ortet, G., Fañanás, L., 2011. Childhood abuse, the BDNF-Val66Met polymorphism and adult psychotic-like experiences. Br. J. Psychiatry 199, 38-42.

Amann, L.C., Gandal, M.J., Halene, T.B., Ehrlichman, R.S., White, S.L., McCarren, H.S., Siegel, S.J., 2010. Mouse behavioral endophenotypes for schizophrenia. Brain Res. Bull. 83, 147-161.

Andreasson, S., Allebeck, P., Engstrom, A., Rydberg, U., 1987. Cannabis and schizophrenia. A longitudinal study of Swedish conscripts. Lancet 2, 1483-1486.

Anon, 1999. Complete sequence and gene map of a human major histocompatibility complex. The MHC sequencing consortium. Nature 401, 921-923.

Argyropoulos, A., Gilby, K.L., Hill-Yardin, E.L., 2013. Studying autism in rodent models: reconciling endophenotypes with comorbidities. Front. Hum. Neurosci. 7, 417.

Arseneault, L., Cannon, M., Poulton, R., Murray, R., Caspi, A., Moffitt, T.E., 2002. Cannabis use in adolescence and risk for adult psychosis: longitudinal prospective study. BMJ 325, 1212-1213.
Asada, A., Takahashi, J., Taniguchi, M., Yamamoto, H., Kimura, T., Saito, T., Hisanaga, S., 2010. Neuronal expression of two isoforms of mouse Septin 5. J. Neurosci. Res. 88, 1309-1316.

Asp, L., Beraki, S., Kristensson, K., Ogren, S.O., Karlsson, H., 2009. Neonatal infection with neurotropic influenza A virus affects working memory and expression of type III Nrg1 in adult mice. Brain Behav. Immun. 23, 733-741.

Asp, L., Holtze, M., Powell, S.B., Karlsson, H., Erhardt, S., 2010. Neonatal infection with neurotropic influenza A virus induces the kynurenine pathway in early life and disrupts sensorimotor gating in adult Tap1-/- mice. Int. J. Neuropsychopharmacol. 13, 475-485.

Ayhan, Y., Sawa, A., Ross, C.A., Pletnikov, M.V., 2009. Animal models of geneenvironment interactions in schizophrenia. Behav. Brain Res. 204, 274-281.

Ayhan, Y., Abazyan, B., Nomura, J., Kim, R., Ladenheim, B., Krasnova, I.N., Sawa, A. Margolis, R.L., Cadet, J.L., Mori, S., Vogel, M.W., Ross, C.A., Pletnikov, M.V., 2011a. Differential effects of prenatal and postnatal expressions of mutant human DISC1 on neurobehavioral phenotypes in transgenic mice: evidence for neurodevelopmental origin of major psychiatric disorders. Mol. Psychiatry 16, 293-306.

Ayhan, Y., Jaaro-Peled, H., Sawa, A., Pletnikov, M., 2011b. DISC1 mouse models. In: O'Donell, P. (Ed.), Animal Models of Schizophrenia and Related Disorders. Humana Press, pp. 211-229.

Babovic, D., O’Tuathaigh, C.M., O'Sullivan, G.J., Clifford, J.J., Tighe, O., Croke, D.T., Karayiorgou, M., Gogos, J.A., Cotter, D., Waddington, J.L., 2007. Exploratory and habituation phenotype of heterozygous and homozygous COMT knockout mice. Behav. Brain Res. 183, 236-239.

Bagot, R.C., Meaney, M.J., 2010. Epigenetics and the biological basis of gene $\times$ environment interactions. J. Am. Acad. Child Adolesc. Psychiatry 49, $752-771$.

Ballinger, M.D., Saito, A., Abazyan, B., Taniguchi, Y., Huang, C.H., Ito, K., Zhu, X., Segal, H., Jaaro-Peled, H., Sawa, A., Mackie, K., Pletnikov, M.V., Kamiya, A., 2015. Adolescent cannabis exposure interacts with mutant DISC1 to produce impaired adult emotional memory. Neurobiol. Dis. 82, 176-184.

Bao, Y., Ibram, G., Blaner, W.S., Quesenberry, C.P., Shen, L., McKeague, I.W., Schaefer, C.A., Susser, E.S., Brown, A.S., 2012. Low maternal retinol as a risk factor for schizophrenia in adult offspring. Schizophr. Res. 137, 159-165.

Barnes, T.R., Mutsatsa, S.H., Hutton, S.B., Watt, H.C., Joyce, E.M., 2006. Comorbid substance use and age at onset of schizophrenia. Br. J. Psychiatry 188, 237-242.

Baxter, J., Kingi, T.K., Tapsell, R., Durie, M., McGee, M.A., New Zealand Mental Health Survey Research Team, 2006. Prevalence of mental disorders among Maori in Te Rau Hinengaro: the New Zealand Mental Health Survey. Aust. N. Z. J. Psychiatry 40, 914-923.

Bayer, T.A., Falkai, P., Maier, W., 1999. Genetic and non-genetic vulnerability factors in schizophrenia: the basis of the "two hit hypothesis". J. Psychiatr. Res. 33, 543-548.

Behan, A.T., Hryniewiecka, M., O’Tuathaigh, C.M., Kinsella, A., Cannon, M., Karayiorgou, M., Gogos, J.A., Waddington, J.L., Cotter, D.R., 2012. Chronic adolescent exposure to delta9-tetrahydrocannabinol in COMT mutant mice: impact on indices of dopaminergic, endocannabinoid and GABAergic pathways. Neuropsychopharmacology 37, 1773-1783.

Beites, C.L., Campbell, K.A., Trimble, W.S., 2005. The septin Sept5/CDCrel-1 competes with alpha-SNAP for binding to the SNARE complex. Biochem. J. $385,347-353$

Belvederi Murri, M., Respino, M., Masotti, M., Innamorati, M., Mondelli, V., Pariante, C., Amore, M., 2013. Vitamin D and psychosis: mini meta-analysis. Schizophr. Res. 150, 235-239.

Beneyto, M., Morris, H.M., Rovensky, K.C., Lewis, D.A., 2012. Lamina- and cellspecific alterations in cortical somatostatin receptor 2 mRNA expression in schizophrenia. Neuropharmacology 62, 1598-1605.

Berger, N., Vaillancourt, C., Boksa, P., 2000. Genetic factors modulate effects of C-section birth on dopaminergic function in the rat. Neuroreport 11, 639-643.

Berrios, G.E., Luque, R., Villagran-Moreno, J.M., 2003. Schizophrenia: a conceptual history. Int. J. Psychol. Psychol. Ther. 3, 111-140.

Bersani, G., Quartini, A., Manuali, G., Iannitelli, A., Pucci, D., Conforti, F., Di Biasi, C. Gualdi, G., 2009. Influence of obstetric complication severity on brain morphology in schizophrenia: an MR study. Neuroradiology 51, 363-371.

Bisogno, T., Hanus, L., De Petrocellis, L., Tchilibon, S., Ponde, D.E., Brandi, I., Moriello, A.S., Davis, J.B., Mechoulam, R., Di Marzo, V., 2001. Molecular targets for cannabidiol and its synthetic analogues: effect on vanilloid VR1 receptors and on the cellular uptake and enzymatic hydrolysis of anandamide. Br. J. Pharmacol. 134, 845-852.

Boardman, J.P., Walley, A., Ball, G., Takousis, P., Krishnan, M.L., Hughes-Carre, L., Aljabar, P., Serag, A., King, C., Merchant, N., Srinivasan, L., Froguel, P., Hajnal, J., Rueckert, D., Counsell, S., Edwards, A.D., 2014. Common genetic variants and risk of brain injury after preterm birth. Pediatrics 133, e1655-e1663.

Boksa, P., 2004. Animal models of obstetric complications in relation to schizophrenia. Brain Res. Brain Res. Rev. 45, 1-17.

Boksa, P., 2007. Of rats and schizophrenia. J. Psychiatry Neurosci. 32, 8-10.

Borglum, A.D., Demontis, D., Grove, J., Pallesen, J., Hollegaard, M.V., Pedersen, C.B., Hedemand, A., Mattheisen, M., investigators, G., Uitterlinden, A., Nyegaard, M., Orntoft, T., Wiuf, C., Didriksen, M., Nordentoft, M., Nothen, M.M., Rietschel, M., Ophoff, R.A., Cichon, S., Yolken, R.H., Hougaard, D.M., Mortensen, P.B., Mors, O., 2014. Genomewide study of association and interaction with maternal cytomegalovirus infection suggests new schizophrenia loci. Mol. Psychiatry 19, 325-333.

Boucher, A.A., Arnold, J.C., Duffy, L., Schofield, P.R., Micheau, J., Karl, T., 2007. Heterozygous neuregulin 1 mice are more sensitive to the behavioural effects of Delta9tetrahydrocannabinol. Psychopharmacology 192, 325-336. 
Boucher, A.A., Hunt, G.E., Micheau, J., Huang, X., McGregor, I.S., Karl, T., Arnold, J.C. 2011. The schizophrenia susceptibility gene neuregulin 1 modulates tolerance to the effects of cannabinoids. Int. J. Neuropsychopharmacol. 14, 631-643.

Boydell, J., van Os, J., Caspi, A., Kennedy, N., Giouroukou, E., Fearon, P., Farrell, M. Murray, R.M., 2006. Trends in cannabis use prior to first presentation with schizophrenia, in South-East London between 1965 and 1999. Psychol. Med. 36, 1441-1446.

Brandon, N.J., Sawa, A., 2011. Linking neurodevelopmental and synaptic theories of mental illness through DISC1. Nat. Rev. Neurosci. 12, 707-722.

Brenneisen, R., 2007. Chemistry and analysis of phytocannabinoids and other cannabis constituents. In: ElSouhly, M. (Ed.), Marijuana and the Cannabinoids. Humana Press, pp. 17-49.

Breslau, J., Marshall, G.N., Pincus, H.A., Brown, R.A., 2014. Are mental disorders more common in urban than rural areas of the United States? J. Psychiatr. Res. 56, 50-55.

Blackwood, D.H., Visscher, P.M., Muir, W.J., Brown, A.S., Bottiglieri, T., Schaefer, C.A Quesenberry Jr., C.P., Liu, L., Bresnahan, M., Susser, E.S., 2007. Elevated prenata homocysteine levels as a risk factor for schizophrenia. Arch. Gen. Psychiatry 64, 31-39.

Brown, A.S., 2011. The environment and susceptibility to schizophrenia. Prog. Neurobiol. 93, 23-58.

Brown, A.S., Bottiglieri, T., Schaefer, C.A., Quesenberry Jr., C.P., Liu, L., Bresnahan, M. Susser, E.S., 2007. Elevated prenatal homocysteine levels as a risk factor for schizophrenia. Arch. Gen. Psychiatry 64, 31-39.

Buervenich, S., Carmine, A., Arvidsson, M., Xiang, F., Zhang, Z., Sydow, O., Jonsson, E.G. Sedvall, G.C., Leonard, S., Ross, R.G., Freedman, R., Chowdari, K.V., Nimgaonkar V.L., Perlmann, T., Anvret, M., Olson, L., 2000. NURR1 mutations in cases of schizophrenia and manic-depressive disorder. Am. J. Med. Genet. 96, 808-813.

Buizer-Voskamp, J.E., Muntjewerff, J.W., Genetic Risk and Outcome in Psychosis (GROUP) Consortium Members, Strengman, E., Sabatti, C., Stefansson, H., Vorstman, J.A., Ophoff, R.A., 2011. Genomewide analysis shows increased frequency of copy number variation deletions in Dutch schizophrenia patients. Biol. Psychiatry 70, 655-662.

Burrows, E.L., McOmish, C.E., Hannan, A.J., 2011. Gene-environment interactions and construct validity in preclinical models of psychiatric disorders. Prog. Neuropsychopharmacol. Biol. Psychiatry 35, 1376-1382.

Burrows, E.L., McOmish, C.E., Buret, L.S., Van den Buuse, M., Hannan, A.J., 2015. Environmental enrichment ameliorates behavioral impairments modeling schizophrenia in mice lacking metabotropic glutamate receptor 5. Neuropsychopharmacology.

Canetta, S.E., Brown, A.S., 2012. Prenatal infection, maternal immune activation, and risk for schizophrenia. Transl. Neurosci. 3, 320-327.

Cannon, T.D., Mednick, S.A., Parnas, J., Schulsinger, F., Praestholm, J., Vestergaard, A. 1993. Developmental brain abnormalities in the offspring of schizophrenic mothers. I. Contributions of genetic and perinatal factors. Arch. Gen. Psychiatry $50,551-564$

Cannon, T.D., Thompson, P.M., van Erp, T.G., Toga, A.W., Poutanen, V.P., Huttunen, M., Lonnqvist, J., Standerskjold-Nordenstam, C.G., Narr, K.L., Khaledy, M., Zoumalan, C.I., Dail, R., Kaprio, J., 2002a. Cortex mapping reveals regionally specific patterns of genetic and disease-specific gray-matter deficits in twins discordant for schizophrenia. Proc. Natl. Acad. Sci. U. S. A. 99, 3228-3233.

Cannon, M., Jones, P.B., Murray, R.M., 2002b. Obstetric complications and schizophrenia: historical and meta-analytic review. Am. J. Psychiatry 159, 1080-1092.

Cannon, T.D., van Erp, T.G., Rosso, I.M., Huttunen, M., Lonnqvist, J., Pirkola, T. Salonen, O., Valanne, L., Poutanen, V.P., Standertskjold-Nordenstam, C.G. 2002c. Fetal hypoxia and structural brain abnormalities in schizophrenic patients, their siblings, and controls. Arch. Gen. Psychiatry 59, 35-41.

Canteras, N.S., Resstel, L.B., Bertoglio, L.J., Carobrez Ade, P., Guimaraes, F.S., 2010. Neuroanatomy of anxiety. Curr. Top. Behav. Neurosci. 2, 77-96.

Carter, C.J., 2009. Schizophrenia susceptibility genes directly implicated in the life cycles of pathogens: cytomegalovirus, influenza, herpes simplex, rubella, and Toxoplasma gondii. Schizophr. Bull. 35, 1163-1182.

Carroll, L.S., Kendall, K., O’Donovan, M.C., Owen, M.J., Williams, N.M., 2009. Evidence that putative ADHD low risk alleles at SNAP25 may increase the risk of schizophrenia. Am. J. Med. Genet. B: Neuropsychiatr. Genet. 150B, 893-899.

Cash-Padgett, T., Jaaro-Peled, H., 2013. DISC1 mouse models as a tool to deciphe gene-environment interactions in psychiatric disorders. Front. Behav. Neurosci. 7, 113

Caspi, A., Moffitt, T.E., Cannon, M., McClay, J., Murray, R., Harrington, H., Taylor, A Arseneault, L. Williams, B., Braithwaite, A., Poulton, R., Craig, I.W., 2005. Moderation of the effect of adolescent-onset cannabis use on adult psychosis by a functional polymorphism in the catechol-O-methyltransferase gene: longitudinal evidence of a gene $\times$ environment interaction. Biol. Psychiatry 57 1117-1127.

Chanasong, R., Thanoi, S., Watiktinkorn, P., Reynolds, G.P., Nudmamud-Thanoi, S., 2013. Genetic variation of GRIN1 confers vulnerability to methamphetaminedependent psychosis in a Thai population. Neurosci. Lett. 551, 58-61.

Chen, C.K., Hu, X., Lin, S.K., Sham, P.C., Loh el, W., Li, T., Murray, R.M., Ball, D.M., 2004 Association analysis of dopamine D2-like receptor genes and methamphetamine abuse. Psychiatr. Genet. 14, 223-226.

Chen, J., Lipska, B.K., Weinberger, D.R., 2006. Genetic mouse models of schizophrenia: from hypothesis-based to susceptibility gene-based models. Biol. Psychiatry $59,1180-1188$.

Chen, Y.A., Scheller, R.H., 2001. Nat. Rev. Mol. Cell. Biol. 2, 98-106.

Chesworth, R., Yulyaningsih, E., Cappas, E., Arnold, J., Sainsbury, A., Karl, T., 2012 The response of neuregulin 1 mutant mice to acute restraint stress. Neurosci. Lett. 515, 82-86.
Chitwood, D., Timmermans, M., 2010. Small RNAs are on the move. Nature 467, 415-419.

Chohan, T.W., Boucher, A.A., Spencer, J.R., Kassem, M.S., Hamdi, A.A., Karl, T., Fok, S.Y., Bennett, M.R., Arnold, J.C., 2014a. Partial genetic deletion of neuregulin 1 modulates the effects of stress on sensorimotor gating, dendritic morphology, and HPA axis activity in adolescent mice. Schizophr. Bull. 40, $1272-1284$

Chohan, T.W., Nguyen, A., Todd, S.M., Bennett, M.R., Callaghan, P., Arnold, J.C., 2014b. Partial genetic deletion of neuregulin 1 and adolescent stress interact to alter NMDA receptor binding in the medial prefrontal cortex. Front. Behav. Neurosci. 8, 298.

Chong, V.Z., Thompson, M., Beltaifa, S., Webster, M.J., Law, A.J., Weickert, C.S., 2008. Elevated neuregulin-1 and ErbB4 protein in the prefrontal cortex of schizophrenic patients. Schizophr. Res. 100, 270-280.

Chotai, J., Serretti, A., Lattuada, E., Lorenzi, C., Lilli, R., 2003. Gene-environment interaction in psychiatric disorders as indicated by season of birth variations in tryptophan hydroxylase (TPH), serotonin transporter (5-HTTLPR) and dopamine receptor (DRD4) gene polymorphisms. Psychiatry Res. 119, 99-111.

Clapcote, S.J., Lipina, T.V., Millar, J.K., Mackie, S., Christie, S., Ogawa, F., Lerch, J.P., Trimble, K., Uchiyama, M., Sakuraba, Y., Kaneda, H., Shiroishi, T., Houslay, M.D., Henkelman, R.M., Sled, J.G., Gondo, Y., Porteous, D.J., Roder, J.C., 2007. Behavioral phenotypes of Disc1 missense mutations in mice. Neuron 54, 387-402.

Collip, D., van Winkel, R., Peerbooms, O., Lataster, T., Thewissen, V., Lardinois, M. Drukker, M., Rutten, B.P., Van Os, J., Myin-Germeys, I., 2011. COMT Val158Metstress interaction in psychosis: role of background psychosis risk. CNS Neurosci. Ther. 17, 612-619.

Costa, E., Davis, J., Pesold, C., Tueting, P., Guidotti, A., 2002. The heterozygote reeler mouse as a model for the development of a new generation of antipsychotics. Curr. Opin. Pharmacol. 2, 56-62.

Costas, J., Sanjuan, J., Ramos-Rios, R., Paz, E., Agra, S., Tolosa, A., Paramo, M., Brenlla, J., Arrojo, M., 2011. Interaction between COMT haplotypes and cannabis in schizophrenia: a case-only study in two samples from Spain. Schizophr. Res. 127, 22-27.

Cryan, J.F., Slattery, D.A., 2007. Animal models of mood disorders: recent developments. Curr. Opin. Psychiatry 20, 1-7.

Curley, A.A., Arion, D., Volk, D.W., Asafu-Adjei, J.K., Sampson, A.R., Fish, K.N., Lewis, D.A., 2011. Cortical deficits of glutamic acid decarboxylase 67 expression in schizophrenia: clinical, protein, and cell type-specific features. Am. J. Psychiatry $168,921-929$

Cuthbert, B.N., 2014. The RDoC framework: facilitating transition from ICD/DSM to dimensional approaches that integrate neuroscience and psychopathology. World Psychiatry 13, 28-35.

D’Arcangelo, G., 2005. The reeler mouse: anatomy of a mutant. Int. Rev. Neurobiol. $71,383-417$.

D’Souza, D.C., Perry, E., MacDougall, L., Ammerman, Y., Cooper, T., Wu, Y.T., Braley, G., Gueorguieva, R., Krystal, J.H., 2004. The psychotomimetic effects of intravenous delta-9-tetrahydrocannabinol in healthy individuals: implications for psychosis. Neuropsychopharmacology 29, 1558-1572.

Dai, D., Wang, Y., Yuan, J., Zhou, X., Jiang, D., Li, J., Zhang, Y., Yin, H., Duan, S., 2014. Meta-analyses of 10 polymorphisms associated with the risk of schizophrenia. Biomed. Rep. 2, 729-736.

Dantzer, R., O’Connor, J.C., Freund, G.G., Johnson, R.W., Kelley, K.W., 2008. From inflammation to sickness and depression: when the immune system subjugates the brain. Nat. Rev. Neurosci. 9, 46-56.

de Mello Schier, A.R., de Oliveira Ribeiro, N.P., Coutinho, D.S., Machado, S., AriasCarrion, O., Crippa, J.A., Zuardi, A.W., Nardi, A.E., Silva, A.C., 2014. Antidepressant-like and anxiolytic-like effects of cannabidiol: a chemical compound of Cannabis sativa. CNS Neurol. Disord. Drug Targets 13, 953-960.

Demontis, D., Nyegaard, M., Buttenschon, H.N., Hedemand, A., Pedersen, C.B., Grove, J., Flint, T.J., Nordentoft, M., Werge, T., Hougaard, D.M., Sorensen, K.M., Yolken, R.H., Mors, O., Borglum, A.D., Mortensen, P.B., 2011. Association of GRIN1 and GRIN2A-D with schizophrenia and genetic interaction with maternal herpes simplex virus-2 infection affecting disease risk. Am. J. Med. Genet. B: Neuropsychiatr. Genet. 156B, 913-922.

Deng, C., Dean, B., 2013. Mapping the pathophysiology of schizophrenia: interactions between multiple cellular pathways. Front. Cell. Neurosci. 7, 238.

Desbonnet, L., O’Tuathaigh, C., Clarke, G., O’Leary, C., Petit, E., Clarke, N., Tighe, O., Lai, D., Harvey, R., Cryan, J.F., Dinan, T.G., Waddington, J.L., 2012. Phenotypic effects of repeated psychosocial stress during adolescence in mice mutant for the schizophrenia risk gene neuregulin-1: a putative model of gene $\times$ environenvironment interaction. Brain Behav. Immun. 26, 660-671.

Desbonnet, L., Waddington, J.L., Tuathaigh, C.M., 2009. Mice mutant for genes associated with schizophrenia: common phenotype or distinct endophenotypes? Behav. Brain Res. 204, 258-273.

Dethoff, E., Chugh, J., Mustoe, A., Al-Hashimi, H., 2012. Functional complexity and regulation through RNA dynamics. Nature 482, 322-330.

Devinsky, O., Cilio, M.R., Cross, H., Fernandez-Ruiz, J., French, J., Hill, C., Katz, R., Di Marzo, V., Jutras-Aswad, D., Notcutt, W.G., Martinez-Orgado, J., Robson, P.J., Rohrback, B.G., Thiele, E., Whalley, B., Friedman, D., 2014. Cannabidiol: pharmacology and potential therapeutic role in epilepsy and other neuropsychiatric disorders. Epilepsia 55, 791-802.

Di Forti, M., Iyegbe, C., Sallis, H., Kolliakou, A., Falcone, M.A., Paparelli, A., Sirianni, M., La Cascia, C., Stilo, S.A., Marques, T.R., Handley, R., Mondelli, V., Dazzan, P., Pariante, C., David, A.S., Morgan, C., Powell, J., Murray, R.M., 2012. Confirmation that the AKT1 (rs2494732) genotype influences the risk of psychosis in cannabis users. Biol. Psychiatry 72, 811-816. 
Dick, D.M., 2011. Gene-environment interaction in psychological traits and disorders. Annu. Rev. Clin. Psychol. 7, 383-409.

Dickerson, F., Lillehoj, E., Stallings, C., Wiley, M., Origoni, A., Vaughan, C., Khushalani, S., Sabunciyan, S., Yolken, R., 2012. Antibodies to retroviruses in recent onset psychosis and multi-episode schizophrenia. Schizophr. Res. 138, 198-205.

Duncan, L.E., Keller, M.C., 2011. A critical review of the first 10 years of candidate gene-by-environment interaction research in psychiatry. Am. J. Psychiatry 168, 1041-1049.

Dvir, Y., Denietolis, B., Frazier, J.A., 2013. Childhood trauma and psychosis. Child Adolesc. Psychiatr. Clin. N. Am. 22, 629-641.

Eastwood, S.L., Harrison, P.J., 2003. Interstitial white matter neurons express less reelin and are abnormally distributed in schizophrenia: towards an integration of molecular and morphologic aspects of the neurodevelopmental hypothesis. Mol. Psychiatry 8, 769, 821-831.

Eells, J.B., Misler, J.A., Nikodem, V.M., 2006. Early postnatal isolation reduces dopamine levels, elevates dopamine turnover and specifically disrupts prepulse inhibition in Nurr1-null heterozygous mice. Neuroscience 140, 1117-1126.

Eells, J.B., Varela-Stokes, A., Guo-Ross, S.X., Kummari, E., Smith, H.M., Cox, E., Lindsay, D.S., 2015. Chronic Toxoplasma gondii in Nurr1-null heterozygous mice exacerbates elevated open field activity. PLOS ONE 10 (4)

Egger, G., Liang, G., Aparicio, A., Jones, P.A., 2004. Epigenetics in human disease and prospects for epigenetic therapy. Nature 429, 457-463.

Ellenbroek, B., Cools, A.R., 2002. Apomorphine susceptibility and animal models for psychopathology: genes and environment. Behav. Genet. 32, 349-361.

Ellenbroek, B., 2004. Pre-attentive processing and schizophrenia: animal studies. Psychopharmacology 174, 65-74.

Ellenbroek, B., Cools, A.R., 1995. Animal models of psychotic disturbances. In: Den Boer, J.A., Westenberg, H.G.M., van Praag, H.M. (Eds.), Advances in the Neurobiology of Schizophrenia. John Wiley \& Sons Ltd., New York, pp. 89-109.

Evins, A.E., Green, A.I., Kane, J.M., Murray, R.M., 2012. The effect of marijuana use on the risk for schizophrenia. J. Clin. Psychiatry 73, 1463-1468.

Eykelenboom, J.E., Briggs, G.J., Bradshaw, N.J., Soares, D.C., Ogawa, F., Christie, S. Malavasi, E.L., Makedonopoulou, P., Mackie, S., Malloy, M.P., Wear, M.A., Blackburn, E.A., Bramham, J., McIntosh, A.M., Blackwood, D.H., Muir, W.J., Porteous, D.J., Millar, J.K., 2012. A t $(1 ; 11)$ translocation linked to schizophrenia and affective disorders gives rise to aberrant chimeric DISC1 transcripts that encode structurally altered, deleterious mitochondrial proteins. Hum. Mol. Genet. 21, 3374-3386.

Ezaki, N., Nakamura, K., Sekine, Y., Thanseem, I., Anitha, A., Iwata, Y., Kawai, M., Takebayashi, K., Suzuki, K., Takei, N., Iyo, M., Inada, T., Iwata, N., Harano, M., Komiyama, T., Yamada, M., Sora, I., Ujike, H., Mori, N., 2008. Short allele of 5HTTLPR as a risk factor for the development of psychosis in Japanese methamphetamine abusers. Ann. N.Y. Acad. Sci. 1139, 49-56.

Faraone, S.V., Skol, A.D., Tsuang, D.W., Young, K.A., Haverstock, S.L., Prabhudesai, S., Mena, F., Menon, A.S., Leong, L., Sautter, F., Baldwin, C., Bingham, S., Weiss, D., Collins, J., Keith, T., Vanden Eng, J.L., Boehnke, M., Tsuang, M.T., Schellenberg, G.D., 2005. Genome scan of schizophrenia families in a large Veterans Affairs Cooperative Study sample: evidence for linkage to $18 \mathrm{p} 11.32$ and for racial heterogeneity on chromosomes 6 and 14. Am. J. Med. Genet. B: Neuropsychiatr. Genet. 139B, 91-100.

Fatemi, S.H., Earle, J.A., McMenomy, T., 2000. Reduction in Reelin immunoreactivity in hippocampus of subjects with schizophrenia, bipolar disorder and major depression. Mol. Psychiatry 5, 654-663, 571.

Fatemi, S.H., Kroll, J.L., Stary, J.M., 2001. Altered levels of Reelin and its isoforms in schizophrenia and mood disorders. Neuroreport 12, 3209-3215.

Fatemi, S.H., Stary, J.M., Earle, J.A., Araghi-Niknam, M., Eagan, E., 2005. GABAergic dysfunction in schizophrenia and mood disorders as reflected by decreased levels of glutamic acid decarboxylase 65 and $67 \mathrm{kDa}$ and Reelin proteins in cerebellum. Schizophr. Res. 72, 109-122.

Feigenson, K.A., Kusnecov, A.W., Silverstein, S.M., 2014. Inflammation and the twohit hypothesis of schizophrenia. Neurosci. Biobehav. Rev. 38, 72-93.

Feinberg, A.P., 2007. Phenotypic plasticity and the epigenetics of human disease. Nature 447, 433-440.

Fergusson, D.M., Horwood, L.J., Ridder, E.M., 2005. Tests of causal linkages between cannabis use and psychotic symptoms. Addiction 100, 354-366.

Fernando, A.B., Robbins, T.W., 2011. Animal models of neuropsychiatric disorders. Annu. Rev. Clin. Psychol. 7, 39-61.

Fine, R., Zhang, J., Stevens, H.E., 2014. Prenatal stress and inhibitory neuron systems: implications for neuropsychiatric disorders. Mol. Psychiatry 19, 641-651.

Fisher, H.L., McGuffin, P., Boydell, J., Fearon, P., Craig, T.K., Dazzan, P., Morgan, K., Doody, G.A., Jones, P.B., Leff, J., Murray, R.M., Morgan, C., 2014. Interplay between childhood physical abuse and familial risk in the onset of psychotic disorders. Schizophr. Bull.

Forsyth, J.K., Ellman, L.M., Tanskanen, A., Mustonen, U., Huttunen, M.O., Suvisaari, J., Cannon, T.D., 2013. Genetic risk for schizophrenia, obstetric complications, and adolescent school outcome: evidence for gene-environment interaction. Schizophr. Bull. 39, 1067-1076.

Frank, O., Giehl, M., Zheng, C., Hehlmann, R., Leib-Mösch, C., Seifarth, W., 2005. Human endogenous retrovirus expression profiles in samples from brains of patients with schizophrenia and bipolar disorders. J. Virol. 79, 10890-10901.

Friso, S., Choi, S.W., Girelli, D., Mason, J.B., Dolnikowski, G.G., Bagley, P.J., Olivieri, O., Jacques, P.F., Rosenberg, I.H., Corrocher, R., Selhub, J., 2002. A common mutation in the 5,10-methylenetetrahydrofolate reductase gene affects genomic DNA methylation through an interaction with folate status. Proc. Natl. Acad. Sci. U. S. A. 99, 5606-5611.

Fromer, M., Pocklington, A.J., Kavanagh, D.H., Williams, H.J., Dwyer, S., Gormley, P., Georgieva, L., Rees, E., Palta, P., Ruderfer, D.M., Carrera, N., Humphreys, I.,
Johnson, J.S., Roussos, P., Barker, D.D., Banks, E., Milanova, V., Grant, S.G. Hannon, E., Rose, S.A., Chambert, K., Mahajan, M., Scolnick, E.M., Moran, J.L., Kirov, G., Palotie, A., McCarroll, S.A., Holmans, P., Sklar, P., Owen, M.J., Purcell, S.M., O’Donovan, M.C., 2014. De novo mutations in schizophrenia implicate synaptic networks. Nature 506, 179-184.

Geoffroy, P.A., Etain, B., Houenou, J., 2013. Gene $\times$ environment interactions in schizophrenia and bipolar disorder: evidence from neuroimaging. Front. Psychiatry 4,136 .

Gilbody, S., Lewis, S., Lightfoot, T., 2007. Methylenetetrahydrofolate reductase (MTHFR) genetic polymorphisms and psychiatric disorders: a HuGE review. Am. J. Epidemiol. 165, 1-13.

Gilman, S.E., Ni, M.Y., Dunn, E.C., Breslau, J., McLaughlin, K.A., Smoller, J.W., Perlis, R.H., 2014. Contributions of the social environment to first-onset and recurrent mania. Mol. Psychiatry.

Giovanoli, S., Weber, L., Meyer, U., 2014. Single and combined effects of prenatal immune activation and peripubertal stress on parvalbumin and reelin expression in the hippocampal formation. Brain Behav. Immun. 40, 48-54.

Giovanoli, S., Engler, H., Engler, A., Richetto, J., Voget, M., Willi, R., Winter, C., Riva, M.A., Mortensen, P.B., Feldon, J., Schedlowski, M., Meyer, U., 2013. Stress in puberty unmasks latent neuropathological consequences of prenatal immune activation in mice. Science 339, 1095-1099.

Glaser, B., Ades, A.E., Lewis, S., Emmet, P., Lewis, G., Smith, G.D., Zammit, S., 2010. Perinatal folate-related exposures and risk of psychotic symptoms in the ALSPAC birth cohort. Schizophr. Res. 120, 177-183.

Goate, A., Chartier-Harlin, M.C., Mullan, M., Brown, J., Crawford, F., Fidani, L., Giuffra, L., Haynes, A., Irving, N., James, L., et al., 1991. Segregation of a missense mutation in the amyloid precursor protein gene with familial Alzheimer's disease. Nature 349, 704-706.

Godar, S.C., Bortolato, M., 2014. Gene-sex interactions in schizophrenia: focus on dopamine neurotransmission. Front. Behav. Neurosci. 8, 71

Gogos, J.A., Morgan, M., Luine, V., Santha, M., Ogawa, S., Pfaff, D., Karayiorgou, M. 1998. Catechol-O-methyltransferase-deficient mice exhibit sexually dimorphic changes in catecholamine levels and behavior. Proc. Natl. Acad. Sci. U. S. A. 95, 9991-9996.

Golub, M.S., Germann, S.L., Lloyd, K.C., 2004. Behavioral characteristics of a nervous systemspecific erbB4 knock-out mouse. Behav. Brain Res. 153, 159-170.

Goriely, A., McGrath, J.J., Hultman, C.M., Wilkie, A.O., Malaspina, D., 2013. "Selfish spermatogonial selection": a novel mechanism for the association between advanced paternal age and neurodevelopmental disorders. Am. J. Psychiatry 170, 599-608.

Gothelf, D., Law, A.J., Frisch, A., Chen, J., Zarchi, O., Michaelovsky, E., Ren-Patterson R., Lipska, B.K., Carmel, M., Kolachana, B., Weizman, A., Weinberger, D.R., 2014 Biological effects of COMT haplotypes and psychosis risk in 22q11.2 deletion syndrome. Biol. Psychiatry 75, 406-413.

Gottesman, I.I., Gould, T.D., 2003. The endophenotype concept in psychiatry: etymology and strategic intentions. Am. J. Psychiatry 160, 636-645.

Grayson, D.R., Jia, X., Chen, Y., Sharma, R.P., Mitchell, C.P., Guidotti, A., Costa, E., 2005 Reelin promoter hypermethylation in schizophrenia. Proc. Natl. Acad. Sci. U. S. A. $102,9341-9346$

Green, E.K., Norton, N., Peirce, T., Grozeva, D., Kirov, G., Owen, M.J., O’Donovan, M.C., Craddock, N., 2006. Evidence that a DISC1 frame-shift deletion associated with psychosis in a single family may not be a pathogenic mutation. Mol. Psychiatry 11, 798-799.

Green, J.G., McLaughlin, K.A., Berglund, P.A., Gruber, M.J., Sampson, N.A., Zaslavsky, A.M., Kessler, R.C., 2010. Childhood adversities and adult psychiatric disorders in the national comorbidity survey replication I: associations with first onset of DSM-IV disorders. Arch. Gen. Psychiatry 67, 113-123.

Grishkevich, V., Yanai, I., 2013. The genomic determinants of genotype $\times$ environenvironment interactions in gene expression. Trends Genet. 29, 479-487.

Guidotti, A., Auta, J., Davis, J.M., Di-Giorgi-Gerevini, V., Dwivedi, Y., Grayson, D.R., Impagnatiello, F., Pandey, G., Pesold, C., Sharma, R., Uzunov, D., Costa, E., 2000. Decrease in reelin and glutamic acid decarboxylase67 (GAD67) expression in schizophrenia and bipolar disorder: a postmortem brain study. Arch. Gen. Psychiatry 57, 1061-1069.

Guilarte, T.R., Opler, M., Pletnikov, M., 2012. Is lead exposure in early life an environmental risk factor for Schizophrenia? Neurobiological connections and testable hypotheses. Neurotoxicology 33, 560-574.

Guilarte, T.R., 2009. Prenatal lead exposure and schizophrenia: further evidence and more neurobiological connections. Environ. Health Perspect. 117, A190-A191.

Hahn, C.G., Wang, H.Y., Cho, D.S., Talbot, K., Gur, R.E., Berrettini, W.H., Bakshi, K., Kamins, J., Borgmann-Winter, K.E., Siegel, S.J., Gallop, R.J., Arnold, S.E., 2006. Altered neuregulin 1-erbB4 signaling contributes to NMDA receptor hypofunction in schizophrenia. Nat. Med. 12, 824-828.

Hall, J., Trent, S., Thomas, K.L., O’Donovan, M.C., Owen, M.J., 2015. Genetic risk for schizophrenia: convergence on synaptic pathways involved in plasticity. Biol. Psychiatry 77, 52-58.

Han, S., Yang, B.Z., Kranzler, H.R., Oslin, D., Anton, R., Farrer, L.A., Gelernter, J., 2012. Linkage analysis followed by association show NRG1 associated with cannabis dependence in African Americans. Biol. Psychiatry 72, 637-644.

Hannon, G.J., 2002. RNA interference. Nature 418, 244-251.

Haque, F.N., Lipina, T.V., Roder, J.C., Wong, A.H., 2012. Social defeat interacts with Disc1 mutations in the mouse to affect behavior. Behav. Brain Res. 233 , 337-344.

Harano, M., Uchimura, N., Abe, H., Ishibashi, M., Iida, N., Yanagimoto, K., Tanaka, T. Maeda, H., Sora, I., Iyo, M., Komiyama, T., Yamada, M., Sekine, Y., Inada, T., Ozaki, 
N., Ujike, H., 2004. A polymorphism of DRD2 gene and brain atrophy in methamphetamine psychosis. Ann. N.Y. Acad. Sci. 1025, 307-315.

Harper, K.M., Hiramoto, T., Tanigaki, K., Kang, G., Suzuki, G., Trimble, W., Hiroi, N. 2012. Alterations of social interaction through genetic and environmental manipulation of the 22q11.2 gene Sept5 in the mouse brain. Hum. Mol. Genet. 21, 3489-3499.

Harrison, P.J., 2015. Recent genetic findings in schizophrenia and their therapeutic relevance. J. Psychopharmacol. 29, 85-96.

Harvey, L., Boksa, P., 2013. Do prenatal immune activation and maternal iron deficiency interact to affect neurodevelopment and early behavior in rat offspring? Brain Behav. Immun. S0889-S01591.

Hashimoto, R., Straub, R.E., Weickert, C.S., Hyde, T.M., Kleinman, J.E., Weinberger D.R., 2004. Expression analysis of neuregulin-1 in the dorsolateral prefrontal cortex in schizophrenia. Mol. Psychiatry 9, 299-307.

Hashimoto, T., Hashimoto, K., Matsuzawa, D., Shimizu, E., Sekine, Y., Inada, T., Ozaki, N., Iwata, N., Harano, M., Komiyama, T., Yamada, M., Sora, I., Ujike, H., Iyo, M., 2005. A functional glutathione S-transferase P1 gene polymorphism is associated with methamphetamine-induced psychosis in Japanese population. Am. J. Med. Genet. B: Neuropsychiatr. Genet. 135B, 5-9.

Hashimoto, T., Hashimoto, K., Miyatake, R., Matsuzawa, D., Sekine, Y., Inada, T. Ozaki, N., Iwata, N., Harano, M., Komiyama, T., Yamada, M., Sora, I., Ujike, H., Iyo, M., 2008. Association study between polymorphisms in glutathione-related genes and methamphetamine use disorder in a Japanese population. Am. J. Med Genet. B: Neuropsychiatr. Genet. 147B, 1040-1046.

Hattori, T., Baba, K., Matsuzaki, S., Honda, A., Miyoshi, K., Inoue, K., Taniguchi, M. Hashimoto, H., Shintani, N., Baba, A., Shimizu, S., Yukioka, F., Kumamoto, N. Yamaguchi, A., Tohyama, M., Katayama, T., 2007. A novel DISC1-interacting partner DISC1-Binding Zinc-finger protein: implication in the modulation of DISC1-dependent neurite outgrowth. Mol. Psychiatry 12, 398-407.

Haukvik, U.K., Saetre, P., McNeil, T., Bjerkan, P.S., Andreassen, O.A., Werge, T. Jonsson, E.G., Agartz, I., 2010. An exploratory model for $\mathrm{G} \times \mathrm{E}$ interaction on hippocampal volume in schizophrenia; obstetric complications and hypoxiarelated genes. Prog. Neuropsychopharmacol. Biol. Psychiatry 34, 1259-1265.

Heckers, S., 2013. What is the core of schizophrenia? JAMA Psychiatry 70 1009-1010.

Helin, K., Dhanak, D., 2013. Chromatin proteins and modifications as drug targets. Nature 502, 480-488.

Heim, A.F., Coyne, M.J., Kamboh, M.I., Ryan, C., Jennings, J.R., 2013. The catechol-omethyltransferase Val158 Met polymorphism modulates organization of regional cerebral blood flow response to working memory in adults. Int. J. Psychophysiol. 90, 149-156.

Heins, M., Simons, C., Lataster, T., Pfeifer, S., Versmissen, D., Lardinois, M., Marcelis, M., Delespaul, P., Krabbendam, L., van Os, J., Myin-Germeys, I., 2011. Childhood trauma and psychosis: a case-control and case-sibling comparison across different levels of genetic liability, psychopathology, and type of trauma. Am. J. Psychiatry 168, 1286-1294.

Henquet, C., Rosa, A., Delespaul, P., Papiol, S., Fananás, L., van Os, J., Myin-Germeys, I., 2009. COMT ValMet moderation of cannabis-induced psychosis: a momentary assessment study of 'switching on' hallucinations in the flow of daily life. Acta Psychiatr. Scand. 119, 156-160.

Henquet, C., Rosa, A., Krabbendam, L., Papiol, S., Fananás, L., Drukker, M., Ramaekers, J.G., van Os, J., 2006. An experimental study of catechol-o-methyltransferase Val158Met moderation of delta-9-tetrahydrocannabinol-induced effects on psychosis and cognition. Neuropsychopharmacology 31, 2748-2757.

Hida, H., Mouri, A., Noda, Y., 2013. Behavioral phenotypes in schizophrenic animal models with multiple combinations of genetic and environmental factors. J. Pharmacol. Sci. 121, 185-191.

Hida, H., Mouri, A., Ando, Y., Mori, K., Mamiya, T., Iwamoto, K., Ozaki, N., Yamada, K. Nabeshima, T., Noda, Y., 2014. Combination of neonatal Polyl:C and adolescent phencyclidine treatments is required to induce behavioral abnormalities with overexpression of GLAST in adult mice. Behav. Brain Res. 258, 34-42.

Hikida, T., Jaaro-Peled, H., Seshadri, S., Oishi, K., Hookway, C., Kong, S., Wu, D., Xue R., Andrade, M., Tankou, S., Mori, S., Gallagher, M., Ishizuka, K., Pletnikov, M. Kida, S., Sawa, A., 2007. Dominant-negative DISC1 transgenic mice display schizophreniaassociated phenotypes detected by measures translatable to humans. Proc. Natl. Acad. Sci. U. S. A. 104, 14501-14506.

Ho, B.C., Wassink, T.H., Ziebell, S., Andreasen, N.C., 2011. Cannabinoid receptor 1 gene polymorphisms and marijuana misuse interactions on white matter and cognitive deficits in schizophrenia. Schizophr. Res. 128, 66-75.

Hoffman, K.L., 2013. Role of murine models in psychiatric illness drug discovery: a dimensional view. Expert Opin. Drug Discov. 8, 865-877.

Hosak, L., Sery, O., Beranek, M., Alda, M., 2011. Lack of association between the Val158Met catechol-O-methyltransferase gene polymorphism and methamphetamine dependence. Neuro Endocrinol. Lett. 32, 469-474.

Howes, O.D., Murray, R.M., 2014. Schizophrenia: an integrated sociodevelopmentalcognitive model. Lancet 383, 1677-1687.

Hu, C.Y., Qian, Z.Z., Gong, F.F., Lu, S.S., Feng, F., Wu, Y.L., Yang, H.Y., Sun, Y.H., 2014 Methylenetetrahydrofolate reductase (MTHFR) polymorphism susceptibility to schizophrenia and bipolar disorder: an updated meta-analysis. J. Neural Transm.

Huang, W.J., Liu, Z.C., Wei, W., Wang, G.H., Wu, J.G., Zhu, F., 2006. Human endogenous retroviral pol RNA and protein detected and identified in the blood of individuals with schizophrenia. Schizophr. Res. 83, 193-199.

Hultman, C.M., Sparen, P., Takei, N., Murray, R.M., Cnattingius, S., 1999. Prenatal and perinatal risk factors for schizophrenia, affective psychosis, and reactive psychosis of early onset: case-control study. BMJ 318, 421-426.
Huotari, M., Garcia-Horsman, J.A., Karayiorgou, M., Gogos, J.A., Mannisto, P.T., 2004. Damphetamine responses in catechol-O-methyltransferase (COMT) disrupted mice. Psychopharmacology 172, 1-10.

Huotari, M., Gogos, J.A., Karayiorgou, M., Koponen, O., Forsberg, M., Raasmaja, A., Hyttinen, J., Mannisto, P.T., 2002. Brain catecholamine metabolism in catecholOmethyltransferase (COMT)-deficient mice. Eur. J. Neurosci. 15, 246-256.

Husted, J.A., Ahmed, R., Chow, E.W., Brzustowicz, L.M., Bassett, A.S., 2010. Childhood trauma and genetic factors in familial schizophrenia associated with the NOS1AP gene. Schizophr. Res. 121, 187-192.

Ibi, D., Nagai, T., Kitahara, Y., Mizoguchi, H., Koike, H., Shiraki, A., Takuma, K., Kamei, H., Noda, Y., Nitta, A., Nabeshima, T., Yoneda, Y., Yamada, K., 2009. Neonatal polyI:C treatment in mice results in schizophrenia-like behavioral and neurochemical abnormalities in adulthood. Neurosci. Res. 64, 297-305.

Ibi, D., Nagai, T., Koike, H., Kitahara, Y., Mizoguchi, H., Niwa, M., Jaaro-Peled, H., Nitta, A., Yoneda, Y., Nabeshima, T., Sawa, A., Yamada, K., 2010. Combined effect of neonatal immune activation and mutant DISC1 on phenotypic changes in adulthood. Behav. Brain Res. 206, 32-37.

Ibi, D., González-Maeso, J., 2015. Epigenetic signaling in schizophrenia. Cell Signal. 27, 2131-2136.

Iijima, T., Emi, K., Yuzaki, M., 2009. Activity-dependent repression of Cbln1 expression: mechanism for developmental and homeostatic regulation of synapses in the cerebellum. J. Neurosci. 29, 5425-5434.

Ikeda, M., Okahisa, Y., Aleksic, B., Won, M., Kondo, N., Naruse, N., Aoyama-Uehara, K., Sora, I., Iyo, M., Hashimoto, R., Kawamura, Y., Nishida, N., Miyagawa, T., Takeda, M., Sasaki, T., Tokunaga, K., Ozaki, N., Ujike, H., Iwata, N., 2013. Evidence for shared genetic risk between methamphetamine-induced psychosis and schizophrenia. Neuropsychopharmacology 38, 1864-1870.

Impagnatiello, F., Guidotti, A.R., Pesold, C., Dwivedi, Y., Caruncho, H., Pisu, M.G., Uzunov, D.P., Smalheiser, N.R., Davis, J.M., Pandey, G.N., Pappas, G.D., Tueting, P., Sharma, R.P., Costa, E., 1998. A decrease of reelin expression as a putative vulnerability factor in schizophrenia. Proc. Natl. Acad. Sci. U. S. A. 95, 1571815723

Insel, T.R., 2010. Rethinking schizophrenia. Nature 468 (7321), 187-193, http:// dx.doi.org/10.1038/nature09552.

Iseger, T.A., Bossong, M.G., 2015. A systematic review of the antipsychotic properties of cannabidiol in humans. Schizophr. Res. 162, 153-161.

Ishihama, T., Ago, Y., Shintani, N., Hashimoto, H., Baba, A., Takuma, K., Matsuda, T. 2010. Environmental factors during early developmental period influence psychobehavioral abnormalities in adult PACAP-deficient mice. Behav. Brain Res. 209, 274-280.

Iwata, N., Suzuki, T., Ikeda, M., Kitajima, T., Yamanouchi, Y., Inada, T., Ozaki, N., 2004. No association with the neuregulin 1 haplotype to Japanese schizophrenia. Mol. Psychiatry 9, 126-127.

Iyegbe, C., Campbell, D., Butler, A., Ajnakina, O., Sham, P., 2014. The emerging molecular architecture of schizophrenia, polygenic risk scores and the clinical implications for $G \times$ E research. Soc. Psychiatry Psychiatr. Epidemiol. 49, 169-182.

Jaaro-Peled, H., 2009. Gene models of schizophrenia: DISC1 mouse models. Prog. Brain Res. 179, 75-86.

Jeans, A.F., Oliver, P.L., Johnson, R., Capogna, M., Vikman, J., Molnar, Z., Babbs, A., Partridge, C.J., Salehi, A., Bengtsson, M., Eliasson, L., Rorsman, P., Davies, K.E., 2007. A dominant mutation in Snap25 causes impaired vesicle trafficking, sensorimotor gating, and ataxia in the blind-drunk mouse. Proc. Natl. Acad. Sci. U. S. A. 104, 2431-2436

Jones, P.B., Rantakallio, P., Hartikainen, A.L., Isohanni, M., Sipila, P., 1998. Schizophrenia as a long-term outcome of pregnancy, delivery, and perinatal complications: a 28-year follow-up of the 1966 north Finland general population birth cohort. Am. J. Psychiatry 155, 355-364.

Juckel, G., Roser, P., Nadulski, T., Stadelmann, A.M., Gallinat, J., 2007. Acute effects of Delta9-tetrahydrocannabinol and standardized cannabis extract on the auditory evoked mismatch negativity. Schizophr. Res. 97, 109-117.

Jugurnauth, S.K., Chen, C.K., Barnes, M.R., Li, T., Lin, S.K., Liu, H.C., Collier, D.A., Breen, G., 2011. A COMT gene haplotype associated with methamphetamine abuse. Pharmacogenet. Genomics 21, 731-740.

Jurado, S., Goswami, D., Zhang, Y., Molina, A.J., Südhof, T.C., Malenka, R.C., 2013. LTP requires a unique postsynaptic SNARE fusion machinery. Neuron 77, 542-558.

Kaffman, A., Krystal, J.H., 2012. New frontiers in animal research of psychiatric illness. Methods Mol. Biol. 829, 3-30.

Kalayasiri, R., Verachai, V., Gelernter, J., Mutirangura, A., Malison, R.T., 2014. Clinical features of methamphetamine-induced paranoia and preliminary genetic association with $\mathrm{DBH}-1021 \mathrm{C} \rightarrow \mathrm{T}$ in a Thai treatment cohort. Addiction 109, 965-976.

Kannan, G., Sawa, A., Pletnikov, M.V., 2013. Mouse models of gene-environment interactions in schizophrenia. Neurobiol. Dis. 57, 5-11.

Kantrowitz, J.T., Malhotra, A.K., Cornblatt, B., Silipo, G., Balla, A., Suckow, R.F., D’Souza, C., Saksa, J., Woods, S.W., Javitt, D.C., 2010. High dose D-serine in the treatment of schizophrenia. Schizophr. Res. 121, 125-130.

Kantrowitz, J.T., Nolan, K.A., Sen, S., Simen, A.A., Lachman, H.M., Bowers Jr., M.B., 2009. Adolescent cannabis use, psychosis and catechol-O-methyltransferase genotype in African Americans and Caucasians. Psychiatr. Q. 80, 213-218.

Karayiorgou, M., Gogos, J.A., Galke, B.L., Wolyniec, P.S., Nestadt, G., Antonarakis, S.E., Kazazian, H.H., Housman, D.E., Pulver, A.E., 1998. Identification of sequence variants and analysis of the role of the catechol-O-methyl-transferase gene in schizophrenia susceptibility. Biol. Psychiatry 43, 425-431.

Karl, T., 2013. Neuregulin 1: a prime candidate for research into gene-environment interactions in schizophrenia? Insights from genetic rodent models. Front. Behav. Neurosci. 7, 106. 
Karlsson, H., Bachmann, S., Schroder, J., McArthur, J., Torrey, E.F., Yolken, R.H., 2001. Retroviral RNA identified in the cerebrospinal fluids and brains of individuals with schizophrenia. Proc. Natl. Acad. Sci. U. S. A. 98, 4634-4639.

Karlsson, H., Schröder, J., Bachmann, S., Bottmer, C., Yolken, R.H., 2004. HERV-Wrelated RNA detected in plasma from individuals with recent-onset schizophrenia or schizoaffective disorder. Mol. Psychiatry 9, 12-13.

Karson, C.N., Mrak, R.E., Schluterman, K.O., Sturner, W.Q., Sheng, J.G., Griffin, W.S., 1999. Mol. Psychiatry 4, 39-45.

Kawashima, K., Kishi, T., Ikeda, M., Kitajima, T., Yamanouchi, Y., Kinoshita, Y., Takahashi, N., Saito, S., Ohi, K., Yasuda, Y., Hashimoto, R., Takeda, M., Inada, T., Ozaki, N., Iwata, N., 2008. No association between tagging SNPs of SNARE complex genes (STX1A, VAMP2 and SNAP25) and schizophrenia in a Japanese population. Am. J. Med. Genet. B: Neuropsychiatr. Genet. 147B, 1327-1331.

Keeler, J.F., Robbins, T.W., 2011. Translating cognition from animals to humans. Biochem. Pharmacol. 81, 1356-1366.

Kellendonk, C., Simpson, E.H., Kandel, E.R., 2009. Modeling cognitive endophenotypes of schizophrenia in mice. Trends Neurosci. 32, 347-358.

Kelly, B.D., O'Callaghan, E., Waddington, J.L., Feeney, L., Browne, S., Scully, P.J., Clarke, M., Quinn, J.F., McTigue, O., Morgan, M.G., Kinsella, A., Larkin, C., 2010. Schizophrenia and the city: a review of literature and prospective study of psychosis and urbanicity in Ireland. Schizophr. Res. 116, 75-89.

Kendler, K.S., Eaves, L.J., 1986. Models for the joint effect of genotype and environment on liability to psychiatric illness. Am. J. Psychiatry 143, 279-289.

Keri, S., Kiss, I., Seres, I., Kelemen, O., 2009. A polymorphism of the neuregulin 1 gene (SNP8NRG243177/rs6994992) affects reactivity to expressed emotion in schizophrenia. Am. J. Med. Genet. B: Neuropsychiatr. Genet. 150B, 418-420.

Khandaker, G.M., Stochl, J., Zammit, S., Lewis, G., Jones, P.B., 2014. Childhood Epstein-Barr Virus infection and subsequent risk of psychotic experiences in adolescence: a population-based prospective serological study. Schizophr. Res. 158, 19-24.

Kim, J.J., Shirts, B.H., Dayal, M., Bacanu, S.A., Wood, J., Xie, W., Zhang, X., Chowdari, K.V., Yolken, R., Devlin, B., Nimgaonkar, V.L., 2007. Are exposure to cytomegalovirus and genetic variation on chromosome $6 \mathrm{p}$ joint risk factors for schizophrenia? Ann. Med. 39, 145-153.

Kim, J.Y., Liu, C.Y., Zhang, F., Duan, X., Wen, Z., Song, J., Feighery, E., Lu, B., Rujescu, D., St Clair, D., Christian, K., Callicott, J.H., Weinberger, D.R., Song, H., Ming, G.L., 2012. Interplay between DISC1 and GABA signaling regulates neurogenesis in mice and risk for schizophrenia. Cell 148, 1051-1064.

Kimoto, S., Bazmi, H.H., Lewis, D.A., 2014. Lower expression of glutamic acid decarboxylase 67 in the prefrontal cortex in schizophrenia: contribution of altered regulation by Zif268. Am. J. Psychiatry 171, 969-978.

Kirov, G., Pocklington, A.J., Holmans, P., Ivanov, D., Ikeda, M., Ruderfer, D., Moran, J., Chambert, K., Toncheva, D., Georgieva, L., Grozeva, D., Fjodorova, M., Wollerton, R., Rees, E., Nikolov, I., van de Lagemaat, L.N., Bayes, A., Fernandez, E., Olason, P.I. Bottcher, Y., Komiyama, N.H., Collins, M.O., Choudhary, J., Stefansson, K., Stefansson, H., Grant, S.G., Purcell, S., Sklar, P., O’Donovan, M.C., Owen, M.J., 2012. De novo CNV analysis implicates specific abnormalities of postsynaptic signalling complexes in the pathogenesis of schizophrenia. Mol. Psychiatry 17, 142-153.

Kishi, T., Fukuo, Y., Okochi, T., Kitajima, T., Kawashima, K., Naitoh, H., Ujike, H., Inada, T., Yamada, M., Uchimura, N., Sora, I., Iyo, M., Ozaki, N., Iwata, N., 2011. Serotonin 6 receptor gene is associated with methamphetamine-induced psychosis in a Japanese population. Drug Alcohol Depend. 113, 1-7.

Kishi, T., Ikeda, M., Kitajima, T., Yamanouchi, Y., Kinoshita, Y., Kawashima, K., Okochi, T., Tsunoka, T., Okumura, T., Inada, T., Ujike, H., Yamada, M., Uchimura, N., Sora, I., Iyo, M., Ozaki, N., Iwata, N., 2009. A functional polymorphism in estrogen receptor alpha gene is associated with Japanese methamphetamine induced psychosis. Prog. Neuropsychopharmacol. Biol. Psychiatry 33, 895-898.

Kishi, T., Tsunoka, T., Ikeda, M., Kitajima, T., Kawashima, K., Okochi, T., Okumura, T., Yamanouchi, Y., Kinoshita, Y., Ujike, H., Inada, T., Yamada, M., Uchimura, N., Sora, I., Iyo, M., Ozaki, N., Iwata, N., 2010. Serotonin 1A receptor gene is associated with Japanese methamphetamine-induced psychosis patients. Neuropharmacology 58, 452-456.

Kishimoto, M., Ujike, H., Motohashi, Y., Tanaka, Y., Okahisa, Y., Kotaka, T., Harano, M., Inada, T., Yamada, M., Komiyama, T., Hori, T., Sekine, Y., Iwata, N., Sora, I., Iyo, M., Ozaki, N., Kuroda, S., 2008a. The dysbindin gene (DTNBP1) is associated with methamphetamine psychosis. Biol. Psychiatry 63, 191-196.

Kishimoto, M., Ujike, H., Okahisa, Y., Kotaka, T., Takaki, M., Kodama, M., Inada, T., Yamada, M., Uchimura, N., Iwata, N., Sora, I., Iyo, M., Ozaki, N., Kuroda, S., 2008b. The Frizzled 3 gene is associated with methamphetamine psychosis in the Japanese population. Behav. Brain Funct. 4, 37.

Klein, C., Westenberger, A., 2012. Genetics of Parkinson's disease. Cold Spring Harbor Perspect. Med. 2, a008888.

Kobayashi, H., Ide, S., Hasegawa, J., Ujike, H., Sekine, Y., Ozaki, N., Inada, T., Harano, M., Komiyama, T., Yamada, M., Iyo, M., Shen, H.W., Ikeda, K., Sora, I., 2004. Study of association between alpha-synuclein gene polymorphism and methamphetamine psychosis/dependence. Ann. N.Y. Acad. Sci. 1025, 325-334.

Koenig, J.I., 2006. Schizophrenia: a unique translational opportunity in behavioral neuroendocrinology. Horm. Behav. 50, 602-611.

Koga, M., Ishiguro, H., Horiuchi, Y., Inada, T., Ujike, H., Itokawa, M., Otowa, T., Watanabe, Y., Someya, T., Arinami, T., 2010. Replication study of association between ADCYAP1 gene polymorphisms and schizophrenia. Psychiatr. Genet. $20,123-125$.

Kotaka, T., Ujike, H., Okahisa, Y., Takaki, M., Nakata, K., Kodama, M., Inada, T., Yamada, M., Uchimura, N., Iwata, N., Sora, I., Iyo, M., Ozaki, N., Kuroda, S., 2009. G72 gene is associated with susceptibility to methamphetamine psychosis. Prog. Neuropsychopharmacol. Biol. Psychiatry 33, 1046-1049.
Labrie, V., Roder, J.C., 2010. The involvement of the NMDA receptor D-serine/glycine site in the pathophysiology and treatment of schizophrenia. Neurosci. Biobehav. Rev. 34, 351-372

Labrie, V., Pai, S., Petronis, A., 2012. Epigenetics of major psychosis: progress, problems and perspectives. Trends Genet. 28, 427-435.

Lambert, K.G., Nelson, R.J., Jovanovic, T., Cerdá, M., 2015. Brains in the city: neurobiological effects of urbanization. Neurosci. Biobehav. Rev. S0149-S7634.

Lai, C.S., Fisher, S.E., Hurst, J.A., Vargha-Khadem, F., Monaco, A.P., 2001. A forkheaddomain gene is mutated in a severe speech and language disorder. Nature 413, 519-523.

Laviola, G., Adriani, W., Gaudino, C., Marino, R., Keller, F., 2006. Paradoxical effects of prenatal acetylcholinesterase blockade on neuro-behavioral development and druginduced stereotypies in reeler mutant mice. Psychopharmacology 187 $331-344$.

Laviola, G., Hannan, A.J., Macri, S., Solinas, M., Jaber, M., 2008. Effects of enriched environment on animal models of neurodegenerative diseases and psychiatric disorders. Neurobiol. Dis. 31, 159-168.

Laviola, G., Ognibene, E., Romano, E., Adriani, W., Keller, F., 2009. Gene-environment interaction during early development in the heterozygous reeler mouse: clues for modelling of major neurobehavioral syndromes. Neurosci. Biobehav. Rev. 33, 560-572.

Leboyer, M., Tamouza, R., Charron, D., Faucard, R., Perron, H., 2013. Human endogenous retrovirus type W (HERV-W) in schizophrenia: a new avenue of research at the geneenvironment interface. World J. Biol. Psychiatry 14, 80-90.

Lee, F.H., Fadel, M.P., Preston-Maher, K., Cordes, S.P., Clapcote, S.J., Price, D.J., Roder J.C., Wong, A.H., 2011. Disc1 point mutations in mice affect development of the cerebral cortex. J. Neurosci. 31, 3197-3206.

Levin, E.D., Addy, N., Baruah, A., Elias, A., Christopher, N.C., Seidler, F.J., Slotkin, T.A., 2002. Prenatal chlorpyrifos exposure in rats causes persistent behavioral alterations. Neurotoxicol. Teratol. 24, 733-741.

Levinson, D.F., Duan, J., Oh, S., Wang, K., Sanders, A.R., Shi, J., Zhang, N., Mowry, B.J., Olincy, A., Amin, F., Cloninger, C.R., Silverman, J.M., Buccola, N.G., Byerley, W.F., Black, D.W., Kendler, K.S., Freedman, R., Dudbridge, F., Pe'er, I., Hakonarson, H., Bergen, S.E., Fanous, A.H., Holmans, P.A., Gejman, P.V., 2011. Copy number variants in schizophrenia: confirmation of five previous findings and new evidence for 3q29 microdeletions and VIPR2 duplications. Am. J. Psychiatry $168,302-316$

Lewis, S.J., Zammit, S., Gunnell, D., Smith, G.D., 2005. A meta-analysis of the MTHFR C677T polymorphism and schizophrenia risk. Am. J. Med. Genet. B: Neuropsychiatr. Genet. 135B, 2-4.

Li, B., Woo, R.S., Mei, L., Malinow, R., 2007. The neuregulin-1 receptor erbB4 controls glutamatergic synapse maturation and plasticity. Neuron 54, 583-597.

Li, H., Lu, Q. Xiao, E., Li, Q., He, Z., Mei, X., 2014. Methamphetamine enhances the development of schizophrenia in first-degree relatives of patients with schizophrenia. Can. J. Psychiatry 59, 107-113.

Lipina, T.V., Zai, C., Hlousek, D., Roder, J.C., Wong, A.H., 2013. Maternal immune activation during gestation interacts with Disc1 point mutation to exacerbate schizophrenia-related behaviors in mice. J. Neurosci. 33, 7654-7666.

Liu, H.C., Lin, S.K., Liu, S.K., Chen, S.L., Hu, C.J., Chang, J.G., Leu, S.J., 2004. DAT polymorphism and diverse clinical manifestations in methamphetamine abusers. Psychiatr. Genet. 14, 33-37.

Liu, X.C., Holtze, M., Powell, S.B., Terrando, N., Larsson, M.K., Persson, A., Olsson, S.K. Orhan, F., Kegel, M., Asp, L., Goiny, M., Schwieler, L., Engberg, G., Karlsson, H., Erhardt, S., 2014. Behavioral disturbances in adult mice following neonatal virus infection or kynurenine treatment - role of brain kynurenic acid. Brain Behav. Immun. 36, 80-89.

Lochman, J., Balcar, V.J., St’astný, F., Serý, O., 2013. Preliminary evidence for association between schizophrenia and polymorphisms in the regulatory Regions of the ADRA2A, DRD3 and SNAP-25 Genes. Psychiatry Res. 205, 7-12.

Long, L.E., Chesworth, R., Huang, X.F., Wong, A., Spiro, A., McGregor, I.S., Arnold, J.C., Karl, T., 2012. Distinct neurobehavioural effects of cannabidiol in transmembrane domain neuregulin 1 mutant mice. PLoS ONE 7, e34129.

Long, L.E., Chesworth, R., Huang, X.F., McGregor, I.S., Arnold, J.C., Karl, T., 2013. Transmembrane domain Nrg1 mutant mice show altered susceptibility to the neurobehavioural actions of repeated THC exposure in adolescence. Int. J. Neuropsychopharmacol. 16, 163-175.

Lundberg, P., Cantor-Graae, E., Rukundo, G., Ashaba, S., Ostergren, P.O., 2009. Urbanicity of place of birth and symptoms of psychosis, depression and anxiety in Uganda. Br. J. Psychiatry 195, 156-162.

Ma, T.M., Abazyan, S., Abazyan, B., Nomura, J., Yang, C., Seshadri, S., Sawa, A., Snyder, S.H., Pletnikov, M.V., 2013. Pathogenic disruption of DISC1-serine racemase binding elicits schizophrenia-like behavior via D-serine depletion. Mol. Psychiatry $18,557-567$.

Mahoney, M.K., Olmstead, M.C., 2013. Neurobiology of an endophenotype: modeling the progression of alcohol addiction in rodents. Curr. Opin. Neurobiol. 23 607-614.

Malchow, B., Hasan, A., Schneider-Axmann, T., Jatzko, A., Gruber, O., Schmitt, A., Falkai, P. Wobrock, T. 2013. Effects of cannabis and familial loading on subcortical brain volumes in first-episode schizophrenia. Eur. Arch. Psychiatry Clin. Neurosci. 263 (Suppl. 2), S155-S168.

Macrì, S., Laviola, G., 2004. Single episode of maternal deprivation and adult depressive profile in mice: interaction with cannabinoid exposure during adolescence. Behav. Brain Res. 23, 154.

Martin, D.I., Cropley, J.E., Suter, C.M., 2011. Epigenetics in disease: leader or follower? Epigenetics 7, 843-848. 
Matheson, S.L., Shepherd, A.M., Laurens, K.R., Carr, V.J., 2011. A systematic metareview grading the evidence for non-genetic risk factors and putative antecedents of schizophrenia. Schizophr. Res. 133, 133-142.

Matsuzawa, D., Hashimoto, K., Miyatake, R., Shirayama, Y., Shimizu, E., Maeda, K. Suzuki, Y., Mashimo, Y., Sekine, Y., Inada, T., Ozaki, N., Iwata, N., Harano, M. Komiyama, T., Yamada, M., Sora, I., Ujike, H., Hata, A., Sawa, A., Iyo, M., 2007. Identification of functional polymorphisms in the promoter region of the human PICK1 gene and their association with methamphetamine psychosis Am. J. Psychiatry 164, 1105-1114.

Matthysse, S., 1986. Animal models in psychiatric research. Prog. Brain Res. 65, 259-270.

Maynard, T.M., Sikich, L., Lieberman, J.A., LaMantia, A.S., 2001. Neural development, cell-cell signaling, and the "two-hit" hypothesis of schizophrenia. Schizophr. Bull. 27, 457-476.

McCarroll, S.A., Feng, G., Hyman, S.E., 2014. Genome-scale neurogenetics: methodology and meaning. Nat. Neurosci. 17, 756-763.

McCarthy-Jones, S., Green, M.J., Scott, R.J., Tooney, P.A., Cairns, M.J., Wu, J.Q., Oldmeadow, C., Carr, V., Australian Schizophrenia Research Bank, 2014. Prelimi nary evidence of an interaction between the FOXP2 gene and childhood emotional abuse predicting likelihood of auditory verbal hallucinations in schizophrenia. J. Psychiatr. Res. 50, 66-72.

McDonald, C., Grech, A., Toulopoulou, T., Schulze, K., Chapple, B., Sham, P., Walshe, M., Sharma, T., Sigmundsson, T., Chitnis, X., Murray, R.M., 2002. Brain volumes in familial and non-familial schizophrenic probands and their unaffected relatives. Am. J. Med. Genet. 114, 616-625

McGrath, J.J., Eyles, D.W., Pedersen, C.B., Anderson, C., Ko, P., Burne, T.H., NorgaardPedersen, B., Hougaard, D.M., Mortensen, P.B., 2010. Neonatal vitamin D status and risk of schizophrenia: a population-based case-control study. Arch. Gen. Psychiatry 67, 889-894.

McGrath, J.J., Mortensen, P.B., Visscher, P.M., Wray, N.R., 2013. Where GWAS and epidemiology meet: opportunities for the simultaneous study of genetic and environmental risk factors in schizophrenia. Schizophr. Bull. 39, 955-959.

McKetin, R., Hickey, K., Devlin, K., Lawrence, K., 2010. The risk of psychotic symptoms associated with recreational methamphetamine use. Drug Alcohol Rev. 29, 358-363.

McKetin, R., Lubman, D.I., Baker, A.L., Dawe, S., Ali, R.L., 2013. Dose-related psychotic symptoms in chronic methamphetamine users: evidence from a prospective longitudinal study. JAMA Psychiatry 70, 319-324.

McKetin, R., McLaren, J., Lubman, D.I., Hides, L., 2006. The prevalence of psychotic symptoms among methamphetamine users. Addiction 101, 1473-1478.

McKinney Jr., W.T., Bunney Jr., W.E., 1969. Animal model of depression. I. Review of evidence: implications for research. Arch. Gen. Psychiatry 21, 240-248.

McLoughlin, B.C., Pushpa-Rajah, J.A., Gillies, D., Rathbone, J., Variend, H., Kalakouti, E., Kyprianou, K., 2014. Cannabis and schizophrenia. Cochrane Database Syst. Rev. 10, CD004837.

McOmish, C.E., Burrows, E., Howard, M., Scarr, E., Kim, D., Shin, H.S., Dean, B., van den Buuse, M., Hannan, A.J., 2008. Phospholipase C-beta1 knockout mice exhibit endophenotypes modeling schizophrenia which are rescued by environmental enrichment and clozapine administration. Mol. Psychiatry 13, 661-672.

McOmish, C.E., Burrows, E.L., Hannan, A.J., 2014. Identifying novel interventional strategies for psychiatric disorders: integrating genomics, 'enviromics' and gene-environment interactions in valid preclinical models. Br. J. Pharmacol. $171,4719-4728$

Mei, L., Nave, K.A., 2014. Neuregulin-ERBB signaling in the nervous system and neuropsychiatric diseases. Neuron 83, 27-49.

Mei, L., Xiong, W.C., 2008. Neuregulin 1 in neural development, synaptic plasticity and schizophrenia. Nat. Rev. Neurosci. 9, 437-452.

Mello, C.C., Conte Jr., D., 2004. Revealing the world of RNA interference. Nature 431 338-342.

Merikangas, A.K., Segurado, R., Cormican, P., Heron, E.A., Anney, R.J., Moore, S., Kelleher, E., Hargreaves, A., Anderson-Schmidt, H., Gill, M., Gallagher, L., Corvin, A., 2014. The phenotypic manifestations of rare CNVs in schizophrenia. Schizophr. Res.

Meyer, U., Feldon, J., Schedlowski, M., Yee, B.K., 2005. Towards an immuno-precipitated neurodevelopmental animal model of schizophrenia. Neurosci. Biobehav. Rev. 29, 913-947.

Meyer, U., Nyffeler, M., Engler, A., Urwyler, A., Schedlowski, M., Knuesel, I., Yee, B.K., Feldon, J., 2006. The time of prenatal immune challenge determines the specificity of inflammation-mediated brain and behavioral pathology. J. Neurosci. 26, 4752-4762.

Meyer, U., Feldon, J., 2010. Epidemiology-driven neurodevelopmental animal models of schizophrenia. Prog. Neurobiol. 90, 285-326.

Meyer, U., 2014. Prenatal poly(i:C) exposure and other developmental immune activation models in rodent systems. Biol. Psychiatry 75, 307-315

Meyer, U., Feldon, J., 2012. To poly(I:C) or not to poly(I:C): advancing preclinical schizophrenia research through the use of prenatal immune activation models. Neuropharmacology 62, 1308-1321.

Mihali, A., Subramani, S., Kaunitz, G., Rayport, S., Gaisler-Salomon, I., 2012. Modeling resilience to schizophrenia in genetically modified mice: a novel approach to drug discovery. Expert Rev. Neurother. 12, 785-799.

Millar, J.K., Pickard, B.S., Mackie, S., James, R., Christie, S., Buchanan, S.R., Malloy, M.P., Chubb, J.E., Huston, E., Baillie, G.S., Thomson, P.A., Hill, E.V., Brandon, N.J. Rain, J.C., Camargo, L.M., Whiting, P.J., Houslay, M.D., Blackwood, D.H., Muir, W.J., Porteous, D.J., 2005. DISC1 and PDE4B are interacting genetic factors in schizophrenia that regulate cAMP signaling. Science 310, 1187-1191.

Millar, J.K., Wilson-Annan, J.C., Anderson, S., Christie, S., Taylor, M.S., Semple, C.A Devon, R.S., St Clair, D.M., Muir, W.J., Blackwood, D.H., Porteous, D.J., 2000.
Disruption of two novel genes by a translocation co-segregating with schizophrenia. Hum. Mol. Genet. 9, 1415-1423.

Mitchell, K.J., Porteous, D.J., 2011. Rethinking the genetic architecture of schizophrenia. Psychol. Med. 41, 19-32.

Mittal, V.A., Ellman, L.M., Cannon, T.D., 2008. Gene-environment interaction and covariation in schizophrenia: the role of obstetric complications. Schizophr. Bull. 34, 1083-1094

Modinos, G., Iyegbe, C., Prata, D., Rivera, M., Kempton, M.J., Valmaggia, L.R., Sham, P.K., van Os, J., McGuire, P., 2013. Molecular genetic gene-environment studies using candidate genes in schizophrenia: a systematic review. Schizophr. Res. 150, 356-365

Moffitt, T.E., Caspi, A., Rutter, M., 2005. Strategy for investigating interactions between measured genes and measured environments. Arch. Gen. Psychiatry $62,473-481$.

Moore, T.M., Brown, T., Cade, M., Eells, J.B., 2008. Alterations in amphetaminestimulated dopamine overflow due to the Nurr1-null heterozygous genotype and postweaning isolation. Synapse 62, 764-774.

Moore, T.H., Zammit, S., Lingford-Hughes, A., Barnes, T.R., Jones, P.B., Burke, M., Lewis, G., 2007. Cannabis use and risk of psychotic or affective mental health outcomes: a systematic review. Lancet 370, 319-328.

Morita, Y., Ujike, H., Tanaka, Y., Kishimoto, M., Okahisa, Y., Kotaka, T., Harano, M., Inada, T., Komiyama, T., Hori, T., Yamada, M., Sekine, Y., Iwata, N., Iyo, M., Sora, I., Ozaki, N., Kuroda, S., 2008. The glycine transporter 1 gene (GLYT1) is associated with methamphetamine-use disorder. Am. J. Med. Genet. B: Neuropsychiatr. Genet. 147B, 54-58.

Mortensen, P.B., Pedersen, C.B., Westergaard, T., Wohlfahrt, J., Ewald, H., Mors, O. Andersen, P.K., Melbye, M., 1999. Effects of family history and place and season of birth on the risk of schizophrenia. N. Engl. J. Med. 340, 603-608.

Mullen, B.R., Khialeeva, E., Hoffman, D.B., Ghiani, C.A., Carpenter, E.M., 2013. Decreased reelin expression and organophosphate pesticide exposure alters mouse behaviour and brain morphology. ASN Neuro 5, e00106.

Mukaetova-Ladinska, E., Hurt, J., Honer, W.G., Harrington, C.R., Wischik, C.M., 2002. Loss of synaptic but not cytoskeletal proteins in the cerebellum of chronic schizophrenics. Neurosci. Lett. 317, 161-165.

Mukherjee, O., Meera, P., Ghosh, S., Kubendran, S., Kiran, K., Manjunath, K.R., Subhash, M.N., Benegal, V., Brahmachari, S.K., Majumder, P.P., Jain, S., 2006. Evidence of linkage and association on 18p11.2 for psychosis. Am. J. Med. Genet. B: Neuropsychiatr. Genet. 141B, 868-873.

Muntjewerff, J.W., Ophoff, R.A., Buizer-Voskamp, J.E., Strengman, E., den Heijer, M., Consortium, G., 2011. Effects of season of birth and a common MTHFR gene variant on the risk of schizophrenia. Eur. Neuropsychopharmacol. 21, 300-305.

Murphy, K.C., Jones, L.A., Owen, M.J., 1999. High rates of schizophrenia in adults with velo-cardio-facial syndrome. Arch. Gen. Psychiatry 56, 940-945.

Murray, C.J., Vos, T., Lozano, R., Naghavi, M., Flaxman, A.D., Michaud, C., Ezzati, M., Shibuya, K., Salomon, J.A., Abdalla, S., Aboyans, V., Abraham, J., Ackerman, I., Aggarwal, R., Ahn, S.Y., Ali, M.K., Alvarado, M., Anderson, H.R., Anderson, L.M., Andrews, K.G., Atkinson, C., Baddour, L.M., Bahalim, A.N., Barker-Collo, S., Barrero, L.H. Bartels, D. B. Basanez, M.G. Baxter, A, Bell, M.L, Benjamin, EJ. Bennett, D., Bernabe, E., Bhalla, K., Bhandari, B., Bikbov, B., Bin Abdulhak, A., Birbeck, G., Black, J.A., Blencowe, H., Blore, J.D., Blyth, F., Bolliger, I., Bonaventure, A., Boufous, S., Bourne, R., Boussinesq, M., Braithwaite, T., Brayne, C., Bridgett, L., Brooker, S., Brooks, P., Brugha, T.S., Bryan-Hancock, C., Bucello, C., Buchbinder, R., Buckle, G., Budke, C.M., Burch, M., Burney, P., Burstein, R., Calabria, B., Campbell, B., Canter, C.E., Carabin, H., Carapetis, J., Carmona, L., Cella, C., Charlson, F., Chen, H., Cheng, A.T., Chou, D., Chugh, S.S., Coffeng, L.E., Colan, S.D., Colquhoun, S., Colson, K.E., Condon, J., Connor, M.D., Cooper, L.T., Corriere, M., Cortinovis, M., de Vaccaro, K.C., Couser, W., Cowie, B.C., Criqui, M.H., Cross, M., Dabhadkar, K.C., Dahiya, M., Dahodwala, N., Damsere-Derry, J., Danaei, G., Davis, A., De Leo, D., Degenhardt, L., Dellavalle, R., Delossantos, A., Denenberg, J., Derrett, S., Des Jarlais, D.C., Dharmaratne, S.D., Dherani, M., Diaz-Torne, C., Dolk, H., Dorsey, E.R., Driscoll, T., Duber, H., Ebel, B., Edmond, K., Elbaz, A., Ali, S.E., Erskine, H., Erwin, P.J., Espindola, P., Ewoigbokhan, S.E., Farzadfar, F., Feigin, V., Felson, D.T., Ferrari, A., Ferri, C.P., Fevre, E.M., Finucane, M.M., Flaxman, S., Flood, L., Foreman, K., Forouzanfar, M.H., Fowkes, F.G., Fransen, M., Freeman, M.K., Gabbe, B.J., Gabriel, S.E., Gakidou, E., Ganatra, H.A., Garcia, B., Gaspari, F., Gillum, R.F., Gmel, G., Gonzalez-Medina, D., Gosselin, R., Grainger, R., Grant, B., Groeger, J., Guillemin, F., Gunnell, D., Gupta, R., Haagsma, J., Hagan, H., Halasa, Y.A., Hall, W., Haring, D., Haro, J.M., Harrison, J.E., Havmoeller, R., Hay, R.J., Higashi, H., Hill, C., Hoen, B., Hoffman, H., Hotez, P.J., Hoy, D., Huang, J.J., Ibeanusi, S.E., Jacobsen, K.H., James, S.L., Jarvis, D., Jasrasaria, R., Jayaraman, S., Johns, N., Jonas, J.B., Karthikeyan, G., Kassebaum, N., Kawakami, N., Keren, A., Khoo, J.P., King, C.H., Knowlton, L.M., Kobusingye, O., Koranteng, A., Krishnamurthi, R., Laden, F., Lalloo, R., Laslett, L.L., Lathlean, T., Leasher, J.L., Lee, Y.Y., Leigh, J., Levinson, D., Lim, S.S., Limb, E., Lin, J.K., Lipnick, M., Lipshultz, S.E., Liu, W., Loane, M., Ohno, S.L., Lyons, R., Mabweijano, J., MacIntyre, M.F., Malekzadeh, R., Mallinger, L., Manivannan, S., Marcenes, W., March, L., Margolis, DJ., Marks, G.B., Marks, R. Matsumori, A., Matzopoulos, R., Mayosi, B.M., McAnulty, J.H., McDermott, M.M., McGill, N., McGrath, J., Medina-Mora, M.E., Meltzer, M., Mensah, G.A., Merriman, T.R., Meyer, A.C., Miglioli, V., Miller, M., Miller, T.R., Mitchell, P.B., Mock, C., Mocumbi, A.O., Moffitt, T.E., Mokdad, A.A., Monasta, L., Montico, M., MoradiLakeh, M., Moran, A., Morawska, L., Mori, R., Murdoch, M.E., Mwaniki, M.K., Naidoo, K., Nair, M.N., Naldi, L., Narayan, K.M., Nelson, P.K., Nelson, R.G., Nevitt, M.C., Newton, C. R. Nolte, S., Norman, P. Norman, R O'Donnell, M., O'Hanlon, S. Olives, C., Omer, S.B., Ortblad, K., Osborne, R., Ozgediz, D., Page, A., Pahari, B., Pandian, J.D., Rivero, A.P., Patten, S.B., Pearce, N., Padilla, R.P., Perez-Ruiz, F., Perico, N., Pesudovs, K., Phillips, D., Phillips, M.R., Pierce, K., Pion, S., Polanczyk, 
G.V., Polinder, S., Pope 3rd, C.A., Popova, S., Porrini, E., Pourmalek, F., Prince, M., Pullan, R.L., Ramaiah, K.D., Ranganathan, D., Razavi, H., Regan, M., Rehm, J.T. Rein, D.B., Remuzzi, G., Richardson, K., Rivara, F.P., Roberts, T., Robinson, C., De Leon, F.R., Ronfani, L., Room, R., Rosenfeld, L.C., Rushton, L., Sacco, R.L., Saha, S., Sampson, U., Sanchez-Riera, L., Sanman, E., Schwebel, D.C., Scott, J.G., SeguiGomez, M., Shahraz, S., Shepard, D.S., Shin, H., Shivakoti, R., Singh, D., Singh, G.M., Singh, J.A., Singleton, J., Sleet, D.A., Sliwa, K., Smith, E., Smith, J.L., Stapelberg, N.J., Steer, A., Steiner, T., Stolk, W.A., Stovner, L.J., Sudfeld, C., Syed, S., Tamburlini, G., Tavakkoli, M., Taylor, H.R., Taylor, J.A., Taylor, W.J., Thomas, B., Thomson, W.M., Thurston, G.D., Tleyjeh, I.M., Tonelli, M., Towbin, J.A., Truelsen, T., Tsilimbaris, M.K., Ubeda, C., Undurraga, E.A., van der Werf, M.J., van Os, J., Vavilala, M.S., Venketasubramanian, N., Wang, M., Wang, W., Watt, K., Weatherall, D.J., Weinstock, M.A., Weintraub, R., Weisskopf, M.G., Weissman, M.M. White, R.A., Whiteford, H., Wiebe, N., Wiersma, S.T., Wilkinson, J.D., Williams, H.C., Williams, S.R., Witt, E., Wolfe, F., Woolf, A.D., Wulf, S., Yeh, P.H., Zaidi, A.K., Zheng, Z.J., Zonies, D., Lopez, A.D., AlMazroa, M.A., Memish, Z.A., 2012. Disability-adjusted life years (DALYs) for 291 diseases and injuries in 21 regions, 19902010: a systematic analysis for the Global Burden of Disease Study 2010. Lancet 380, 2197-2223.

Nakamura, K., Sekine, Y., Takei, N., Iwata, Y., Suzuki, K., Anitha, A., Inada, T., Harano, M., Komiyama, T., Yamada, M., Iwata, N., Iyo, M., Sora, I., Ozaki, N., Ujike, H., Mori, N., 2009. An association study of monoamine oxidase A (MAOA) gene polymorphism in methamphetamine psychosis. Neurosci. Lett. 455, 120-123.

Narita, K., Sasaki, T., Akaho, R., Okazaki, Y., Kusumi, I., Kato, T., Hashimoto, O., Fukuda, R., Koyama, T., Matsuo, K., Okabe, Y., Nanko, S., Hohjoh, H., Tokunaga, K., 2000. Human leukocyte antigen and season of birth in Japanese patients with schizophrenia. Am. J. Psychiatry 157, 1173-1175.

Neal, A.P., Stansfield, K.H., Worley, P.F., Thompson, R.E., Guilarte, T.R., 2010. Lead exposure during synaptogenesis alters vesicular proteins and impairs vesicular release: potential role of NMDA receptor-dependent BDNF signaling. Toxicol. Sci. 116, 249-263.

Neal, A.P., Worley, P.F., Guilarte, T.R., 2011. Lead exposure during synaptogenesis alters NMDA receptor targeting via NMDA receptor inhibition. Neurotoxicology 32, 281-289.

Neale, B.M., Sklar, P., 2015. Genetic analysis of schizophrenia and bipolar disorder reveals polygenicity but also suggests new directions for molecular interrogation. Curr. Opin. Neurobiol. 30C, 131-138.

Nestler, E.J., Hyman, S.E., 2010. Animal models of neuropsychiatric disorders. Nat. Neurosci. 13, 1161-1169.

Newell, K.A., Karl, T., Huang, X.F., 2013. A neuregulin 1 transmembrane domain mutation causes imbalanced glutamatergic and dopaminergic receptor expression in mice. Neuroscience 248, 670-680.

Nicodemus, K.K., Marenco, S., Batten, A.J., Vakkalanka, R., Egan, M.F., Straub, R.E., Weinberger, D.R., 2008. Serious obstetric complications interact with hypoxiaregulated/vascular-expression genes to influence schizophrenia risk. Mol. Psychiatry $13,873-877$.

Nithianantharajah, J., Hannan, A.J., 2006. Enriched environments, experience-dependent plasticity and disorders of the nervous system. Nat. Rev. Neurosci. 7, 697-709.

Niwa, M., Jaaro-Peled, H., Tankou, S., Seshadri, S., Hikida, T., Matsumoto, Y., Cascella, N.G., Kano, S., Ozaki, N., Nabeshima, T., Sawa, A., 2013. Adolescent stressinduced epigenetic control of dopaminergic neurons via glucocorticoids. Science 339, 335-339.

Nixon, D.C., Prust, M.J., Sambataro, F., Tan, H.Y., Mattay, V.S., Weinberger, D.R., Callicott, J.H., 2011. Interactive effects of DAOA (G72) and catechol-O-methyltransferase on neurophysiology in prefrontal cortex. Biol. Psychiatry 69, 10061008.

NLM, 2014. Genetics Home Reference [Internet]: The Library. NLM, Bethesda, MD.

O'Leary, C., Desbonnet, L., Clarke, N., Petit, E., Tighe, O., Lai, D., Harvey, R., Waddington, J.L., O'Tuathaigh, C., 2014. Phenotypic effects of maternal immune activation and early postnatal milieu in mice mutant for the schizophrenia risk gene neuregulin-1. Neuroscience 277, 294-305.

O’Tuathaigh, C.M., Babovic, D., O'Sullivan, G.J., Clifford, J.J., Tighe, O., Croke, D.T., Harvey, R., Waddington, J.L., 2007. Phenotypic characterization of spatial cognition and social behavior in mice with 'knockout' of the schizophrenia risk gene neuregulin 1 . Neuroscience $147,18-27$.

O’Tuathaigh, C.M., Harte, M., O'Leary, C., O’Sullivan, G.J., Blau, C., Lai, D., Harvey, R.P., Tighe, O., Fagan, A.J., Kerskens, C., Reynolds, G.P., Waddington, J.L., 2010. Schizophrenia-related endophenotypes in heterozygous neuregulin-1 'knockout' mice. Eur. J. Neurosci. 31, 349-358.

O'Tuathaigh, C.M., Gantois, I., Waddington, J.L., 2014. Genetic dissection of the psychotomimetic effects of cannabinoid exposure. Prog. Neuropsychopharmacol. Biol. Psychiatry 52, 33-40.

O’Tuathaigh, C.M., Clarke, G., Walsh, J., Desbonnet, L., Petit, E., O'Leary, C., Tighe, O., Clarke, N., Karayiorgou, M., Gogos, J.A., Dinan, T.G., Cryan, J.F., Waddington, J.L., 2012. Genetic vs. pharmacological inactivation of COMT influences cannabinoidinduced expression of schizophrenia-related phenotypes. Int. J. Neuropsychopharmacol. 15, 1331-1342.

O'Tuathaigh, C.M., Waddington, J.L., 2015. Closing the translational gap between mutant mouse models and the clinical reality of psychotic illness. Neurosci. Biobehav. Rev. S0149-S7634.

Ognibene, E., Adriani, W., Macri, S., Laviola, G., 2007. Neurobehavioural disorders in the infant reeler mouse model: interaction of genetic vulnerability and consequences of maternal separation. Behav. Brain Res. 177, 142-149.

Ognibene, E., Adriani, W., Caprioli, A., Ghirardi, O., Ali, S.F., Aloe, L., Laviola, G., 2008. The effect of early maternal separation on brain derived neurotrophic factor and monoamine levels in adult heterozygous reeler mice. Prog. Neuropsychopharmacol. Biol. Psychiatry 32, 1269-1276.

Ohgake, S., Hashimoto, K., Shimizu, E., Koizumi, H., Okamura, N., Koike, K., Matsuzawa, D., Sekine, Y., Inada, T., Ozaki, N., Iwata, N., Harano, M., Komiyama, T. Yamada, M., Sora, I., Ujike, H., Shirayama, Y., Iyo, M., 2005. Functional polymorphism of the NQO2 gene is associated with methamphetamine psychosis. Addict. Biol. 10, 145-148.

Okahisa, Y., Ujike, H., Kotaka, T., Morita, Y., Kodama, M., Inada, T., Yamada, M., Iwata, N., Iyo, M., Sora, I., Ozaki, N., Kuroda, S., 2009. Association between neuropeptide Y gene and its receptor Y1 gene and methamphetamine dependence. Psychiatry Clin. Neurosci. 63, 417-422.

Oliver, P.L., Davies, K.E., 2009. Interaction between environmental and genetic factors modulates schizophrenic endophenotypes in the Snap-25 mouse mutant blind-drunk. Hum. Mol. Genet. 18, 4576-4589.

Oliver, P.L., Sobczyk, M.V., Maywood, E.S., Edwards, B., Lee, S., Livieratos, A., Oster, H., Butler, R., Godinho, S.I., Wulff, K., Peirson, S.N., Fisher, S.P., Chesham, J.E., Smith, J.W., Hastings, M.H., Davies, K.E., Foster, R.G., 2012. Disrupted circadian rhythms in a mouse model of schizophrenia. Curr. Biol. 22, 314-319.

Opler, M.G., Brown, A.S., Graziano, J., Desai, M., Zheng, W., Schaefer, C., Factor-Litvak, P., Susser, E.S., 2004. Prenatal lead exposure, delta-aminolevulinic acid, and schizophrenia. Environ. Health Perspect. 112, 548-552.

Opler, M.G., Buka, S.L., Groeger, J., McKeague, I., Wei, C., Factor-Litvak, P., Bresnahan, M., Graziano, J., Goldstein, J.M., Seidman, L.J., Brown, A.S., Susser, E.S., 2008 Prenatal exposure to lead, delta-aminolevulinic acid, and schizophrenia: further evidence. Environ. Health Perspect. 116, 1586-1590.

Opler, M.G., Susser, E.S., 2005. Fetal environment and schizophrenia. Environ. Health Perspect. 113, 1239-1242.

Paksarian, D., Eaton, W.W., Mortensen, P.B., Pedersen, C.B., 2014. Childhood residential mobility, schizophrenia, and bipolar disorder: a population-based study in Denmark. Schizophr. Bull..

Pang, T.Y., Hannan, A.J., 2013. Enhancement of cognitive function in models of brain disease through environmental enrichment and physical activity. Neuropharmacology 64, 515-528.

Papaleo, F., Erickson, L., Liu, G., Chen, J., Weinberger, D.R., 2012. Effects of sex and COMT genotype on environmentally modulated cognitive control in mice. Proc. Natl. Acad. Sci. U. S. A. 109, 20160-20165.

Park, Y.U., Jeong, J., Lee, H., Mun, J.Y., Kim, J.H., Lee, J.S., Nguyen, M.D., Han, S.S., Suh, P.G., Park, S.K., 2010. Disrupted-in-schizophrenia 1 (DISC1) plays essential roles in mitochondria in collaboration with Mitofilin. Proc. Natl. Acad. Sci. U. S. A. 107, 17785-17790.

Paterlini, M., Zakharenko, S.S., Lai, W.S., Qin, J., Zhang, H., Mukai, J., Westphal, K.G., Olivier, B., Sulzer, D., Pavlidis, P., Siegelbaum, S.A., Karayiorgou, M., Gogos, J.A., 2005. Transcriptional and behavioral interaction between 22 q11.2 orthologs modulates schizophrenia-related phenotypes in mice. Nat. Neurosci. 11, 1586-1594.

Paukert, M., Agarwal, A., Cha, J., Doze, V.A., Kang, J.U., Bergles, D.E., 2014. Norepinephrine controls astroglial responsiveness to local circuit activity. Neuron 82, 1263-1270.

Peerbooms, O., Rutten, B.P., Collip, D., Lardinois, M., Lataster, T., Thewissen, V., Rad, S.M., Drukker, M., Kenis, G., van Os, J., Myin-Germeys, I., van Winkel, R., 2012 Evidence that interactive effects of COMT and MTHFR moderate psychotic response to environmental stress. Acta Psychiatr. Scand. 125, 247-256.

Pertwee, R.G., 2008. The diverse CB1 and CB2 receptor pharmacology of three plant cannabinoids: delta9-tetrahydrocannabinol, cannabidiol and delta9-tetrahydrocannabivarin. Br. J. Pharmacol. 153, 199-215.

Petrinovic, M.M., Kunnecke, B., 2014. Neuroimaging endophenotypes in animal models of autism spectrum disorders: lost or found in translation? Psychopharmacology 231, 1167-1189.

Petronis, A., Paterson, A.D., Kennedy, J.L., 1999. Schizophrenia: an epigenetic puzzle? Schizophr. Bull. 25, 639-655.

Pietrek, C., Elbert, T., Weierstall, R., Muller, O., Rockstroh, B., 2013. Childhood adversities in relation to psychiatric disorders. Psychiatry Res. 206, 103-110.

Pishva, E., Kenis, G., van den Hove, D., Lesch, K.P., Boks, M.P., van Os, J., Rutten, B.P. 2014. The epigenome and postnatal environmental influences in psychotic disorders. Soc. Psychiatry Psychiatr. Epidemiol. 49, 337-348.

Pletnikov, M.V., Ayhan, Y., Nikolskaia, O., Xu, Y., Ovanesov, M.V., Huang, H., Mori, S., Moran, T.H., Ross, C.A., 2008a. Inducible expression of mutant human DISC1 in mice is associated with brain and behavioral abnormalities reminiscent of schizophrenia. Mol. Psychiatry 13, 173-186, 115

Pletnikov, M.V., Ayhan, Y., Xu, Y., Nikolskaia, O., Ovanesov, M., Huang, H., Mori, S., Moran, T.H., Ross, C.A., 2008b. Enlargement of the lateral ventricles in mutant DISC1 transgenic mice. Mol. Psychiatry 13, 115.

Pletnikov, M.V., Moran, T.H., Carbone, K.M., 2002. Borna disease virus infection of the neonatal rat: developmental brain injury model of autism spectrum disorders. Front. Biosci. 7, d593-d607.

Pogorelov, V.M., Nomura, J., Kim, J., Kannan, G., Ayhan, Y., Yang, C., Taniguchi, Y. Abazyan, B., Valentine, H., Krasnova, I.N., Kamiya, A., Cadet, J.L., Wong, D.F., Pletnikov, M.V., 2012. Mutant DISC1 affects methamphetamine-induced sensitization and conditioned place preference: a comorbidity model. Neuropharmacology 62, 1242-1251.

Powell, C.M., Miyakawa, T., 2006. Schizophrenia-relevant behavioral testing in rodent models: a uniquely human disorder? Biol. Psychiatry 59, 1198-1207.

Power, R.A., Verweij, K.J., Zuhair, M., Montgomery, G.W., Henders, A.K., Heath, A.C., Madden, P.A., Medland, S.E., Wray, N.R., Martin, N.G., 2014. Genetic predisposition to schizophrenia associated with increased use of cannabis. Mol. Psychiatry 19, 1201-1204. 
Prasad, K.M., Bamne, M.N., Shirts, B.H., Goradia, D., Mannali, V., Pancholi, K.M., Xue B., McClain, L., Yolken, R.H., Keshavan, M.S., Nimgaonkar, V.L., 2010. Grey matter changes associated with host genetic variation and exposure to Herpes Simplex Virus 1 (HSV1) in first episode schizophrenia. Schizophr. Res. 118, 232-239.

Pratt, J., Winchester, C., Dawson, N., Morris, B., 2012. Advancing schizophrenia drug discovery: optimizing rodent models to bridge the translational gap. Nat. Rev. Drug Discov. 11, 560-579.

Price, A.L., Zaitlen, N.A., Reich, D., Patterson, N., 2010. New approaches to population stratification in genome-wide association studies. Nat. Rev. Genet. 11, 459-463.

Pryce, C.R., Klaus, F., 2013. Translating the evidence for gene association with depression into mouse models of depression-relevant behaviour: current limitations and future potential. Neurosci. Biobehav. Rev. 37, 1380-1402.

Purcell, S.M., Moran, J.L., Fromer, M., Ruderfer, D., Solovieff, N., Roussos, P., O’Dushlaine, C., Chambert, K., Bergen, S.E., Kahler, A., Duncan, L., Stahl, E., Genovese, G., Fernandez, E., Collins, M.O., Komiyama, N.H., Choudhary, J.S., Magnusson, P.K. Banks, E., Shakir, K., Garimella, K., Fennell, T., DePristo, M., Grant, S.G., Haggarty, S.J., Gabriel, S., Scolnick, E.M., Lander, E.S., Hultman, C.M., Sullivan, P.F., McCarroll, S.A., Sklar, P., 2014. A polygenic burden of rare disruptive mutations in schizophrenia. Nature 506, 185-190.

Quednow, B.B., Brzozka, M.M., Rossner, M.J., 2014. Transcription factor 4 (TCF4) and schizophrenia: integrating the animal and the human perspective. Cell. Mol. Life Sci. 71, 2815-2835.

Rabl, U., Meyer, B.M., Diers, K., Bartova, L., Berger, A., Mandorfer, D., Popovic, A Scharinger, C., Huemer, J., Kalcher, K., Pail, G., Haslacher, H., Perkmann, T., Windischberger, C., Brocke, B., Sitte, H.H., Pollak, D.D., Dreher, J.C., Kasper, S., Praschak-Rieder, N., Moser, E., Esterbauer, H., Pezawas, L., 2014. Additive geneenvironment effects on hippocampal structure in healthy humans. J. Neurosci. 34, 9917-9926

Radhakrishnan, R., Wilkinson, S.T., D’Souza, D.C., 2014. Gone to pot - a review of the association between cannabis and psychosis. Front. Psychiatry 5, 54

Ratajczak, P., Wozniak, A., Nowakowska, E., 2013. Animal models of schizophrenia: developmental preparation in rats. Acta Neurobiol. Exp. 73, 472-484.

Reeves, W.C., Lin, J.M., Nater, U.M., 2013. Mental illness in metropolitan, urban and rural Georgia populations. BMC Public Health 13, 414.

Réthelyi, J.M., Benkovits, J., Bitter, I., 2013. Genes and environments in schizophrenia: the different pieces of a manifold puzzle. Neurosci. Biobehav. Rev. 37, 2424-2437.

Ridley, R.M., Baker, H.F., 1982. Stereotypy in monkeys and humans. Psychol. Med. $12,61-72$.

Rogaev, E.I., Sherrington, R., Rogaeva, E.A., Levesque, G., Ikeda, M., Liang, Y., Chi, H., Lin, C., Holman, K., Tsuda, T., et al., 1995. Familial Alzheimer's disease in kindreds with missense mutations in a gene on chromosome 1 related to the Alzheimer's disease type 3 gene. Nature 376, 775-778.

Rogers, J.T., Weeber, E.J., 2008. Reelin and apoE actions on signal transduction, synaptic function and memory formation. Neuron Glia Biol. 4, 259-270.

Rojas, P., Joodmardi, E., Hong, Y., Perlmann, T., Ogren, S.O., 2007. Adult mice with reduced Nurr1 expression: an animal model for schizophrenia. Mol. Psychiatry $12,756-766$

Roser, P., Juckel, G., Rentzsch, J., Nadulski, T., Gallinat, J., Stadelmann, A.M., 2008. Effects of acute oral Delta9-tetrahydrocannabinol and standardized cannabis extract on the auditory P300 event-related potential in healthy volunteers. Eur. Neuropsychopharmacol. 18, 569-577.

Rossler, W., Hengartner, M.P., Ajdacic-Gross, V., Haker, H., Angst, J., 2014. Impact of childhood adversity on the onset and course of subclinical psychosis symptoms - results from a 30-year prospective community study. Schizophr. Res. 153, 189-195.

Ruderfer, D.M., Chambert, K., Moran, J., Talkowski, M., Chen, E.S., Gigek, C., Gusella, J.F., Blackwood, D.H., Corvin, A., Gurling, H.M., Hultman, C.M., Kirov, G., Magnusson, P., O’Donovan, M.C., Owen, M.J., Pato, C., St Clair, D., Sullivan, P.F., Purcell, S.M., Sklar, P., Ernst, C., 2013. Mosaic copy number variation in schizophrenia. Eur. J. Hum. Genet. 21, 1007-1011.

Rutter, M., 2008. Biological implications of gene-environment interaction. J. Abnorm. Child Psychol. 36, 969-975.

Rutter, M., Moffitt, T.E., Caspi, A., 2006. Gene-environment interplay and psychopathology: multiple varieties but real effects. J. Child Psychol. Psychiatry 47, 226-261.

Sachs, N.A., Sawa, A., Holmes, S.E., Ross, C.A., DeLisi, L.E., Margolis, R.L., 2005. A frameshift mutation in Disrupted in Schizophrenia 1 in an American family with schizophrenia and schizoaffective disorder. Mol. Psychiatry 10, 758-764.

Saha, S., Chant, D., Welham, J., McGrath, J., 2005. A systematic review of the prevalence of schizophrenia. PLoS Med. 2, e141.

Sasaki, T., Beppu, K., Tanaka, K.F., Fukazawa, Y., Shigemoto, R., Matsui, K., 2012 Application of an optogenetic byway for perturbing neuronal activity via glial photostimulation. Proc. Natl. Acad. Sci. U. S. A. 109, 20720-20725.

Sato, M., 1992. A lasting vulnerability to psychosis in patients with previous methamphetamine psychosis. Ann. N.Y. Acad. Sci. 654, 160-170.

Scattoni, M.L., Crawley, J., Ricceri, L., 2009. Ultrasonic vocalizations: a tool for behavioural phenotyping of mouse models of neurodevelopmental disorders. Neurosci. Biobehav. Rev. 33, 508-515.

Schizophrenia Working Group of the Psychiatric Genomics Consortium, 2014. Biological insights from 108 schizophrenia-associated genetic loci. Nature 511, 421-427.

Schmidt-Kastner, R., van Os, J., Esquivel, G., Steinbusch, H.W., Rutten, B.P., 2012. An environmental analysis of genes associated with schizophrenia: hypoxia and vascular factors as interacting elements in the neurodevelopmental model. Mol. Psychiatry 17, 1194-1205.
Schubart, C.D., Sommer, I.E., Fusar-Poli, P., de Witte, L., Kahn, R.S., Boks, M.P., 2014. Cannabidiol as a potential treatment for psychosis. Eur. Neuropsychopharmacol. 24, 51-64.

Schwab, S.G., Hallmayer, J., Lerer, B., Albus, M., Borrmann, M., Hönig, S., Strauss, M., Segman, R., Lichtermann, D., Knapp, M., Trixler, M., Maier, W., Wildenauer, D.B., 1998. Support for a chromosome 18 p locus conferring susceptibility to functional psychoses in families with schizophrenia, by association and linkage analysis. Am. J. Hum. Genet. 63, 1139-1152.

Severance, E.G., Yolken, R.H., Eaton, W.W. 2014. Autoimmune diseases, gastrointestinal disorders and the microbiome in schizophrenia: more than a gut feeling. Schizophr. Res. S0920-S9964.

Shannon, C., Douse, K., McCusker, C., Feeney, L., Barrett, S., Mulholland, C., 2011. The association between childhood trauma and memory functioning in schizophrenia. Schizophr. Bull. 37, 531-537.

Shirts, B.H., Kim, J.J., Reich, S., Dickerson, F.B., Yolken, R.H., Devlin, B., Nimgaonkar, V.L., 2007. Polymorphisms in MICB are associated with human herpes virus seropositivity and schizophrenia risk. Schizophr. Res. 94, 342-353.

Shirts, B.H., Wood, J., Yolken, R.H., Nimgaonkar, V.L., 2008. Comprehensive evaluation of positional candidates in the IL-18 pathway reveals suggestive associations with schizophrenia and herpes virus seropositivity. Am. J. Med. Genet. B: Neuropsychiatr. Genet. 147, 343-350.

Shorter, K.R., Miller, B.H., 2015. Epigenetic mechanisms in schizophrenia. Prog. Biophys. Mol. Biol. 118, 1-7.

Simons, C.J., Wichers, M., Derom, C., Thiery, E., Myin-Germeys, I., Krabbendam, L., van Os, J., 2009. Subtle gene-environment interactions driving paranoia in daily life. Genes Brain Behav. 8, 5-12.

Smith, S.E., Li, J., Garbett, K., Mirnics, K., Patterson, P.H., 2007. Maternal immune activation alters fetal brain development through interleukin-6. J. Neurosci. 27, 10695-10702.

St Clair, D., Blackwood, D., Muir, W. Carothers, A., Walker, M., Spowart, G., Gosden, C., Evans, H.J., 1990. Association within a family of a balanced autosomal translocation with major mental illness. Lancet 336, 13-16.

Staal, S.P., Hartley, J.W., Rowe, W.P., 1977. Isolation of transforming murine leukemia viruses from mice with a high incidence of spontaneous lymphoma. Proc. Natl. Acad. Sci. U. S. A. 74, 3065-3067.

Stadelmann, A.M., Roser, P., Arning, L., Gallinat, J., Epplen, J.T., Juckel, G., 2010. Acute effects of delta9-tetrahydrocannabinol on the auditory evoked mismatch negativity are modulated by the NRG1 gene. Pharmacopsychiatry 43, 194-195.

Stefanis, N.C., Henquet, C., Avramopoulos, D., Smyrnis, N., Evdokimidis, I., MyinGermeys, I., Stefanis, C.N., Van Os, J., 2007. COMT Val158Met moderation of stress-induced psychosis. Psychol. Med. 37, 1651-1656.

Stefansson, H., Sarginson, J., Kong, A., Yates, P., Steinthorsdottir, V., Gudfinnsson, E., Gunnarsdottir, S., Walker, N., Petursson, H., Crombie, C., Ingason, A., Gulcher, J.R., Stefansson, K., St Clair, D., 2003. Association of neuregulin 1 with schizophrenia confirmed in a Scottish population. Am. J. Hum. Genet. 72, 83-87.

Stefansson, H., Sigurdsson, E., Steinthorsdottir, V., Bjornsdottir, S., Sigmundsson, T. Ghosh, S., Brynjolfsson, J., Gunnarsdottir, S., Ivarsson, O., Chou, T.T., Hjaltason, O., Birgisdottir, B., Jonsson, H., Gudnadottir, V.G., Gudmundsdottir, E., Bjornsson, A., Ingvarsson, B., Ingason, A., Sigfusson, S., Hardardottir, H., Harvey, R.P., Lai, D. Zhou, M., Brunner, D., Mutel, V., Gonzalo, A., Lemke, G., Sainz, J., Johannesson, G., Andresson, T., Gudbjartsson, D., Manolescu, A., Frigge, M.L., Gurney, M.E., Kong, A., Gulcher, J.R., Petursson, H., Stefansson, K., 2002. Neuregulin 1 and susceptibility to schizophrenia. Am. J. Hum. Genet. 71, 877-892.

Sullivan, P.F., 2010. The psychiatric GWAS consortium: big science comes to psychiatry. Neuron 68, 182-186.

Sullivan, P.F., Daly, M.J., O’Donovan, M., 2012. Genetic architectures of psychiatric disorders: the emerging picture and its implications. Nat. Rev. Genet. 13, 537-551.

Sullivan, S., Wills, A., Lawlor, D., McGrath, J., Zammit, S., 2013. Prenatal vitamin D status and risk of psychotic experiences at age 18 years - a longitudinal birth cohort. Schizophr. Res. 148, 87-92.

Suvisaari, J.M., Taxell-Lassas, V., Pankakoski, M., Haukka, J.K., Lonnqvist, J.K., Hakkinen, L.T., 2013. Obstetric complications as risk factors for schizophrenia spectrum psychoses in offspring of mothers with psychotic disorder. Schizophr. Bull. 39, 1056-1066.

Suzuki, A., Nakamura, K., Sekine, Y., Minabe, Y., Takei, N., Suzuki, K., Iwata, Y., Kawai, M., Takebayashi, K., Matsuzaki, H., Iyo, M., Ozaki, N., Inada, T., Iwata, N., Harano, M., Komiyama, T., Yamada, M., Sora, I., Ujike, H., Mori, N., 2006. An association study between catechol-O-methyl transferase gene polymorphism and methamphetamine psychotic disorder. Psychiatr. Genet. 16, 133-138.

Suzuki, G., Harper, K.M., Hiramoto, T., Sawamura, T., Lee, M., Kang, G., Tanigaki, K. Buell, M., Geyer, M.A., Trimble, W.S., Agatsuma, S., Hiroi, N., 2009. Sept5 deficiency exerts pleiotropic influence on affective behaviors and cognitive functions in mice. Hum. Mol. Genet. 18, 1652-1660

Svrakic, D.M., Zorumski, C.F., Svrakic, N.M., Zwir, I., Cloninger, C.R., 2013. Risk architecture of schizophrenia: the role of epigenetics. Curr. Opin. Psychiatry 26, 188-195.

Szatkiewicz, J.P., O’Dushlaine, C., Chen, G., Chambert, K., Moran, J.L., Neale, B.M., Fromer, M., Ruderfer, D., Akterin, S., Bergen, S.E., Kahler, A., Magnusson, P.K., Kim, Y., Crowley, J.J., Rees, E., Kirov, G., O’Donovan, M.C., Owen, M.J., Walters, J., Scolnick, E., Sklar, P., Purcell, S., Hultman, C.M., McCarroll, S.A., Sullivan, P.F., 2014. Copy number variation in schizophrenia in Sweden. Mol. Psychiatry 19, $762-773$.

Szoke, A., Charpeaud, T., Galliot, A.M., Vilain, J., Richard, J.R., Leboyer, M., Llorca, P.M., Schurhoff, F., 2014. Rural-urban variation in incidence of psychosis in France: a 
prospective epidemiologic study in two contrasted catchment areas. BMC Psychiatry 14, 78 .

Takuma, K., et al., 2011. Preventive effects of an enriched environment on rodent psychiatric disorder models. J. Pharmacol. Sci. 117, 71-76.

Takuma, K., Maeda, Y., Ago, Y., Ishihama, T., Takemoto, K., Nakagawa, A., Shintani, N., Hashimoto, H., Baba, A., Matsuda, T., 2014. An enriched environment ameliorates memory impairments in PACAP-deficient mice. Behav. Brain Res. 272, 269-278.

Tamamaki, N., Yanagawa, Y., Tomioka, R., Miyazaki, J., Obata, K., Kaneko, T., 2003. Green fluorescent protein expression and colocalization with calretinin, parvalbumin, and somatostatin in the GAD67-GFP knock-in mouse. J. Comp. Neurol. 467, 60-79.

Tandon, R., Keshavan, M.S., Nasrallah, H.A., 2008. Schizophrenia, "just the facts" what we know in 2008. 2. Epidemiology and etiology. Schizophr. Res. 102, 1-18.

Taniguchi, Y., Young-Pearse, T., Sawa, A., Kamiya, A., 2012. In utero electroporation as a tool for genetic manipulation in vivo to study psychiatric disorders: from genes to circuits and behaviors. Neuroscientist 18, 169-179.

Taylor, A.R., Taylor, S.B., Koenig, J.I., 2012. The involvement of Type II Neuregulin-1 in rat visuospatial learning and memory. Neurosci. Lett. 531, 131-135.

Taylor, S.B., Taylor, A.R., Koenig, J.I., 2013. The interaction of disrupted type II neuregulin 1 and chronic adolescent stress on adult anxiety- and fear-related behaviors. Neuroscience 249, 31-42.

Taylor, S.B., Taylor, A.R., Markham, J.A., Geurts, A.M., Kanaskie, B.Z., Koenig, J.I., 2011. Disruption of the neuregulin 1 gene in the rat alters HPA axis activity and behavioral responses to environmental stimuli. Physiol. Behav. 104, 205-214.

Thiselton, D.L., Webb, B.T., Neale, B.M., Ribble, R.C., O'Neill, F.A., Walsh, D., Riley, B.P. Kendler, K.S., 2004. No evidence for linkage or association of neuregulin-1 (NRG1) with disease in the Irish study of high-density schizophrenia families (ISHDSF). Mol. Psychiatry 9, 777-783.

Thompson, J.L., Kelly, M., Kimhy, D., Harkavy-Friedman, J.M., Khan, S., Messinger, J.W., Schobel, S., Goetz, R., Malaspina, D., Corcoran, C., 2009. Childhood trauma and prodromal symptoms among individuals at clinical high risk for psychosis. Schizophr. Res. 108, 176-181.

Thompson, P.M., Sower, A.C., Perrone-Bizzozero, N.I., 1998. Altered levels of the synaptosomal associated protein SNAP-25 in schizophrenia. Biol. Psychiatry 43, 239-243.

Thompson, P.M., Egbufoama, S., Vawter, M.P., 2003. SNAP-25 reduction in the hippocampus of patients with schizophrenia. Prog. Neuropsychopharmacol. Biol. Psychiatry 27, 411-417.

Timms, A.E., Dorschner, M.O., Wechsler, J., Choi, K.Y., Kirkwood, R., Girirajan, S., Baker, C., Eichler, E.E., Korvatska, O., Roche, K.W., Horwitz, M.S., Tsuang, D.W., 2013. Support for the N-methyl-D-aspartate receptor hypofunction hypothesis of schizophrenia from exome sequencing in multiplex families. JAMA Psychiatry $70,582-590$.

Tochigi, M., Iwamoto, K., Bundo, M., Komori, A., Sasaki, T., Kato, N., Kato, T., 2008 Methylation status of the reelin promoter region in the brain of schizophrenic patients. Biol. Psychiatry 63, 530-533.

Tochigi, M., Ohashi, J., Umekage, T., Kohda, K., Hibino, H., Otowa, T., Marui, T., Masui, K., Sugahara, Y., Kanamori, R., Juji, T., Kato, N., Tokunaga, K., Sasaki, T., 2002. Human leukocyte antigen-A specificities and its relation with season of birth in Japanese patients with schizophrenia. Neurosci. Lett. 329, 201-204.

Torrey, E.F., Miller, J., Rawlings, R., Yolken, R.H., 1997. Seasonality of births in schizophrenia and bipolar disorder: a review of the literature. Schizophr. Res. $28,1-38$.

Tsunoka, T., Kishi, T., Kitajima, T., Okochi, T., Okumura, T., Yamanouchi, Y., Kinoshita, Y., Kawashima, K., Naitoh, H., Inada, T., Ujike, H., Yamada, M., Uchimura, N., Sora, I., Iyo, M., Ozaki, N., Iwata, N., 2010. Association analysis of GRM2 and HTR2A with methamphetamine-induced psychosis and schizophrenia in the Japanese population. Prog. Neuropsychopharmacol. Biol. Psychiatry 34, 639-644.

Uchida, T., Oki, Y., Yanagawa, Y., Fukuda, A., 2011. A heterozygous deletion in the glutamate decarboxylase 67 gene enhances maternal and fetal stress vulnerability. Neurosci. Res. 69, 276-282.

Uchida, T., Furukawa, T., Iwata, S., Yanagawa, Y., Fukuda, A., 2014. Selective loss of parvalbumin-positive GABAergic interneurons in the cerebral cortex of maternally stressed Gad1-heterozygous mouse offspring. Transl. Psychiatry 4, e371.

Ucok, A., Ozturk, M., Duman, Z., Saruhan-Direskeneli, G.l., 2010. COMT Val 158 Met polymorphism is related with interpersonal problem solving in schizophrenia. Eur. Psychiatry 25, 320-322.

Uher, R., 2014. Gene environment interactions in severe mental illness. Front. Psychiatry 5, 48.

Ujike, H., Harano, M., Inada, T., Yamada, M., Komiyama, T., Sekine, Y., Sora, I., Iyo, M., Katsu, T., Nomura, A., Nakata, K., Ozaki, N., 2003. Nine- or fewer repeat alleles in VNTR polymorphism of the dopamine transporter gene is a strong risk factor for prolonged methamphetamine psychosis. Pharmacogenomics J. 3, 242-247.

Uhlhaas, P.J., Singer, W., 2015. Oscillations and neuronal dynamics in schizophrenia: the search for basic symptoms and translational opportunities. Biol. Psychiatry 77, 1001-1009.

Ujike, H., Sato, M., 2004. Clinical features of sensitization to methamphetamine observed in patients with methamphetamine dependence and psychosis. Ann. N.Y. Acad. Sci. 1025, 279-287.

Van Erp, T.G., Saleh, P.A., Rosso, I.M., Huttunen, M., Lonnqvist, J., Pirkola, T., Salonen, O., Valanne, L., Poutanen, V.P., Standertskjold-Nordenstam, C.G., Cannon, T.D., 2002. Contributions of genetic risk and fetal hypoxia to hippocampal volume in patients with schizophrenia or schizoaffective disorder, their unaffected siblings, and healthy unrelated volunteers. Am. J. Psychiatry 159, 1514-1520. van Os, J., 2009. 'Salience syndrome' replaces ‘schizophrenia' in DSM-V and ICD-11: psychiatry's evidence-based entry into the 21st century? Acta Psychiatr. Scand. $120,363-372$.

van Os, J., Bak, M., Hanssen, M., Bijl, R.V., de Graaf, R., Verdoux, H., 2002. Cannabis use and psychosis: a longitudinal population-based study. Am. J. Epidemiol. $156,319-327$

van Os, J., Hanssen, M., Bak, M., Bijl, R.V., Vollebergh, W., 2003. Do urbanicity and familial liability coparticipate in causing psychosis? Am. J. Psychiatry 160 477-482.

van Os, J., Hanssen, M., Bijl, R.V., Vollebergh, W., 2001. Prevalence of psychotic disorder and community level of psychotic symptoms: an urban-rural comparison. Arch. Gen. Psychiatry 58, 663-668.

van Os, J., Kapur, S., 2009. Schizophrenia. Lancet 374, 635-645.

van Os, J., Pedersen, C.B., Mortensen, P.B., 2004. Confirmation of synergy between urbanicity and familial liability in the causation of psychosis. Am. J. Psychiatry 161, 2312-2314.

van Winkel, R., Esquivel, G., Kenis, G., Wichers, M., Collip, D., Peerbooms, O., Rutten B., Myin-Germeys, I., Van Os, J., 2010. Genome-wide findings in schizophrenia and the role of gene-environment interplay. CNS Neurosci. Ther. 16, 185-192.

van Winkel, R., Genetic Risk and Outcome of Psychosis (GROUP) Investigators, 2011 Family-based analysis of genetic variation underlying psychosis-inducing effects of cannabis: sibling analysis and proband follow-up. Arch. Gen. Psychiatry $68,148-157$

van Winkel, R., van Beveren, N.J., Simons, C., Genetic Risk and Outcome of Psychosis (GROUP) Investigators, 2011. AKT1 moderation of cannabis-induced cognitive alterations in psychotic disorder. Neuropsychopharmacology 36, 2529-2537.

van Winkel, R., Henquet, C., Rosa, A., Papiol, S., Fananas, L., De Hert, M., Peuskens, J. van Os, J., Myin-Germeys, I., 2008. Evidence that the COMT(Val158Met) polymorphism moderates sensitivity to stress in psychosis: an experience-sampling study. Am. J. Med. Genet. B: Neuropsychiatr. Genet. 147B, 10-17.

Vassos, E., Pedersen, C.B., Murray, R.M., Collier, D.A., Lewis, C.M., 2012. Metaanalysis of the association of urbanicity with schizophrenia. Schizophr. Bull. 38, 1118-1123.

Veldic, M., Kadriu, B., Maloku, E., Agis-Balboa, R.C., Guidotti, A., Davis, J.M., Costa, E. 2007. Epigenetic mechanisms expressed in basal ganglia GABAergic neurons differentiate schizophrenia from bipolar disorder. Scizophrenia Res. 91, 51-61.

Volk, D.W., Austin, M.C., Pierri, J.N., Sampson, A.R., Lewis, D.A., 2000. Decreased glutamic acid decarboxylase67 messenger RNA expression in a subset of prefrontal cortical gamma-aminobutyric acid neurons in subjects with schizophrenia. Arch. Gen. Psychiatry 57, 237-245.

Volk, D.W., Matsubara, T., Li, S., Sengupta, E.J., Georgiev, D., Minabe, Y., Sampson, A. Hashimoto, T., Lewis, D.A., 2012. Deficits in transcriptional regulators of cortical parvalbumin neurons in schizophrenia. Am. J. Psychiatry 169, 1082-1091.

Volkow, N.D., 2004. The reality of comorbidity: depression and drug abuse. Biol. Psychiatry 56, 714-717.

Vuillermot, S., Feldon, J., Meyer, U., 2011. Nurr1 is not essential for the development of prepulse inhibition deficits induced by prenatal immune activation. Brain Behav. Immun. 25, 1316-1321.

Vuillermot, S., Joodmardi, E., Perlmann, T., Ogren, S.O., Feldon, J., Meyer, U., 2012 Prenatal immune activation interacts with genetic Nurr1 deficiency in the development of attentional impairments. J. Neurosci. 32, 436-451.

Wachtel, S.R., ElSohly, M.A., Ross, S.A., Ambre, J., de Wit, H., 2002. Comparison of the subjective effects of Delta(9)-tetrahydrocannabinol and marijuana in humans. Psychopharmacology 161, 331-339.

Waschek, J.A., 2013. VIP and PACAP: neuropeptide modulators of CNS inflammation, injury, and repair. Br. J. Pharmacol. 169, 512-523.

Wakuda, T., Iwata, K., Iwata, Y., Anitha, A., Takahashi, T., Yamada, K., Vasu, M.M. Matsuzaki, H., Suzuki, K., Mori, N., 2015. Perinatal asphyxia alters neuregulin-1 and COMT gene expression in the medial prefrontal cortex in rats. Prog. Neuropsychopharmacol. Biol. Psychiatry 56, 149-154.

Walsh, T., McClellan, J.M., McCarthy, S.E., Addington, A.M., Pierce, S.B., Cooper, G.M., Nord, A.S., Kusenda, M., Malhotra, D., Bhandari, A., Stray, S.M., Rippey, C.F., Roccanova, P., Makarov, V., Lakshmi, B., Findling, R.L., Sikich, L., Stromberg, T., Merriman, B., Gogtay, N., Butler, P., Eckstrand, K., Noory, L., Gochman, P., Long R., Chen, Z., Davis, S., Baker, C., Eichler, E.E., Meltzer, P.S., Nelson, S.F., Singleton, A.B., Lee, M.K., Rapoport, J.L., King, M.C., Sebat, J., 2008. Rare structural variants disrupt multiple genes in neurodevelopmental pathways in schizophrenia. Science 320, 539-543.

Walshe, M., McDonald, C., Boydell, J., Zhao, J.H., Kravariti, E., Touloupoulou, T., Fearon, P., Bramon, E., Murray, R.M., Allin, M., 2011. Long-term maternal recall of obstetric complications in schizophrenia research. Psychiatry Res. 187, 335-340.

Warnica, W., Merico, D., Costain, G., Alfred, S.E., Wei, J., Marshall, C.R., Scherer, S.W., Bassett, A.S., 2014. Copy number variable microRNAs in schizophrenia and their neurodevelopmental gene targets. Biol. Psychiatry.

Weinstock, M., 2008. The long-term behavioural consequences of prenatal stress. Neurosci. Biobehav. Rev. 32, 1073-1086.

Weis, S., Llenos, I.C., Sabunciyan, S., Dulay, J.R., Isler, L., Yolken, R., Perron, H., 2007 Reduced expression of human endogenous retrovirus (HERV)-W GAG protein in the cingulate gyrus and hippocampus in schizophrenia, bipolar disorder, and depression. J. Neural Transm. 114, 645-655.

Wen, Z., Nguyen, H.N., Guo, Z., Lalli, M.A., Wang, X., Su, Y., Kim, N.S., Yoon, K.J., Shin, J., Zhang, C., Makri, G., Nauen, D., Yu, H., Guzman, E., Chiang, C.H., Yoritomo, N., Kaibuchi, K., Zou, J., Christian, K.M., Cheng, L., Ross, C.A., Margolis, R.L., Chen, G., Kosik, K.S., Song, H., Ming, G.L., 2014. Synaptic dysregulation in a human iPS cell model of mental disorders. Nature 515, 414-418. 
Whyatt, R.M., Barr, D.B., 2001. Measurement of organophosphate metabolites in postpartum meconium as a potential biomarker of prenatal exposure: a validation study. Environ. Health Perspect. 109, 417-420.

Wicks, S., Hjern, A., Gunnell, D., Lewis, G., Dalman, C., 2005. Social adversity in childhood and the risk of developing psychosis: a national cohort study. Am. J. Psychiatry 162, 1652-1657.

Williams, N.M., Preece, A., Spurlock, G., Norton, N., Williams, H.J., Zammit, S., O'Donovan, M.C., Owen, M.J., 2003. Support for genetic variation in neuregulin 1 and susceptibility to schizophrenia. Mol. Psychiatry 8, 485-487.

Willner, P., 1984. The validity of animal models of depression. Psychopharmacology $83,1-16$.

Wong, D.F., Kuwabara, H., Horti, A.G., Raymont, V., Brasic, J., Guevara, M., Ye, W., Dannals, R.F., Ravert, H.T., Nandi, A., Rahmim, A., Ming, J.E., Grachev, I., Roy, C., Cascella, N., 2010. Quantification of cerebral cannabinoid receptors subtype 1 (CB1) in healthy subjects and schizophrenia by the novel PET radioligand $\left[{ }^{11} \mathrm{C}\right]$ OMAR. Neuroimage 52, 1505-1513.

Wirgenes, K.V., Djurovic, S., Sundet, K., Agartz, I., Mattingsdal, M., Athanasiu, L. Melle, I., Andreassen, O.A., 2010. Catechol O-methyltransferase variants and cognitive performance in schizophrenia and bipolar disorder versus controls. Schizophr. Res. 122, 31-37.

Wood, J.D., Bonath, F., Kumar, S., Ross, C.A., Cunliffe, V.T., 2009. Disrupted-inschizophrenia 1 and neuregulin 1 are required for the specification of oligodendrocytes and neurons in the zebrafish brain. Hum. Mol. Genet. 18, 391-404.

Wu, C.S., Lin, J.T., Chien, C.L., Chang, W.C., Lai, H.L., Chang, C.P., Chern, Y., 2011. Type VI adenylyl cyclase regulates neurite extension by binding to Snapin and Snap25. Mol. Cell. Biol. 24, 4874-4886.
Xing, G., Zhang, L., Russell, S., Post, R., 2006. Reduction of dopamine-related transcription factors Nurr1 and NGFI-B in the prefrontal cortex in schizophrenia and bipolar disorders. Schizophr. Res. 84, 36-56.

Xu, B., Ionita-Laza, I., Roos, J.L., Boone, B., Woodrick, S., Sun, Y., Levy, S., Gogos, J.A., Karayiorgou, M., 2012. De novo gene mutations highlight patterns of genetic and neural complexity in schizophrenia. Nat. Genet. 44, 1365-1369.

Xu, B., Roos, J.L., Levy, S., van Rensburg, E.J., Gogos, J.A., Karayiorgou, M., 2008. Strong association of de novo copy number mutations with sporadic schizophrenia. Nat. Genet. 40, 880-885.

Yang, C.R., Svensson, K.A., 2008. Allosteric modulation of NMDA receptor via elevation of brain glycine and D-serine: the therapeutic potentials for schizophrenia. Pharmacol. Ther. 120, 317-332.

Yao, Y., Schroder, J., Nellaker, C., Bottmer, C., Bachmann, S., Yolken, R.H., Karlsson, H., 2008. Elevated levels of human endogenous retrovirus-W transcripts in blood cells from patients with first episode schizophrenia. Genes Brain Behav. 7, 103-112.

Young, C.E., Arima, K., Xie, J., Hu, L., Beach, T.G., Falkai, P., Honer, W.G., 1998. SNAP-25 deficit and hippocampal connectivity in schizophrenia. Cereb. Cortex 8, 261-263.

Young, G.R., Stoye, J.P., Kassiotis, G., 2013. Are human endogenous retroviruses pathogenic? An approach to testing the hypothesis. BioEssays 35, 794-803.

Young, J.W., Geyer, M.A., 2015. Developing treatments for cognitive deficits in schizophrenia: the challenge of translation. J. Psychopharmacol. 29, 178-196.

Zammit, S., Spurlock, G., Williams, H., Norton, N., Williams, N., O’Donovan, M.C., Owen, M.J., 2007. Genotype effects of CHRNA7, CNR1 and COMT in schizophrenia: interactions with tobacco and cannabis use. Br. J. Psychiatry 191, 402-407. 